University of San Diego

Digital USD

2000

\title{
On the Edge of the Envelope. A Case Study of the Children's Initiative: An Inquiry into Collaboration and Shared Vision
}

Laurie Coskey EdD

University of San Diego

Follow this and additional works at: https://digital.sandiego.edu/dissertations

Part of the Leadership Studies Commons

\section{Digital USD Citation}

Coskey, Laurie EdD, "On the Edge of the Envelope. A Case Study of the Children's Initiative: An Inquiry into Collaboration and Shared Vision" (2000). Dissertations. 661.

https://digital.sandiego.edu/dissertations/661

This Dissertation: Open Access is brought to you for free and open access by the Theses and Dissertations at Digital USD. It has been accepted for inclusion in Dissertations by an authorized administrator of Digital USD. For more information, please contact digital@sandiego.edu. 


\title{
ON THE EDGE OF THE ENVELOPE--A CASE STUDY OF THE
}

\section{CHILDREN'S INITIATIVE: AN INQUIRY INTO}

COLLABORATION AND SHARED VISION

\author{
by
}

Laurie Coskey

\begin{abstract}
A dissertation submitted in partial fulfillment
of the requirements for the degree of

Doctor of Education
\end{abstract}

University of San Diego

2000

Dissertation Committee

Johanna S. Hunsaker, Ph.D., Director

Mary Woods Scherr, Ph.D.

Herman Gadon, Ph.D.

Natasha Josefowitz, Ph.D. 


\begin{abstract}
While there are many collaborative efforts throughout the country, few have the breadth or the scope of the San Diego Children's Initiative. The general purpose of this research study was to analyze and develop an interpretive case study describing the initial collaborative process of the Strategic Action Committee of the San Diego Children's Initiative. The study focused on the initial phase of the collaboration which took place from November of 1993 through April of 1995.

This study sought to determine some factors that may influence the potential success of a large-scale, multi-sector, private-public collaborative effort. The research analyzed the success of the initial phase of the collaboration through investigating three related organizational dynamics: shared vision, stakeholder issues, and theories-ofaction. The study evaluated the degree to which the perception of various gains and losses by participants influenced their commitment to the shared vision, whether the theories espoused by participants were consistent with their theories-in-use, and whether the variety of stakeholder issues facilitated the collaborative effort. The data was collected through ten interviews, archival documents, and observational notes. The analysis of the data found that the participants both enrolled in the vision and perceived greater gains than losses for themselves personally and their organizations, and that a strong relationship existed between the shared vision, stakeholder concerns, and the theories-in-use. These relationships and their implications for the collaborative


effort are explored at length. The data further revealed specific inferences about the large scale-collaborative process including unintended consequences, initial actions of collaboration and systemic change efforts. The conclusion of the study includes a presentation of the Children's Initiative after five years and compares its current vision and structure to the strategic plan created by the initial phase of the Children's Initiative in April of 1995.

This descriptive case study offered the opportunity to work with individuals who are among the most influential people in the county of San Diego. Because the Strategic Action Committee represented such a high level of local leadership, the opportunity to study the phenomenon of their collaboration was unique and fortuitous. It was hoped that the unique perceptions and experiences of the participants would be of great benefit to other collaboratives that work with the same kind of executive and high profile community leaders. This research demonstrated that the Children's Initiative created a strong, effective and enduring community collaborative. 


\title{
DEDICATION
}

This dissertation is dedicated to my grandmother

\author{
Esther Tarica Altabet \\ who taught me that with \\ dedication, \\ moderation \\ and discipline,
}

I could accomplish any goal upon which I set my sights.

ix 


\section{ACKNOWLEDGMENTS}

Writing a dissertation is a collaborative effort! My deepest thanks goes to my dissertation committee: Johanna Hunsaker, Ph.D., Mary Scherr, Ph.D., Natasha Josefowitz, Ph.D. and Herman Gadon, Ph.D. They each gave to me the gifts of time, energy, feedback, and best of all, their unique and brilliant ideas. I feel blessed to have had their guidance, nurturing, critique and patience throughout this arduous project. Thank you!

Writing a dissertation is a tedious effort! My family and friends inspired, supported, and nudged me throughout. More thank yous than I can say go to my parents, Rhea and Hal, my sisters, Eileen, Susan and Gwen, my nephew Jason, my dearest friends BB, Sirah and Harold, Elaine and Dana, Lynne and Russ, Wendy and Craig, Bruce, Angie, Monique, and Julie.

Writing a dissertation is a family effort! It is not possible for me to express the depth of my gratitude and love for my husband Mark Lohkemper and our sons Tyler, Marshall and Aaron. Marshall and Aaron have been my constant companions, inspirations, diversions and playmates. "Mommy, have you finished your dissertation?" was a constant refrain. Finally, all things go better and easier with my husband who is my best friend, best love, computer expert and companion through all of my endeavors. 


\section{TABLE OF CONTENTS}

Page

DEDICATION $\ldots \ldots \ldots \ldots \ldots \ldots \ldots \ldots \ldots \ldots \ldots \ldots \ldots$

ACKNOWLEDGMENTS $\ldots \ldots \ldots \ldots \ldots \ldots \ldots \ldots \ldots \ldots$

LIST OF FIGURES $\ldots \ldots \ldots \ldots \ldots \ldots \ldots \ldots \ldots \ldots \ldots \ldots$

CHAPTER ONE: STATEMENT OF THE ISSUE $\ldots \ldots \ldots \ldots \ldots \ldots$

Introduction $\ldots \ldots \ldots \ldots \ldots \ldots \ldots \ldots \ldots \ldots \ldots \ldots \ldots \ldots \ldots \ldots \ldots \ldots$

Background of the Children's Initiative $\ldots \ldots \ldots \ldots \ldots \ldots$

Purpose of the Study $\ldots \ldots \ldots \ldots \ldots \ldots \ldots$

Objectives of the Research $\ldots \ldots \ldots \ldots \ldots \ldots \ldots \ldots$

Significance of the Study $\ldots \ldots \ldots \ldots \ldots \ldots \ldots$

Definition of Terms $\ldots \ldots \ldots \ldots \ldots \ldots \ldots$

Outline of the Remainder of the Study $\ldots \ldots \ldots \ldots \ldots$

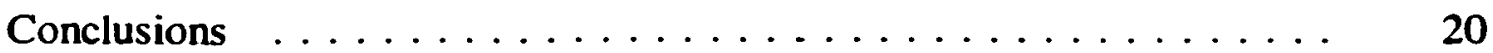

CHAPTER TWO: A NARRATIVE OF THE CHILDREN'S

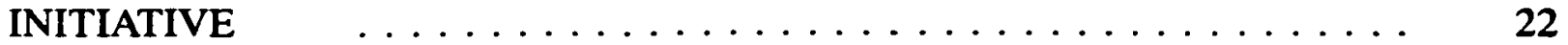

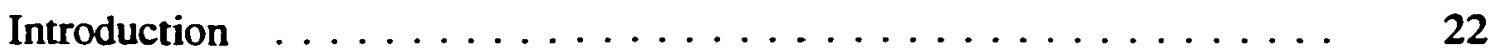

Getting Started $\ldots \ldots \ldots \ldots \ldots \ldots \ldots \ldots \ldots \ldots \ldots \ldots$

Shaping the SAC--The Planning Team $\ldots \ldots \ldots \ldots \ldots$

The SAC Collaboratory $\ldots \ldots \ldots \ldots \ldots \ldots \ldots \ldots \ldots$

xi 
The Roll Out--The Children's Summit, April 27, $1995 \ldots \ldots \ldots$

CHAPTER THREE: REVIEW OF THE LITERATURE $\ldots \ldots \ldots \ldots$

Introduction $\ldots \ldots \ldots \ldots \ldots \ldots \ldots \ldots \ldots \ldots \ldots$

The History and Development of Collaboration $\ldots \ldots \ldots$. . . . 64

Current Theories Relating to Collaboration $\ldots \ldots \ldots \ldots \ldots \ldots$

Shared Vision $\ldots \ldots \ldots \ldots \ldots \ldots \ldots \ldots \ldots \ldots$

Theories of Action $\ldots \ldots \ldots \ldots \ldots \ldots \ldots \ldots$

Stakeholder Analysis $\ldots \ldots \ldots \ldots \ldots \ldots \ldots \ldots \ldots$

Learnings and Results from New Futures $\ldots \ldots \ldots \ldots$

The New Futures Story $\ldots \ldots \ldots \ldots \ldots$

Development of New Futures $\ldots \ldots \ldots \ldots 101$

New Futures Learnings Building the Collaborative Process $\ldots . . .104$

Shared Vision $\ldots \ldots \ldots \ldots \ldots \ldots \ldots \ldots$

Theories of Action $\ldots \ldots \ldots \ldots \ldots \ldots \ldots$

Stakeholder Analysis $\ldots \ldots \ldots \ldots 10 . \ldots \ldots$

Summary of New Futures Findings $\ldots \ldots \ldots \ldots 111$

Initial Study of the Children's Initiative $\ldots \ldots \ldots \ldots \ldots \ldots$

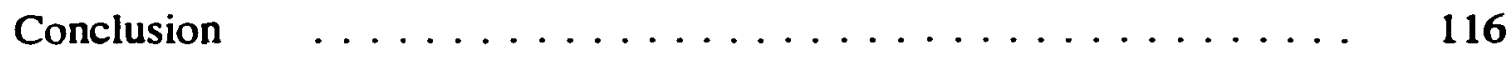

CHAPTER FOUR: RESEARCH METHODOLOGY $\ldots \ldots \ldots \ldots \ldots$

The Descriptive Case Study $\ldots \ldots \ldots \ldots \ldots \ldots \ldots \ldots$

Research Design $\ldots \ldots \ldots \ldots \ldots \ldots \ldots \ldots \ldots \ldots \ldots \ldots \ldots$

Role of the Researcher--The Participant Observer . . . . . . . . 123 
Data Collection ...................... 123

Participant Selection ..................... 127

Pilot Interviews $\ldots \ldots \ldots \ldots \ldots \ldots \ldots \ldots \ldots \ldots$

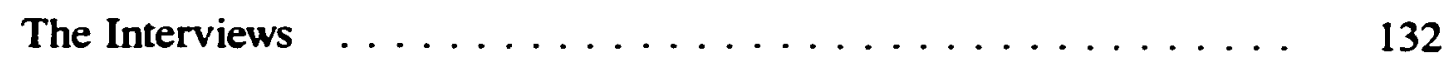

Protection of Human Subjects $\ldots \ldots \ldots \ldots \ldots \ldots$

Data Analysis $\ldots \ldots \ldots \ldots \ldots \ldots \ldots \ldots \ldots \ldots \ldots \ldots$

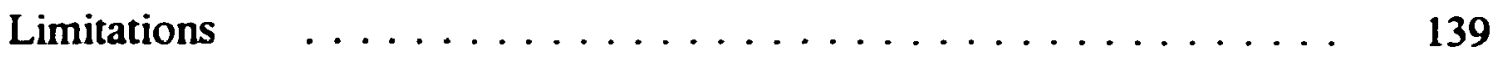

Conclusion $\quad \ldots \ldots \ldots \ldots \ldots \ldots \ldots \ldots \ldots \ldots \ldots \ldots \ldots \ldots$

CHAPTER FIVE: RESULTS $\ldots \ldots \ldots \ldots \ldots \ldots \ldots$

Introduction $\quad \ldots \ldots \ldots \ldots \ldots \ldots \ldots \ldots \ldots \ldots \ldots$

Question One: Degree of Commitment to the Shared Vision ...... 146

Personal Articulation of the Vision $\ldots \ldots \ldots \ldots . \ldots \ldots$

Perceived Gains $\ldots \ldots \ldots \ldots \ldots \ldots \ldots \ldots \ldots$

Perceived Losses . . . . . . . . . . . . . . . . . 161

Question Two: Relationship Among Dynamics ............. 163

Is the Vision Shared? $\ldots \ldots \ldots \ldots \ldots \ldots$

Espoused Theory $\ldots \ldots \ldots \ldots \ldots \ldots \ldots \ldots$

Theories-in-Use $\ldots \ldots \ldots \ldots \ldots \ldots \ldots$. . . . . . . . . . . . . . 169

Tension Derived from Discrepancy $\ldots \ldots \ldots \ldots . \ldots \ldots$

Bureaucracy vs. grass roots $\ldots \ldots \ldots \ldots \ldots \ldots \ldots \ldots$

The doers vs. the processors $\ldots \ldots \ldots \ldots \ldots \ldots$

xiii 
Self-critical vs. take it from here ............... 180

Stakeholder Concerns $\ldots \ldots \ldots \ldots \ldots \ldots$

Summary $\quad \ldots \ldots \ldots \ldots \ldots \ldots \ldots \ldots \ldots$

CHAPTER SIX: DISCUSSIONS AND CONCLUSIONS $\ldots \ldots \ldots \ldots$

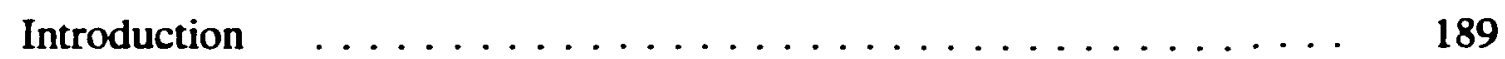

Purpose 1 : Vision, Gains and Losses $\ldots \ldots \ldots \ldots \ldots 1$

Purpose 2: Vision, Theories-in-Use, and Stakeholder Concerns . . . . 197

Recommendations $\ldots \ldots \ldots \ldots \ldots \ldots \ldots \ldots \ldots \ldots$

Purpose 3: Inferences Drawn about the Children's Initiative

Collaborative Effort ...................... 208

Unintended Consequences . . . . . . . . . . . . . . . . 209

Initial Actions of Collaboration $\ldots \ldots \ldots \ldots \ldots \ldots$

The Systemic Change Effort $\ldots \ldots \ldots \ldots \ldots \ldots \ldots$

Summary and Recommendations ................. 219

Purpose 4: Insights $\ldots \ldots \ldots \ldots \ldots \ldots \ldots \ldots \ldots \ldots$

Limitations of Studying Comprehensive Community Initiatives _. . . . 226

Recommendations for Further Study . . . . . . . . . . . . . . 229

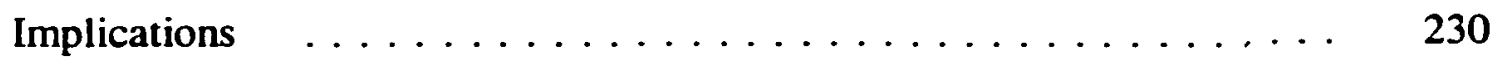

Reflections of the Researcher $\ldots \ldots \ldots \ldots \ldots \ldots \ldots \ldots$

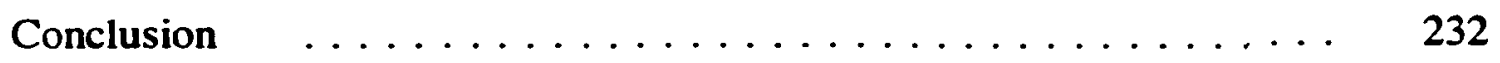

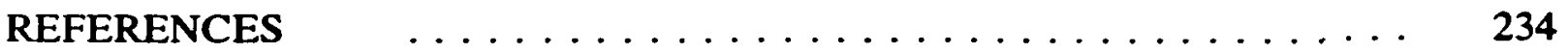

APPENDIX A: THE FUNDERS' BELIEF STATEMENT _ . . . . . . 243

xiv 
APPENDIX B: PARTICIPANT CONSENT FORMS $\ldots \ldots \ldots \ldots \ldots \ldots$

APPENDIX C: THE ROSTER OF THE STRATEGIC ACTION

APPENDIX D: SYSTEM STRATEGIES $\ldots \ldots \ldots \ldots \ldots \ldots$

APPENDIX E: PROGRAM STRATEGIES $\ldots \ldots \ldots \ldots \ldots$

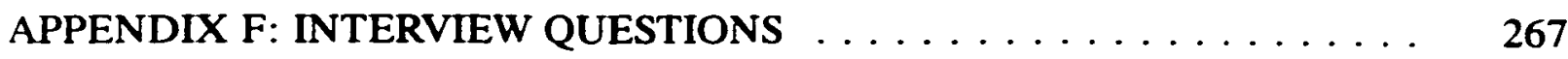

APPENDIX G: CHART OF DATA ON SHARED VISION $\ldots \ldots \ldots \ldots$

APPENDIX H: CHART OF DATA OF ESPOUSED THEORY AND

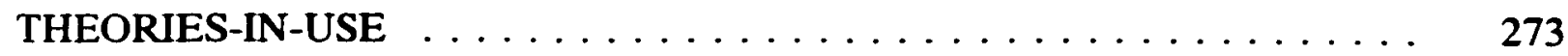

APPENDIX I: CHART O DATA OF STAKEHOLDER ISSUES $\ldots \ldots \ldots$

APPENDIX J: CHART OF DATA ON ISSUES OF COLLABORATION $\ldots . \quad 279$

APPENDIX K: THANK YOU LETTER TO SAC PARTICIPANTS . . . . . . 282

APPENDIX L: DECLARATION OF INTERDEPENDENCE . . . . . . . 284

APPENDIX M: 1999 BROCHURE OF THE CHILDREN'S INITIATIVE . . 286 


\section{LIST OF FIGURES}

Page

1. Transformational and systemic change diagram ............ 36

2. The Year 2000 planning and action pyramid $\ldots \ldots \ldots \ldots$

3. The mastering systemic change diagram $\ldots \ldots \ldots \ldots \ldots$

4. The bullet diagram $\ldots \ldots \ldots \ldots \ldots \ldots \ldots \ldots \ldots \ldots$

5. The double helix $\ldots \ldots \ldots \ldots \ldots \ldots \ldots \ldots \ldots \ldots \ldots$ 


\title{
CHAPTER ONE \\ STATEMENT OF THE ISSUE
}

\author{
Introduction
}

Throughout the country, from large urban centers to small rural towns, communities have taken on the challenge of creating collaboratives on behalf of children and youth. "Creating caring communities and expanding the safety net for children through collaborative community efforts are recommended repeatedly as constructive responses to improve the present status and future well-being of children, youth and their families" (Keith et al., 1993, p. 1). In the early 1990s some of San Diego's most visionary organizations began to investigate the possibility of creating the San Diego Children's Initiative (Children's Initiative). The reasons for creating the collaborative were captured by consultant Judy Chynoweth, an expert in the new and growing field of collaboration. Chynoweth suggested that the rigorous and time consuming effort of collaboration becomes a necessity when people realize that what they are doing now isn't working. "A problem exists that is so serious and complex and so persistent that existing organizations and efforts in isolation of one another have been unable to solve it" (1994, p. vi). Which is to say that the attempt to address a problem as separate organizations, without cooperation can lead to duplication and fragmentation of services. In the area of services directed toward youth and families, agencies and organizations were neither aware nor coordinating services provided, nor 
evaluating the overall effect of the services toward the well being of youth and families. Accordingly, the collaborative strategic planning effort was intended to greatly increase the chances of successful action toward the greater well being of families, youth and children. Cheynoweth noted:

The process can lead to the solution of carefully selected priority problems. It can increase the return on your community's investment of scarce resources as well as encourage other investors to become involved. It can create an environment conducive to the resolution of long-standing conflicts and reduce misunderstanding and prejudice. Finally, although it will not eliminate the need for a wide range of community organizations, a collaboration will enable them to work more closely together to maximize their effectivness. (1994, p. vii) While there are many collaborative efforts throughout the country, few have the breadth or the scope of the Children's Initiative. As will be discussed at length in further chapters, the vision, mission and goals of the Children's Initiative were both perceived and described as being on the furthest edge of the envelope. The beginnings of the Children's Initiative inspired passion within its participants. It is difficult in the introductory section of this dissertation to create the sense of drama, urgency, enthusiasm, energy and electricity that surrounded the workings of the Children's Initiative. In order to capture the degree of difficulty and challenge of this particular collaborative, the participants in the Children's Initiative created a series of metaphors that they were fond of using to describe their efforts. These metaphors were used to point toward the level of difficulty and degree of challenge presented by the 
collaborative effort in attempting to identify and pursue the vision, mission and goals of the collaborative. These metaphorical phrases give to us, the observers, a vivid and graphic introduction to the way the effort was perceived by the participants. Routinely, the work of the collaborative was described as climbing a slippery slope, trying to hang onto a wet bar of soap, pushing past the Berlin Wall, being on the edge of the envelope, or taking us out of our separate silos. The process was insightfully labeled "a collaboratory." By that it was meant that the effort represented a large-scale experiment in the area of inter-agency collaboration. I share these descriptions of the Children's Initiative with you in order to whet your curiosity about the grand scale of this unique collaborative effort.

\section{Background of the Children's Initiative}

The staff of the San Diego Children's Initiative frequently told the story of how the initiative began. The lore of its inception and inspiration became part of its unique appeal. According to the staff of the Children's Initiative in Spring of 1994 we learn that:

At a United Way Board retreat in July 1991, staff and volunteers met to discuss key issues impacting United Way in the coming years. Considerable time was spent discussing the fact that there would never have been enough resources available for any one source (including United Way) to address all community needs. Discussion also focused on the United Way's tendency to be reactive rather than proactive to problems. The retreat participants agreed to explore how to change the paradigm from reactive to proactive. The question became 
how to move the organization toward prevention, long-term, collaborative, "systems change" approaches rather than continuing its focus on short-term, reactive, program-focused funding strategies.

As a result of the retreat, staff was directed to research and present a model to the Board which would move the organization toward the new paradigm. In the course of researching local approaches to children's services, United Way staff discovered that several other organizations were interested in collaborating in the development of the new paradigm. This common interest led to the conceptual commitment to form a private sectors funders collaboration to work together to design an approach to move public and private service delivery systems toward integrated services focused on prevention and collaboration. (Sammy Moon, personal communication, Spring 1994) As an aside Moon added:

Note: This is an exemplary instance of "capturing the passion of the community." In San Diego, the passion was frustration among private funders that considerable resources were having little effect on ameliorating community problems. "Catching the wave" gives an initiative far more staying power than "swimming against the tide." (personal communication, Spring 1994) Because of this passion and catching the wave of the frustration, the Children's Initiative became a collaboration initiated by five major private sector funders of children's services: The San Diego Community Foundation, The Fieldstone Foundation, The Junior League, The Parker Foundation and The United Way. Though 
smaller in stature than the United Way, each of the funding organizations was structured on a similar reactive, project funding model. Each of these organizations had a hiscory of funding programs and organizations which served youth and families. The arm of the United Way reached furthest into the community by bringing together diverse groups of people from business, government, labor and nonprofit arenas in order to assess needs and provide funding for basic necessities. As such the United Way itself functioned more cooperatively with various sectors in the community. The San Diego Community Foundation, Fieldstone Foundation and Parker Foundation contributed generously to the San Diego community based on their respective funding priorities. The Junior League is an organization of women committed to promoting volunteerism and to improving the community through effective action and leadership of trained volunteers. The Junior League served as a founding sponsor of several of the most effective programs serving children and families in San Diego. Many of these former projects went on to become independent organizations.

These five funding organizations came to believe that they might have a greater impact on children and family services by working together rather than separately. The various Boards of Directors agreed to become the funding collaboration and they created an oversight committee called the Steering Group.

The five organizations spent the next 18 months becoming a funding collaborative. In that time, as a group they created a framework for their collaborative efforts. They developed a common vision, mission, beliefs and values statement. The vision was to create a more nurturing, caring and supportive community of people and 
organizations that places top priority on children, youth and families and encourages them to reach their potential. The mission of the Children's Initiative was to strengthen children and families by working for integrated service delivery systems that promote the values of collaboration, prevention and measurable outcomes. They focused on the fields of health, education, safety and economic security. They developed a collaborative governance structure and they pooled the initial operating dollars to provide operating money for the effort. They developed a multi-year funding agreement in order to demonstrate each organization's commitment and be assured of the commitment of the other organizations. They developed an approach to special projects, fundraising, marketing media, and systems change. The five funding organizations agreed to sign a contract of belief statements which was contained in the Multi-year Funding Commitment and can be found in Appendix A.

The funding organizations chose to create a structure for the Initiative that was administratively and fiscally located with one of the collaborating organizations, but was not controlled by that organization. The United Way agreed to be the fiscal agency for the Initiative with governance issues delegated to the Steering Group. The composition of the Steering Group included two representatives from each of the funding agencies. These agencies included the Fieldstone Foundation $(\$ 33,000$ for the first year), the San Diego Community Foundation $(\$ 100,000$ over 3 years) and the United Way ( $\$ 100,000$ over 3 years), one representative from the Parker Foundation ( $\$ 15,000$ for the first year) and the Junior League $(\$ 2,5000$ for the first year), and up to six representatives from the community at large. The initial Chair of the Steering 
Group was named from United Way, and subsequent chairs were elected annually from the Steering Group membership. The steering group began with an initial commitment of approximately $\$ 350,000$ over the first 3 years with the Fieldstone Foundation, San Diego Community Foundation and the United Way as equal partners and the Parker Foundation contributing somewhat less than half of the others and the $\mathrm{Jr}$. League making a smaller contribution. The staff for the Initiative was assigned from United Way. Sammy Moon. a career executive at United Way and the initial dreamer and visionary of the Children's Initiative collaboration, was honored to became the full-time staff for the initiative.

The Steering Group representatives modeled collaboration in their work to create the governance structure for the Initiative. A great deal of time and energy was spent in the first year identifying issues related to turf which could become barriers to the Initiative. Having completed that daunting task, the Steering Group began work on the content of the collaboration. They decided that the emphasis of the Children's Initiative would be systems change rather than program or project development.

With the goals of systems change, the Steering Group mandated the creation of a working group of agencies called the Strategic Action Committee (the SAC). The SAC included representatives from organizations who provided services in the areas of health, education, safety and economic security to children, youth and families. These organizations represented government, business, and community based organizations. Members of the SAC included the top executives of each organization invited to join the SAC and an alternate of high stature in the organizations. The organizations were 
the following: the Chamber of Commerce. Economic Development Corporation, County Health Department, County Social Services, County Administration, County Probation, Union Tribune Publishing Company, Youth Courts, County and City Schools, major youth-serving nonprofit agencies, Military, Private Industry Council, Community Colleges, Police and Sheriff's departments. (See Appendix B for complete roster of the original SAC.) These organizations control a collective budget of approximately $\$ 3$ billion from public and private sources targeted to children and family services. Their charge from the Steering Group was to adopt the vision and mission of the funders' group (see Appendix C) and create new ways of doing business that keep the child in the center. This was an important and novel idea. Keeping the child in the center was distinguished from keeping the well being and maintenance of the service organizations in the center. The phrase was meant to indicate that where the organizations needed to change or sacrifice, for the benefit of children, youth and families, the organizations would readily agree to do so. Following its initial meeting in November of 1993, the SAC agreed to meet monthly and continued to do so throughout the time of this research project. All agreed that it was not enough that the collaborative process create a different way of doing business: rather, that different way must also produce better outcomes for children and families.

In November of 1993, at the orientation meeting of the SAC the following charge was accepted by the members:

1. To develop a better awareness of each sector's business.

2. To explore barriers to cross-sector integration of services. 
3. To develop strategies for new/improved, outcome-focused, cross-sector process relationships.

4. To explore areas of duplication of effort.

5. To discuss common goals/vision regarding how to make children and families top priority for all sectors in San Diego County.

6. To prioritize strategies.

7. To work with the Steering Group to identify potential funding sources to implement top priority strategies.

8. To work with the staff and Steering Group to test/validate strategies at the grass roots level.

Number 5 above has particular interest for this study. The goals of this research included: investigating the degree to which there was in fact common goals and vision; ascertaining what influences the possibility of creating common goals and vision; looking at who was invited to sit at the collaborative table; and determining whether the perception of common goals and vision affect the possibility for success of the collaborative.

At the first meeting, the SAC adopted the vision and mission of the Steering Group. By the following November (1994), the SAC had created three areas of focus, zero to six, safety and violence, and school to career. Zero to six was a confusing title, but to those in the know, it indicated the focus of the committee was childbirth through age six. The development of these areas of focus is discussed in greater detail in 
chapter two. Each area of focus was framed in vision statements, goals and outcome measurements (see Appendix C).

\section{Purpose of the Study}

The general purpose of the research was to analyze and develop an interpretive case study describing the initial collaborative process of the Strategic Action Committee (SAC) of the San Diego Children's Initiative and the implications of the findings for the increasingly important field of collaboration. This study deals solely with the work of the SAC which transpired between November of 1993 and April of 1995 . This is the period which transpires between the first meeting of the SAC and the Children's Summit on April 27, 1995. The development of the SAC from its beginnings through April of 1995 is chronicled in chapter two.

The purpose of the study was to identify some factors that may influence the potential success of a large-scale multi-sector collaborative effort. The research began with the following questions which evolved into the formal research questions addressed in this study. To what extent was the vision shared by individual members of the SAC? If not, what was the SAC member's vision for the collaborative? How did the SAC members demonstrate the degree to which the vision was shared? The research attempted to evaluate the degree to which the perception of various gains and loses by participants influenced their commitment to the shared vision of the collaborative process. What did they perceive were the gains and losses for their respective organizations and/or personally from the work of the Children's Initiative? Did the SAC members concur with the kinds of people sitting at the collaborative table? 
Or to put it simply, were the correct stakeholders represented? Did the SAC members perceive that their actions and their words were giving the same message to their SAC colleagues?

\section{Objectives of the Research}

The purpose of this research was accomplished by addressing the following four research questions and creating a historic narrative of the first phase of the Children's Initiative. The questions are the following:

1. What implications can be articulated about the relationship between perceived gains and losses by members of the SAC and whether these perceptions influence the degree to which the vision is shared?

2. Is it possible to establish a relationship between perceived gains and losses by members of the SAC and whether these perceptions influence the degree to which the vision is shared?

3. What inferences may be drawn about the collaborative process?

4. What insight can be provided into the process of large-scale multi-agency collaboration which is a relatively new field of study and practical endeavor?

Because this study strove to understand the perceptions of the participants, it was decided that naturalistic methodologies and the case study in particular would best serve the purposes of this effort. Qualitative is the preferred methodology when the purpose of the research is understanding perceptions, hearing points of view, and listening to how the participants made sense of the activity. Therefore, the case study approach was utilized in this study because of the high level of local leadership 
involved with the collaborative and the potential this population offered for insights into the collaborative process. It was hoped that the perceptions of the participants would be of great benefit to other collaboratives that work with similar types of executive and high profile community leaders.

In an effort to accomplish these objectives an interview protocol was developed and can be found as Appendix F. Ten SAC members were chosen according to established criteria which can be found in the fourth chapter. The fourth chapter describes in detail the methodology used to complete the research.

Significance of the Study

This case study will increase the knowledge base in the field of multi-agency collaboration by adding to the understanding of what people need to know to develop and promote large scale collaborative efforts. By framing the research within dynamics common to the field of organizational behavior, it is possible to examine them within the intra-organizational arena. These dynamics are presented in the literature review. As the literature review will demonstrate, there are few studies on this subject and the learnings from those studies point forcefully toward the necessity of greater research and deeper understanding of the phenomenon of collaboration.

Additionally this study adds to the understanding of the dynamics of shared vision. stakeholder analysis and theories-in-use. The participants spoke frankly and revealed meaningful insights about how these dynamics influenced their efforts.

Significant portions of the interviews are presented in chapter five and they colorfully present a variety of commentaries by some of the most significant leaders of 
major organizations in San Diego. Their concerns, insights, observations and perspectives may be appreciated and understood by similar kinds of leaders in other places. Since the collaborative effort is often undertaken by those in positions of leadership, the voices of these participants may have enough credibility to assist in the creation of this social phenomenon.

\section{Definition of Terms}

For the purpose of this study certain terms will be defined according to the follow definitions. Agreement upon these definitions is critical because they are used repeatedly in presenting the results of the study. Lack of clarity might lead to misunderstanding the implications of the research effort.

Collaboration--Collaboration is defined simply as "getting the right stakeholders to the table who are committed to a shared vision that they cannot achieve individually" (Johnson. 1993, p. 120). It is a process that leads to actions and results where participants agree to sharing resources and governance, and building consensus. The Amherst $\mathrm{H}$. Wilder Foundation study, whose results were authored by Mattessich and Monsey (1992), defined collaboration as a relationship rather than a process.

Collaboration is a mutually beneficial and well-defined relationship entered into by two or more organizations to achieve common goals. The relationship includes a commitment to: a definition of mutual relationships and goals; a jointly developed structure and shared responsibility; mutual authority and accountability for success; and sharing of resources and rewards. (Mattessich \& Monsey, 1992, p. 5) 
The writers distinguished between coordination, cooperation and collaboration by suggesting a heirarchy of increasingly complex relationships.

Coordination is the least complex and is characterized by short term, informal relationships that exist without any clearly defined mission, structure or planning effort ... there is virtually no risk.

Cooperation is more complex and is characterized by more formal relationships and understanding of compatible missions. Some planning and division of roles is required. . . Authority still rests with the individual organizations, but there is some increased risk to all participants.

Collaboration connotes a more durable and pervasive relationship. Collaborations bring previously separated organizations into a new structure with full commitment to a common mission. Such relationships require comprehensive planning and well defined communication channels operating on many levels. Authority is determined by the collaborative structure. Risk is much greater because each member of the collaboration contributes its resources reputation. Resources are pooled jointly secured and the products are shared. (Mattessich \& Monsey, 1992. p. 37)

Community is a local place where people live and work--a neighborhood, city, a school district (Cheynoweth, 1994, p. vi).

Espoused theory and theory in use are "two kinds of theories of action. Espoused theories are those that an individual claims to follow. Theories-in-use are those that can be inferred from action" (Argyris, 1992, p. 216). 
Shared vision "is a vision that many people are truly committed to, because it reflects their own personal vision" (Senge, 1990, p. 206).

Strategic planning is long-range planning that first defines the desired outcome, then comprehensively assesses the problems and opportunities to use, most effectively, limited resources to achieve results (Cheynoweth, 1994, p. vi).

Stakeholder is any group or individual who can affect or is affected by the achievement of the organization's objectives (Freeman, 1984, p. 46).

Stakeholder approach is a set of theories and strategies for dealing with particular groups and issues. and the processes for integration across issues and groups (Freeman, 1984, p. 27).

\section{Outline of the Remainder of the Study}

Chapter one offered a brief overview and background of the collaboration, and the five research questions that will be explored in order to better understand the phenomenon being studied.

Chapter two documents the beginning phase of the San Diego Children's Initiative. The chapter itself begins and ends with the event that became known as the Roll Out or the Children's Summit, a presentation of the Strategic Action Committee of their Plan for the San Diego Children's Initiative. The meeting before the entire city council and civic leaders from all fields formally concluded the initial phase of Initiative's collaborative efforts. I wrote this chapter as the story of the Strategic Action Committee because I wanted to create in words the sense of excitement, energy, and even frustration that enveloped this initial phase. The second chapter focuses on 
the work of the SAC itself from the time of its inception to the event of the Children's Summit. This chapter provides an in-depth view of the workings of the SAC and the planning team which assisted and charted the course of the SAC.

Chapter three covers the review of the literature. This chapter investigates the scope of the issues involved in large scale, multi-agency collaboration. Several different threads of literature frame this study. The literature chosen is the literature that was most useful in formulating the theories that will emerge from the case study. They include five threads of literature: (a) the history and development of multi-agency coordination and interagency collaborative efforts, (b) current theories about collaboration, (c) shared vision, (d) theories-of-action, and (e) stakeholder analysis. The learnings and results from studying the New Futures collaborative will be presented in this chapter as well as the still unpublished results of an initial study of the Children's Initiative by San Diego State University professor. Anita Harbert. New Futures was a 5-year collaborative "experiment in using private money to leverage public policy and public financing on a major social issue of the day: helping more youth become successful contributing adults" (Center for the Study of Social Policy, 1995. p. ii).

In the fourth chapter, the research design and methodology used in the study are presented. The purpose of this study was to gain a better understanding of the field of large-scale collaboration and the dynamics that influence the potential success of such an endeavor. As a formal social process, the collaborative effort is a relatively new phenomenon. It is becoming a critical component of the organizational menu because 
of the social, political and economic tenor of our times. The collaborative was rich with potential and would have lent itself to many different scholarly efforts either qualitative or quantitative. Because this study strove to understand the perceptions of the participants it was decided that naturalistic methodologies and the case study in particular would best serve the purposes of this effort.

The rationale for the naturalistic approach is the following. The individuals involved with the Strategic Action Committee are among the most influential in the county. Their breadth of experience, individual and collective knowledge, and varied backgrounds created a unique and exiting population to study naturalistically. They would surely have a great deal to say and teach about the collaborative effort. It was in the best interest of this investigation to use the words and ideas of this auspicious group to better understand the dynamics involved in such an endeavor. The case study paradigm allowed for theory to emerge from understanding the collaborative dynamics as perceived by the discrete and contained group of participants representing the Strategic Action Committee. As Merriam suggested, "in this paradigm, there are no predetermined hypotheses, no treatments, and no restrictions on the end product" (1988. p. 17). In this inquiry, the questions being investigated included how are the dynamics of vision, theories-in-use and who is represented at the collaborative table, related and how do these dynamics influence the potential success of the large scale collaborative process? The relationship between these dynamics was best investigated through a descriptive case study where the research is "exploratory, inductive and emphasizes processes rather than ends" (Merriam, 1988, p. 17). 
Several sources of evidence were used in conducting the research. The researcher was the primary instrument for data gathering and analysis. Evidence was gathered from archival documents of the Children's Initiative including: organizational notes, papers, agendas, minutes, publicity material, internally published materials and other materials distributed by the organization. Additional evidence includes notes taken by the researcher and interviews of 10 members of the SAC conducted by the researcher. Two pilot interviews were conducted as well. The SAC members were chosen to represent each of five areas which provide services to youth and families: health. education, safety, economic security and ad hoc community-based organizations. Additionally SAC members were chosen based on their levels of involvement. At the time of conducting the interviews during the spring of 1997 , several SAC members had changed jobs and/or left the county or state. The 10 members of the SAC were chosen to be interviewed by consensus of the researcher, the former director Sammy Moon and the former interim acting director Liz Shear.

Prior to conducting this research study, approval was obtained from the Protection of Human Subjects Committee of the University of San Diego. The participants were each members of the original SAC. All participants of the study voluntarily participated in taped interviews lasting from 30 to 45 minutes in duration. There were no reasonable, anticipated risks or discomfort to the participants other than those ordinarily encountered in daily life. The participants were interviewed in their offices with the exception of one interview which took place in the home of the researcher. 
Each participant was asked to sign a Human Subject Informed Consent Form which included the basic considerations as are specified by the University of San Diego. By signing this form the participants agreed to having their names and organizations used in this study. Further, the inability to provide anonymity was directly discussed with each participant by the researcher prior to the interview (see Appendix B).

The culture of the SAC encouraged free expression of thought even when the thoughts being expressed did not concur with those of the leadership or the majority. The interviews reflected the culture of candor and the participants were more forthcoming than I had anticipated. It is also possible that the passage of time and a sense of nostalgia for the good old days influenced the attitudes of the SAC members.

The fifth chapter presents the findings and results of the interviews with the 10 SAC participants. The chapter is organized according to the theoretical threads presented through the literature review. In this chapter the members of the SAC speak for themselves about how these dynamics influenced the collaborative process. Because so many of the words in this chapter come directly from the mouths of the participants, the chapter presents a lively debate of the collaborative effort as well as the feelings, insights and perceptions of the SAC participants.

The sixth chapter presents the discussion, analysis, conclusions and recommendations according to the issues addressed by the research questions. In addressing the four research questions, relatively straightforward responses will be made for the first two questions. The theoretical material pertaining to these issues has already been discussed in the literature review. The data which are required for 
responding to the questions have been presented and analyzed in the previous chapter. However the third and fourth question are more open-ended and provocative. The third question regarding inferences that may be drawn about the collaborative process will include discussions drawn from the review of the literature and inferences drawn from the data presented in chapters two and five about the unintended consequences, initial actions of collaboration, and the systemic change effort. Finally, in order to answer the last research question and truly provide insight into the large-scale multi-agency collaborative process, members of this dissertation committee suggested that I research the Children's Initiative beyond the scope of its initial phase. To that end, I spoke with the current Executive Director of the Children's Initiative, the chairman of the Board of Directors of the Children's Initiative, and a member of the funders group.

The purpose of these conversations with three individuals currently involved with the work of the Children's Initiative was to investigate what happened during the implementation phase of the Initiative. Those who were advising this project believed that unless we knew something about what happened next as it related to the vision, mission, and goals of the collaborative, it would be difficult to offer insights, perceive implications or suggest learnings.

\section{Conclusions}

As an observer, my goal was to provide a self-reflective document which can serve the Children's' Initiative and others who are attempting large-scale collaborative efforts in the social service fields. Through the scope of this study it has remained clear that the difficulty of the collaborative task is immense. This research may 
facilitate a better understanding of dynamics influence the likelihood of achieving a shared vision which will guide the work of the collaboration and which may be a critical component to the possibility its of long-term success. 


\title{
CHAPTER TWO
}

\section{A NARRATIVE OF THE CHILDREN'S INITIATIVE}

\author{
Introduction
}

The purpose of this study is to better understand particular dynamics that may influence the outcome of a large-scale multi-agency collaborative effort. This investigation focused on attempting to determine the relationship between specific dynamics which influence the success of the large-scale multi-agency collaborative effort. The first chapter outlined the creation and background of the San Diego Children's Initiative. This chapter will focus on the development and initial phase of the SAC. It begins and ends with the event that became known as the Children's Summit, a presentation of the Strategic Action Committee of their Plan for the San Diego. The chapter will document the internal workings and results that led to the Children's Summit in April of 1995. These can be divided into the following categories: getting started, the Planning Team, the SAC collaboratory and the Children's Summit.

Internally, it was called The Roll Out. Formally, it was called the Children's Summit. It took place at the San Diego Convention Center, the morning of April 27, 1995. At that time hundreds of individuals whose lives were in some way involved with providing services to youth and families, witnessed a unique event. They experienced members of the leadership of San Diego making a commitment to "put kids 
first" among their individual and collective priorities. What made this gathering momentous was that the Strategic Action Committee (SAC) members presenting a vision, a mission and some very specific goals and strategies represented organizations which may have been competitive, adversarial or unknown to one another only sixteen months earlier.

Those in attendance that morning might have assumed that the individuals who are the heads of the largest service agencies in a city were accustomed to working together or well known to one another. The audience might have believed that it is only natural for the Chief of Police to be well acquainted with the head of the Probation Department, for example, or for the Superintendent of Schools to be chummy with the heads of the Department of Social Services, or Department of Health Services. We might presume that the individuals who lead the largest organizations would be familiar with the work of the community-based organizations who work with the highest risk youth all over the city. These assumptions were erroneous. Perhaps not even those in attendance understood how miraculous was the gathering of these leaders demonstrating their respect for one another, and their collective commitment to do business differently by putting kids first through collaboration. They were members of the Strategic Action Committee, the SAC, who in December of 1993 as virtual strangers to one another, began the first phase of their collaborative journey which culminated with the Children's Summit in April of 1995. 


\section{Getting Started}

In 1993, the Steering Group sponsored 15 community forums to involve parents and children in discussions regarding significant issues in their lives and neighborhoods. Concurrently a Committee of over 100 individuals developed the Children's Future Scan (United Way/CHAD, 1993) to document the demographic, economic, social, and public sector trends affecting the lives of children. Creating the document provided an opportunity to conduct public education and gave the Initiative a chance to collaborate successfully on a relatively non-controversial, low-risk but important project. The Children's Furure Scan found that several components were missing in order to provide for the well being of all children in the county. Sammy Moon, who became the full time staff for the Children's Initiative, summarized the findings and made the following observations.

There was little coordination between and among systems in the planning and delivery of health and human care services for children and their families. An improved data collection system was needed to track program outcomes and funding trends. There was a need to pursue more public-private collaboration to maximize scarce resources. (personal communication, July 1994)

The findings of the Euture Scan were momentous because visually, through moving photos of children in need, and graphically, through text and vivid quotation, they described the challenge to the community. The Future Scan told stories that allowed children and youth to speak in their own words and some of their stories were chilling and sounded the alarm to service providers. 
The Committee of 100 also crafted the vision of the Children's Initiative. According to initiative lore, the vision and mission was crafted and wordsmithed until no individual or specific group could take credit for its message but it was a creation of the Committee of the 100, the community forums and the Steering Group. This research focuses on the extent to which the vision is shared by SAC members. The theoretical material presented in chapter three debates the value of adopting rather than creating a vision and how this influences commitment to that vision. Therefore, it will become quite significant to this effort that the vision for the Initiative was completed prior to the forming of the Strategic Action Committee.

The vision was adopted by the Steering Group who mandated the creation of a working group of agencies called the Strategic Action Committee (the SAC) and developed a formal charge to the Strategic Action Committee. The charge focused primarily on systems change, though the definition and meaning of systems change proved a constant challenge for the Steering Committee and later the Strategic Action Committee. This will be discussed at some length later in this chapter. At this point, it is fair to suggest that the Steering Committee meant to charge the separate organizations to radically change their internal priorities in order to work with the other organizations which provide services to youth and families.

In order to do so, the Steering Committee mandated that the organizations commit themselves to achieving the several lofty goals. These goals included a commitment to: 
developing better awareness of each sector's business; exploring barriers to cross-sector integration of services; developing strategies for new and improved, outcome-focused cross-sector "process" relationships; discussing common goals and visions regarding how to make children and families top priority for all sectors in San Diego County; developing resource needs to implement new and improved process relationships; prioritize strategies; work with the Steering Group to identify funding sources; and work with the staff and Steering Group to test strategies at grass roots level. (Steering Group Letter, personal communication. Spring 1993)

These goals mandated radical changes in the way that the organizations were responding to the needs of their respective clients, stakeholders, constituents, employees and communities. The phrases that indicate the radical nature of this endeavor include: cross-sector integration of services, and outcome-focused cross sector process relationships. While a bit wordy, their intent was clear. They called for the providers to cooperate. The fulfillment of these required that organizations work together in new ways and reduce the duplication of services found in the larger community. Potentially, the charge presented extreme implications for each organization.

With the charge and vision in hand the Steering Group sought to create the Strategic Action Committee. They sought out the most appropriate individual to chair the SAC. They chose Blair Sadler, president and CEO of Children's Hospital. As a provider of services to the county's children, Children's Hospital was intimately 
involved with many of the other service providers. Sadler himself commented upon his appointment.

When Stan Foster and other members of the Steering Group asked me to chair a Strategic Action Committee to develop an agenda for change for children in San Diego, I was both flattered and humbled by the request. As one who has been involved with children's issues for nearly 15 years, the opportunity to help develop a comprehensive framework for improving the well-being of San Diego's children was a great opportunity. It was especially exciting because it was to go far beyond health issues by including all the other key disciplines relating to kids. It was also daunting to think of the scope of the task at hand. In recruiting committee members, we turned to individuals from major organizations, with the greatest resources, targeted to services for children and families. We also enlisted leaders from the business community and leaders who worked directly at the neighborhood community level. (Sammy Moon \& Veronica Welsh, personal communications, Fall 1995)

In the Summer and Fall of 1993 together with members of the Steering Group, Sadler personally recruited the prospective members of the SAC. Often he paid a visit to the offices of the busy executives, toting in hand the recently adopted vision and mission. For the most part, his colleagues were eager to participate in such a promising opportunity for change although many were concerned about the commitment of time the SAC would require. Because of the time concerns a few took a bit of arm twisting and one or two even declined the opportunity to become involved. By the end 
of the recruitment process the SAC included representatives from organizations who provided services in the areas of health, education, safety and economic security to children. youth and families. These organizations represented government, business, and community based organizations. Members of the SAC included the top executives of each organization invited to join the SAC and an alternate of high stature in the organizations. The organizations were the following: the Chamber of Commerce, Economic Development Corporation, County Health Department, County Social Services, County Administration, County Probation, Union Tribune Publishing Company, Juvenile Courts, County and City Schools, major youth-serving nonprofit agencies, Military, Private Industry Council, Community Colleges, Police and Sheriff's departments. (See Appendix B for complete roster of the original SAC.) These organizations managed a collective budget of approximately $\$ 3$ billion from public and private sources targeted to children and family services.

Having recruited the initial Strategic Action Committee, Sadler set up a schedule of monthly meetings. At the first meeting in December of 1993, 28 virtual strangers began that process of attempting to get to know one another. At that first meeting several important decisions were made relatively quickly. The SAC as a group accepted the charge from the Steering Group and immediately adopted the following vision and mission statement which had previously been adopted by the Steering Group. The Vision Statement of the Children's Initiative was to create a more nurturing, caring, and supportive community of people and organizations that 
places top priority on children and families and encourages them to reach their potential. The Mission Statement of the Children's Initiative stated that the Children's Initiative is a collaborative effort among individuals and organizations representing the government, private nonprofit, and business sectors of San Diego County. It is dedicated to strengthening children and families by working for integrated service delivery systems that promote the values of collaboration, prevention, and measurable outcomes in the fields of health, education, safety and economic security.

The actual acceptance of the vision and mission at this first meeting was the subject of one of the research questions investigated by this doctoral dissertation. The degree to which this vision and mission was accepted will be discussed at some length in the beginning of chapter five and in the discussion section of chapter six.

At the first meeting the SAC accepted the mandate to create new ways of doing business that keep the child in the center. Keeping the child in the center was distinguished from keeping the well being and maintenance of the service organizations in the center. The phrase was meant to indicate that where the organizations needed to change or sacrifice, for the benefit of children, youth and families, the organizations would readily agree to do so. All agreed that it was not enough that the collaborative process create a different way of doing business: rather, that different way must also produce better outcomes for children and families. Following its initial meeting, the SAC agreed to meet monthly and has continued to do so through the time of this research project. 
During the first months, the agendas of the SAC meetings were devoted to presentations from each organization. Sadler began working with an ever-evolving Planning Team including official and unofficial consultants, members of his own staff at Children's Hospital. and Sammy Moon. the full time staff of the Children's Initiative. The Planning Team tried to create a system which would be the most cohesive way for each organization to organize information about itself. The Planning Team devised four questions to be answered by each organization and in doing so, each organization was asked to create and present an organizational profile. The executives responded to the four questions in relation to both the overall organization and how it related to children, youth and families. The questions were:

1. What is your organization's mission?

2. What services do you provide? (Please indicate if the services are primarily remedial or preventive.)

3. Who, specifically, benefits from your services? (Please describe your client population.)

4. How are these services delivered?

Several months were devoted to this important, "getting to know one another phase" of the work of the SAC. SAC members were expected to be candid about the strengths and weaknesses of their organization. Sadler hoped that this extensive sharing would create a camaraderie and level of trust among the SAC members. At the conclusion of the meeting in July of 1994, each SAC member was asked to rate on a scale from 1-10 the difficulty of the collective tasks. The responses were reflective and sincere, with a 
range of responses from impossibly difficult, to difficult but achievable to, in the scheme of life--not that difficult. One of the SAC members reminded the group that for the welfare of children in San Diego the difficulty of the task had better be a 2 and not a 10. If the real Berlin Wall can come down, so can ours.

The months of organizational sharing concluded with a final question posed to the SAC at the August of 1994 meeting. Sadler asked, "What can the Children's Initiative do for you?" Sadler then went around the room, from one person to the next and each executive thoughtfully answered. The responses to that probing question demonstrated a deep commitment to the collaborative process. There were 17 members of the SAC present on that evening. The responses are presented below divided into the areas of health, education, safety and economic security and ad hoc community based organizations.

What can the Children's Initiative do for you?

\section{Health}

1. Enthusiastic about working with the private sector (Department of Social Services).

2. Major infusion of dollars to fully transform the system throughout the organization and not just at the top (Department of Health Services).

3. Help to broaden our horizons and help to build coalitions. Creates an opportunity to pool our resources (American Academy of Pediatrics). 
4. Forge the agenda for the future of San Diego's children, identifying community priorities for action and resource commitment and facing a systems approach (Children's Hospital).

5. Learn techniques for having organizations embrace the philosophical ,change in orientation (Department of Social Services).

\section{Education}

1. Provide a focus on children and families, opportunity for networking and insightful thinking about whole aspects of collaboration, i.e., resources and programs (San Diego City Schools).

2. Provide collaboration to provide protective factors for children--caring and support, high expectations, and opportunities for meaningful participation (County of San Diego, Office of Education).

\section{$\underline{\text { Safety }}$}

1. To encourage understanding among agencies (San Diego Police Department).

2. Create a more nurturing, caring and supportive community of people for every child by:

a. Start training people at an early age in terms of the skills needed to parent and the obligations of a parent.

b. Preference to community rights versus individual rights. 
c. More personal accountability to the community--every program needs to be able to respond to the question, "How does it create community that is consistent and sustained?" (Superior Court).

\section{Economic}

1. Providing big picture leadership and reduce redundancies (San Diego Consortium and Private Industry Council).

2. Create collaborative alliances, while overcoming turf issues and returning to core values (Chamber of Commerce).

3. Help us focus our community efforts (San Diego Union Tribune).

4. Provide more jobs in the basic sectors and leadership for youth (San Diego Economic Corporation).

\section{Ad-hoc Community Based Organizations}

1. Help eliminate some of the red tape and make it easier by cutting across lines to deliver services (Social Advocates for Youth).

2. Address the extent to which communities participate in their own policy development (San Diego Organizing Project).

3. Be an example of a learning organization. By working together we can make change happen, since no organization can do it alone (Social Advocates for Youth).

4. Be more creative and open, developing new synergies in solving problems, and change the definition of the problems (San Diego Organizing Project). These declarations demonstrated the intent and willingness of the SAC members to undertake the challenge of collaboration. The next step was to begin to understand 
what that entailed. Although the SAC meetings took place monthly and for a duration of only 3 hours, a much greater amount of work was done by the Planning Team. The Planning Team met at least twice a week. The Planning Team met so often that, with good humor, Sadler began to remind himself that he already had day job.

Shaping the SAC--The Planning Team

While the progress of the SAC moved more slowly, the Planning Team sped along. It is valuable to spend a moment or two introducing the instrumental members of the Planning Team. This Planning Team was culled from a variety of places. Someone knew of an individual who focused on system change as it related to providing services to children, another person was well known for public relations, another a consultant and trainer of executives. The individuals who comprised the Planning Team varied. They included Sadler and various members of his executive staff (Cheri Fiddler. Jim Boylan); consultants: including Carol Hallstrom, director of the National Conference (formerly the National Conference of Christians and Jews, and who later became a member of the SAC representing a community-based organization), Stephen Haines, president of the Centre for Strategic Management in San Diego, Sid Gardner, director of the Center for Collaboration for Children, California State University. Fullerton: Sammy Moon who was by this time full time executive director with the Children's Initiative, Veronica Welsh who was the assistant director responsible for the SAC: Laurie Coskey, intern, and various members of the SAC depending on the subject of the planning meeting. These meetings took place weekly and much more often with specific work responsibilities for all in between meeting times. 
A typical example of the behind the scenes work of the Planning Team is the following. Using their expertise, the Planning Team brainstormed a set of what they called "Top Barriers" to remove, eliminate and overcome in order to collaborate successfully. At the following SAC meeting this list of barriers was presented to the SAC. The task of the SAC was to chose the top three barriers which together they faced. The "Top Barriers" created by the Planning Team included all of the following.

1. Political barriers/quick fix mentality/categorical funding.

2. Lack of systemic change approach.

3. Community involvement in policy making/planning.

4. Institutional readiness/fear of taking risks.

5. Lack of overall collective leadership--shared/common vision.

6. Intervention/treatment vs. prevention (lack of 0-6 ownership/focus).

7. Lack of respect for diversity/racism.

8. Lack of skills--energy- time- resources for everyone.

9. Failure to recognize/reward importance of good parenting.

10. Lack of emphasis on accountability/outcomes.

The complete SAC received all 10 of these choices. The purpose of the exercise was to trigger conversation in the SAC as to the greatest possible barriers to collaboration. After debating in small groups, the SAC reached consensus and chose the first three barriers as the most critical for their work together. These barriers were then referred to in future meetings as agreed-upon road signs along the way. In this way the Planning Team charted the direction of the SAC. 
The greatest challenge for the planning team and the SAC came in attempting to understand the meaning of systemic change. The consultants presented a pyramid of change (Figure 1) in an attempt to help educate and organize for the undertaking.

\section{TRANSFORMATIONAL AND SYSTEMIC CHANGE}

(How to "Educate and Organize" for this Undertaking?)

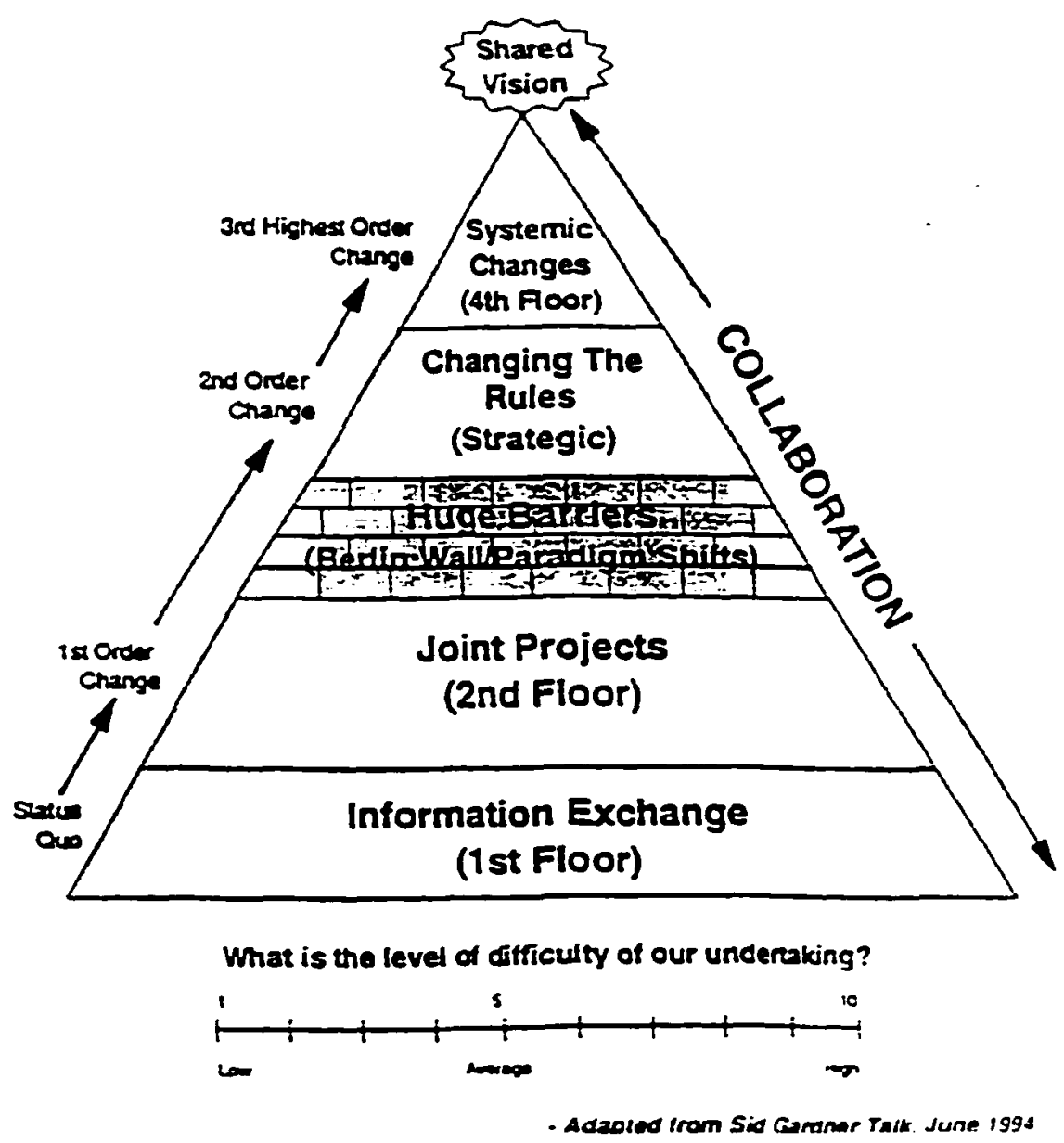

Eigure 1. Transformational and systemic change diagram. 
This pyramid diagram became affectionately known and referred to as the Berlin Wall because it pointed to the difficulty of effecting real change as being comparable to the difficulty of taking down the Berlin Wall (a momentous event of the recent past and an event which was difficult to even imagine). The Berlin Wall diagram presented levels of change beginning with the maintenance of the status quo which is presented as an exchange of information among organizations. The next level is described as first order change and it consists of joint projects. Many of the SAC members had participated in joint projects prior to the convening of the Children's Initiative. According to the diagram in order to proceed to the second order of change the effort must dismantle barriers as established and institutionalized as the Berlin Wall. A paradigm shift must occur in order to dismantle the Wall and reach the second order of change which is described as changing the rules. In this case the paradigm shift referred to putting the child in the center, making the well being of children. youth and families the top priority, rather than the maintenance of the organization as the central organizational task. Dismantling the Berlin Wall represented a change in the governing structure of the country. Dismantling the Berlin Walls that separated organizations was meant to represent significant change in the way that organizations were structured to provide services to youth and families. In the Berlin Wall pyramid diagram, the third, and highest order of change, represented systemic changes that are guided by a shared vision and a high degree of collaboration. This pyramid became the hallmark for both the Planning Team and the SAC as a whole. It was often referred to in terms of measuring the level of change being designed or attempted. The level of difficulty was 
frequently described as being at the Berlin Wall or past the Berlin Wall. In addition to the materials required for each meeting the Berlin Wall pyramid was handed to SAC members in order to recollect the difficulty of the task at hand and the commitment to push beyond joint projects.

A second Action Pyramid (Figure 2) was developed by the Planning Team following the June SAC Advance (the day long meeting of the SAC). The Pyramid was presented as a visual and compelling breakdown of what needed to be accomplished by the SAC. The Year 2000 Planning and Action Pyramid was intended by the Planning Team to be an action blueprint and process road map.

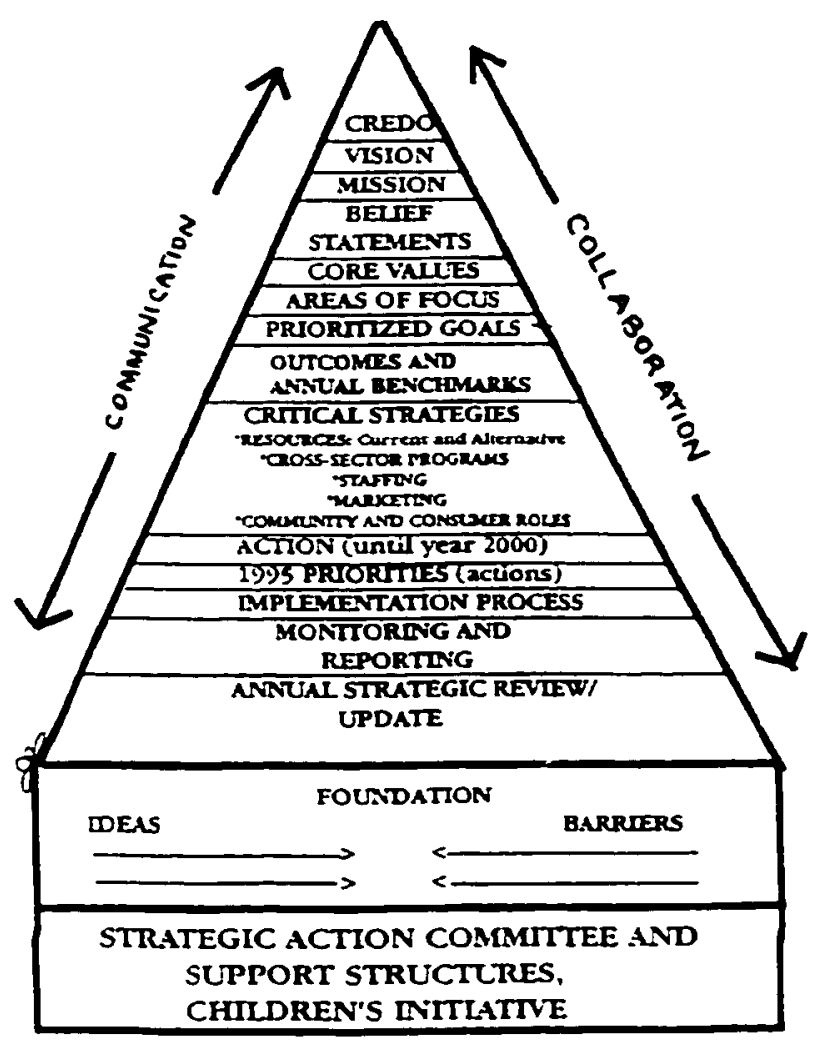

Figure 2. The Year 2000 planning and action pyramid. 
Additionally, the consultants helped the Planning Team and later the full SAC to answer the question of "how does systemic change occur" (see Figure 3). It was a constant challenge for the experts to bring in the information that would be immediately useful without being too simplistic or too dogmatic for a group of practitioners.

These levers to change are dependent upon a shared vision and mission which will be the main focus of later chapters of this dissertation. The identified levers of change describe the magnitude of the undertaking and the scope of the stakeholders. The Planning Team attempted to connect their work with this change effort in order to guide the large SAC toward systemic change rather than joint projects. Consultant Steve Haines gave the SAC criteria by which to measure their burgeoning efforts. Steve Haines' list of criteria is the following:

\section{Criteria for Systemic Change Efforts:}

Does the effort meet these tests of Systemic Change?

1. Does it address removing Political Barriers (or is it a quick fix/short-term mentality)?

2. Does it really deal with Systemic Change (i.e., "changing the rules")?

3. Is there ongoing "community/key stakeholder involvement"?

4. Does it involve shifting of money, roles and responsibilities, and staff?

5. Does it involve proactive prevention as well?

6. Does it involve shared leadership and a collective vision?

7. Does it involve cross-section/horizontal involvement and leadership? 


\section{MASTERING SYSTEMIC/STRATEGIC CHANGE}

What are "the levers" to change to make systemic change happen? (With a shared collective vision - mission - values as "a given.")

The levers include significant (massive) changes to:

1. The full universe/population if target clients/customers.

2. People as resources.

3. Roles/structure.

4. Use of money.

5. Physical location/regular communications and meetings.

6. Rules/policies.

7. Information access around the business/mission.

8. Decision-making access/process.

9. Performance Management System (goal setting - accountability - rewards/ recognition).

10. Capacity building:

- skills = process

- knowledge/awareness $=$ content

11. Fitting pieces/parts together, look at the whole system or process.

12. Clarity and perseverance/visibility of goals/measures/strategic priorities.

13. Political marketing.

14. Management Implementation Process - and a yearly map.

15. A plan to overcome identified barriers.

-and finally-

16. It must involve significant change to the three key underlying fundamentals of the change efforts.

(1) Content (2) Process

(3) Structure Design

Figure 3. The mastering systemic change diagram. 
8. Does it work with a show "system" (i.e., individual-family-teamcommunity-organization)?

9. Does it involve "systems learning"--including feedback, outcome measures-on an ongoing basis?

10. Does it have a contagious-passionate-motivating catalytic effect on others, spreading the results?

Copyrighted by Centre for Strategic Management (personal communication, 1993)

It should be noted that the SAC was given these criteria for systemic change. At that time, there was debate among the planning team members as to whether the SAC understood and bought into the importance of the systemic change part of the collaborative. Since these criteria were created by the consultants, it is unclear whether or not the SAC absorbed or understood the issues.

In order to do the real work of pushing beyond the Berlin Wall, the SAC created a framework of three focus areas. Each SAC member chose to focus her or his attention into one of the three focus area committees: Zero to Six, Safety and Violence and School to Career. The Planning Team and specifically the staff and consultants spent a great deal of time working with statistics regarding the status quo in these areas and developing the cross-cutting issues and the hard questions with which the focus area committees would have to grapple. A charge to the Focus Area Committees was initiated by the Planning Team and driven by the SAC as a whole. The lofty goals of the charge included: 
1. Establish goals, outcome measures for the year 2000 and annual benchmarks in the defined focus area.

2. Develop an awareness of what is either currently being done or planned for throughout the community that advances these goals.

3. Explore barriers to cross-sector integration of services.

4. With community involvement, develop strategies for new/improved, outcome-focused cross sector "process" relationships.

5. Identify action steps to reduce barriers, reduce duplication of effort, and to test/validate strategies at the grass roots level.

6. Develop resource needs to implement new/improved strategies and action steps.

7. Work with SAC to identify potential funding needs to implement top priorities.

The staff and planning committee identified chairpersons and membership for each of the three Focus Area Committees (FACs). Some SAC members were assigned FACs outside of the area of his or her expertise in order to facilitate a fresh perspective in each area. The initial FAC meetings which took place within short range of one another shared the agenda of (a) clarifying the goals delineated by the SAC, (b) adding or changing goals if necessary, (c) specifying outcome indicators and sources of data for the goals identified, and (d) initial discussion of difficult strategy questions. The Planning Team implemented and staffed the work of the FACS including developing a list of potential prioritized county-wide goals based on county, state and national plans. 
It is hardly possible to capture the frenzy of work that went into the punctilious collection of statistical information relating to the concerns of each focus area. This responsibility fell primarily on Welsh's shoulders. The task was tedious and endless. New or improved information was constantly added from a variety of sources since no central clearing house existed for gleaning these significant statistics.

The Planning Team presented their findings at the SAC meetings. The full SAC reviewed and further developed potential prioritized county-wide goals/outcomes for each focus area. Each step that was taken by the SAC was anticipated and prepared for by the Planning Team. This was a great asset to the SAC and also the cause for concern by some that they had been cut out of the loop. However, the Planning Team was open to any SAC member who had the time to commit to its rigorous schedule. By August of 1994, the staff and Planning Team were coordinating the activities and work of three active FACs and the SAC as a whole. The agenda for the Planning Team meeting of August 17, 1994 was the following:

\section{Children's Initiative} $8 / 17 / 94$

Set up task force meetings between Labor Day and September $20^{\text {h }}$ meeting. Call Chairs of each group and arrange dates/times. Tuesdays at 5:30 has seemed to work most often.

Need for catch up meetings for those who have not been able to attend:

Bertha Pendleton, Gene Bell, Bob O'Neil

For discussion:

How to facilitate task force meetings

Ground rules for Steering Committee members who attend the SAC

Review of workplan

Adding resource people to the focus groups 
TO DOs:

Develop "expert" list

Develop "stakeholder list:"

Update roster

Obtain other data sets

Develop list of "hard questions"

Schedule "catch up" meetings

Schedule focus group meetings (Children's Initiative Staff, personal communication, 1994)

This agenda provides just a glimpse of the work taking place behind the scenes by staff, consultants and the Planning Team.

By October an additional Planning Team had been convened. This

Communications Planning Team brought to the forefront questions on publicity, stakeholders, who should have a voice in the process, how should the community be informed about the work of the $\mathrm{CI}$ and other important issues. Chief among the issues was the concern about whether the process should occur from the bottom-up, the topdown or both concurrently. The importance of this question cannot be emphasized enough because in every realm the SAC, the FACS and the Planning Teams became entrenched in this issue. The debate over ownership of change processes both bogged down and buoyed the work of the Children's Initiative at all levels. What became certain is that the individuals engaged in the discussion whether community organizers or lifetime bureaucrats were changed and expanded by the ongoing debates. The agenda of the Communication's Planning Team of October 5, 1994 reflected this debate. 


\section{Children`s Initiative \\ COMMUNICATIONS PLANNING TEAM \\ $10 / 5 / 94$}

Communications Plan Objective: create culture or receptivity to change.

Steps:

1) Build a thorough understanding among funders (education) and as well as among SAC members

2) Reinforce or validate the CI's participants themselves via recognition of individuals and through them their organizations. Reinforce or validate the $\mathrm{Cl}$ participants via involving them as spokespersons.

3) Build cornerstone premises--

To explain why the $\mathrm{CI}$ exists,

What is its value

(CI vision, mission, belief statements?)

4) Build positive goal statements (AC visions?)

5) Create "imagine if" statements

6) Next layer (of the circle) for communications

Educate members of the organizations represented by SAC

To do this: identify content experts from the SAC who will attract attention and capture interests. Have them do presentations using packaged information kits possibly with video and developed for SAC members or other CEOs.

7) Next layer of the circle:

Need to do presentations to the community for buy-in and feedback.

Also develop media presentations for the general public.

8) Next layer:

Politicians/policy makers

9) Youth involvement must also be included at some level.

To help develop the information we will use.

1) Review "What the CI can do for me" document from minutes. Compare this to where we are now to see how it fits.

2) Look at the Statement of Agreement to see if it sheds light on the role of the SAC and CI.

Discussion re group process vs. structured leadership--key points:

1) Need to put on the table who owns this process

2) Maybe need to "open up" and look at the group being actively involved in deciding how to get from where we are now to where we want to be 
3) Be careful not to just get the CBO folks together. Must also include leaders from the big institutions

4) We're going to need to "let go" and not feel that we have to have everything laid out ahead of time. (Children's Initiative Staff, personal communication, 1994)

Note the complexity of the debate even on paper. The last section clearly presents a tension between the group processors vs. the structured leadership. This tension will be dealt with more fully in chapters five and six.

By the fall of 1994, the complexity of the collaborative effort had descended like a dark cloud which might yield much needed rain or a storm which would wreak havoc. Frustrations in the Planning Team reflected frustrations among the SAC members. The tensions surrounded the continuing questions of community involvement and the rate of change. There were some who vocalized frustrations that the Initiative wasn't taking action quickly enough and there were others who vocalized opinions that there was not enough process prior to taking action and the Initiative was moving too fast. And the chair, Sadler, was juggling the frustrations and the tensions of the SAC members trying to accommodate the varying needs and perspectives. These concerns and frustrations, which were critical to the collaborative process, are dealt with at length in chapters five and six.

The Planning Team continued to lead the work of the FACs and to direct the work toward the creation of two categories of strategies: systems change strategies and program strategies. These two categories fulfilled the mandate of the charge to the FACs by establishing goals and outcome measures, creating cross-sector integration of services, and a plan for community involvement and funding. The Planning Team and 
the SAC worked through the remainder of the 1994 year and well into Spring of 1995 to cull, distill, negotiate, debate, cogitate and agitate about the systems change and program strategies. It was believed that the Systems Change Strategies and Program Strategies would lead toward the same set of outcomes. A graphic portrayal of the idea was created by members of the Planning Team (Figure 4).

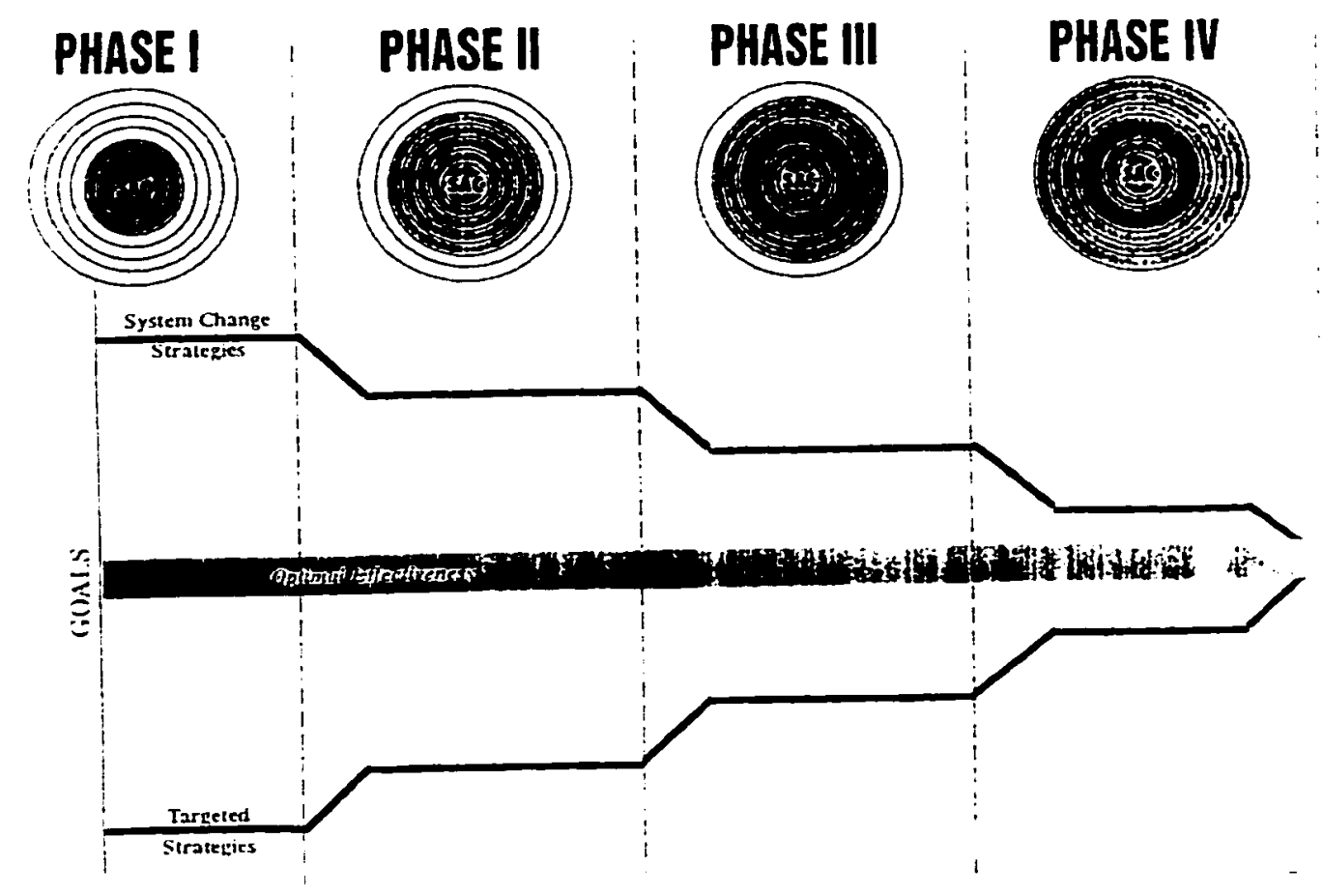

Figure 4. The bullet diagram.

This diagram demonstrated the expanding nature of the SAC community, and stakeholders in the Children's Initiative, over time to include greater community 
involvement and the eventual fusion of the systems and program strategies. The broad band in the center represented the range of optimally effective efforts: strategies which held the greatest promise and required broad based networks of collaborative relationships. The upper line represented strategies targeted specifically on improving the status of children. Its movement toward goal achievement and optimal effectiveness tracks depended upon the progress of the movement toward systems change. As the collaborative relationships improved and expanded, they opened the door for more efficient and effective programs. The lower line represented program strategies that were more problem focused and that more specifically addressed each goal area. The image of the future potential and benefit to children of the systems and program strategies embraced and created by a greater and greater stakeholder community lead Sadler to work with his favorite metaphor, the double helix. He created a dual missions double helix representing an individual organization and the Children's Initiative woven through mission and purpose to the benefit of children and families in San Diego.

Looking at Figure 5, The Double Helix, Sadler envisioned that each organization's vision and mission would be intertwined and interdependent to, and with, that of the Children's Initiative. Each organization would adopt this double helix and write their vision and mission on the left side of the page.

The SAC Collaboratory

As has been described in the last several pages, the Planning Team met several times weekly to fulfill the mandates of the SAC which met as a whole once a month 


\section{The Statement of \\ Mission or Pupose \\ of any \\ organization. \\ public or private, \\ profit or: aOn-profit, \\ which adopts the \\ Mission and Vision \\ of the Children's \\ Initiacive.}

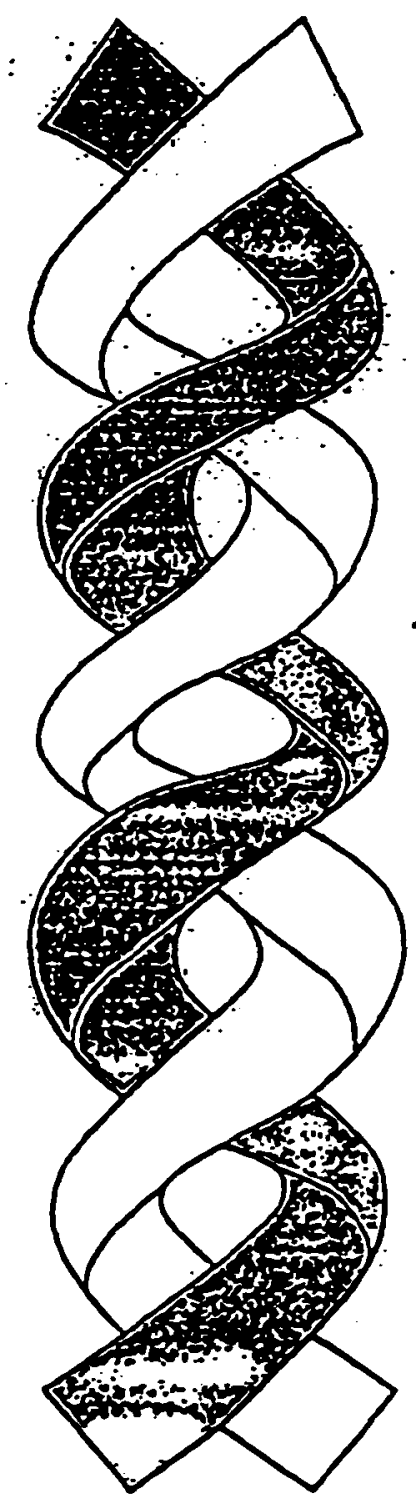

To create a more nurturing

caring and supporive community

of people and organizations that

places top priority on childien

and farnilies and encourages them

to reach their full porescial.

To work to achieve:

Infanes born healthy

Children who stay healthy

Freedom from abuse

Childreo staring school ready wo learn

\section{Reduction of intentional violence and unintentiona!} injury and death

\section{More young adules who are ready to enter the world of work and/or pursue higher education \\ Greater high quality employment opportunities for young adults and family breadwinners.}

Eigure 5. The double helix 
with day or half day advances taking place each quarter. The SAC itself coined the phrase collaboratory. By that the SAC referred to itself as a laboratory in the great experiment of large scale multi-sector collaboration. The phrase was intended to keep the idea that they were charting new territories in the forefront of their minds as they continued to struggle through their efforts.

The members of the SAC collaboratory increasingly understood the necessity for learning at the level of the organization, the community, and even the individual. As heads of bureaucratic organizations the members of the SAC needed to restructure their ideas about doing their business. This was a grave challenge for the members of the SAC who have primarily been trained to work for and protect the turf of their separate silos. The concept of collaboration--the values, framework and action strategies that it demanded--required a significant change of values, mindset and orientation. The implications suggested that the SAC members were no longer able to maintain the paradigms, assumptions and methods that had allowed them to proceed throughout their careers. Moon and Welsh articulated the challenge:

The immense difficulty of changing the cultures of large, long established institutions and the ways in which they operate virtually demands that those pursuing such changes have compelling reasons to do so. The organizational leaders who make up the Strategic Action Committee (SAC) found such reasons in our attempts to define ways of fulfilling the Vision of the Children's Initiative. 
Each of us came to the SAC table knowing the common frustration of achieving less-than-hoped for results in our unilateral efforts. Each of us had already realized that our own organizations cannot accomplish all that we wish without some type of help from others. Working together, the members of the SAC discovered that the scope and complexity of the issues that must be addressed surpass even the formidable resource of the SAC organizations collectively. The strategies which hold the greatest promise lie beyond our reach because they require a web of collaborative relationships which do not exist today: relationships between and among the organizations who make up SAC, and, even more importantly, relationships between and among us and the diverse communities, groups, families and people we serve. (Sammy Moon \& Veronica Welsh, personal communications, January 1995)

Over the next 6 months the SAC took on the rigorous process of creating a collaborative strategic plan which addressed the purpose and goals of the Children's Initiative. Members of the SAC became involved in FACs and, from time to time, the Planning Team. The SAC members were donating an increasing number of hours to the effort and some were lending the time of members of their staff to gather the hard facts and figures necessary to create the systems and program strategies. There existed a sense of frenzy and frenetic activity while data was being sought, analyzed and compiled from endless, incomplete, and sometimes inaccurate sources of data. Information and data relevant to the three Focus Areas was presented at SAC meetings by SAC members, members of their staffs, and city and county experts. 
Meetings were well attended and informal networking and banter took place before, during and after. The atmosphere was filled with goodwill and often marked by laughter and joking. At the same time there were increasing tensions over the issues of community involvement and the directionality of the planning process, top/down or bottom/up. There was continued frustration over the pace of the work with some frustrated by a lack of "action" and others frustrated by moving too quickly. This frustration is addressed at length in chapters five and six.

In addition to frequently describing the difficulty of the collaborative challenge as moving out of the separate silos and past the Berlin Wall, other strong images were invoked to give force and clarity to the work of the SAC. The metaphors used by Sadler and SAC members vividly demonstrate the degree of difficulty of the collaborative tasks at had as they were perceived by SAC members. During this time of information gathering and creative activity Sadler would often suggest that an activity felt like taking a drink of water from a fire hydrant. The work was described as climbing a slippery slope, on the edge of the envelope, attempting to hang on to a wet bar of soap, or attempting to reach a clarity of focus as at the optometrist's office when the patient is asked to distinguish between lens A and lens B. Sadler frequently threw his arms open wide and exclaimed "Hey, we're building this plane as we're flying it!" Concerning the issues and tensions regarding community involvement, the image of bubbling up and down at the same time was used to defend the top down/ bureaucratic approach while giving credence to the necessity for community engagement. When these tensions were exaggerated a driving metaphor was invoked; 
the image of having to choose which side of the road on which to drive. However, the question of who makes the choice brought the issues back full circle. In chapter five the SAC participants in this study describe the process vividly and at length.

Toward the end of 1994 and the beginning of 1995 the questions of community engagement and involvement were continuously addressed by both the Planning Team and the SAC. During the fall of 1994 the SAC maintained a strong focus on the creation of the program and systems strategies. It was anticipated that the work would be completed by the conclusion of the year. However, the task of creating the collaborative strategies proved too demanding for its originally anticipaied deadline. The effort was tedious, time consuming and wearing. The agenda for the December 1994 Advance attempted to stoke the fires of the SAC members. The content of the meeting reinforced the necessity of capacity building, collaboration, overcoming the barriers, commitment to annual reviews of outcomes, community engagement and other nuts and bolts required to build the plane. The content also attempted to reawaken enthusiasm and passion for the effort. SAC members rediscussed what it is that drew them together. what they wanted to do that improves the lives of children in San Diego, and what did they need to know to get there from here. The recommendations from the Advance included: (a) initiating an annual outcome review process, (b) establishing a process to influence public policy, (c) facilitating an integrated data management system for tracking, (d) creating a media collaborative, (e) creating a youth congress, and (f) developing a process for engaging the community on a county-wide basis.. 
The beginning of 1995 saw renewed intensity for the work of the SAC. The FACs were working to refine the program strategies. The Planning Team had created the Two Track Process and presented its diagram to the SAC as a whole together with the systems track which the staff and had refined from SAC work. The SAC completed the work of the FACs and through lengthy and heated debate distilled the systems and program strategies to 7 system strategies and 10 program strategies. The systems strategies are included as Appendix D and the program strategies are included as Appendix E. In writing the SAC members agreed to commit themselves to the implementation of the actions developed by the SAC and to working within their organizations to obtain organizational support (Appendix L).

Plans were made for roll out events--the opportunity to share and discuss with leadership, the Steering Group, and communities the collaborative strategies developed by the SAC. The SAC had become a formidable network for leadership in San Diego and a forum where new laws, grants, and other government actions or proposed activity would be introduced and debated. Because of its scope, the Children's Initiative had captured attention of other collaborative efforts and scholars nationwide as well as funding organizations such as the Robert Wood Johnson Foundation. In chapter five several of the SAC participants comment upon the national advantage and positioning of the Children's Initiative.

The Planning Team and the SAC readied themselves for the Roll Out events to the Funders and Steering Group, the Robert Wood Johnson Foundation and the public at large. These meetings were thoughtfully choreographed so that the collaborative 
nature of the enterprise could be easily ascertained though the style of presentation.

The Funders and Steering Group meeting on March 22, 1995, provides a good example.

\author{
Children's Initiative \\ SPECIAL FUNDERS MEETING \\ March 22, 1995 \\ Embassy Suites Hotel
}

A G E N D A

WELCOME AND SPECIAL RECOGNITIONS . STAN FOSTER, CHAIR CHILDREN'S INITIATIVE CEO, FOSTER INVESTMENTS

WHAT THE INITIATIVE REPRESENTS JUDY MCDONALD PARKER FOUNDATION WHY THE INITIATIVE IS IMPORTANT JANINE MASON-BARONE FIELDSTONE FOUNDATION

WHERE WE STARTED AND WHERE WE ARE NOW $\ldots \ldots \ldots \ldots \ldots$ SAMMY MOON EXECUTIVE DIRECTOR, CHILDREN'S INITIATIVE

SAC'S 14 MONTHS TOGETHER

BLAIR SADLER, CHAIR STRATEGIC ACTION COMMITTEE PRESIDENT AND CEO, CHILDREN'S HOSPITAL

SYSTEMS CHANGE/PROGRAM STRATEGIES/COMMUNITY

ENGAGEMENT

BLAIR SADLER

SYSTEMS CHANGE/PROGRAM STRATEGIES . . . . . . . . VERONICA WELSH, Ph.D. ASSOCIATE DIRECTOR, CHILDREN'S INITIATIVE

A. School to Career

AURELIA KOBY SAC MEMBER DIRECTOR CONSORTIUM/PRIVATE INDUSTRY COUNCIL

B. Zero to Six

BOB ROSS, M.D. SAC MEMBER DIRECTOR COUNTY HEALTH DEPARTMENT 
The then Chairman of the Steering Group, Stan Foster, opened the meeting with welcoming remarks which included recognition of the SAC members and members of the funding organization. Appropriate people were graciously thanked including visitors and especially Sadler. The SAC was commended on the 14 months of work that brought them to this time of presentation and celebration. Judy McDonald, representing the Parker Foundation, was invited to discuss the meaning of the Children's Initiative. She explained the initiative was a unique collaboration of private nonprofit service providers and Funders, public sector providers and Funders and the business sector all focused toward the common goal of making San Diego County a better place for children and their families. The Initiative was described as a unique opportunity to change the paradigm about how services to children and families are funded, delivered, measured and evaluated. The SAC offered the leadership the opportunity to be a learning organization that would take greater risks and learn from itself and others about how to be more effective. McDonald pointed to the uniqueness 
of the original charge to the SAC and shared some thoughts about the learnings of the funding organizations. She introduced fellow steering Group member, Janine MasonBarone from the Fieldstone Foundation who spoke about the critical need for the Children's Initiative at this time in history.

Barone cited statistical proof for the need of interventive measures on behalf of children and families. Choosing her words carefully she indicated that current trends in the government may be less child friendly than would be hoped for and that these trends point toward fewer resources which dictated that more must be done with less. The Children`s Initiative aimed toward reducing duplication and competition, and increasing collaborative use of resources. Barone introduced Moon. the Director of the Initiative, who briefly shared the history of the Initiative and who introduced Sadler who discussed the work of the SAC. Sadler's comments included the challenge, structure, philosophy, evolution, learnings, and frustrations of the 14 months. He explained how the work of the SAC led toward the development of the three focus areas, 10 goals and created outcome indicators, and how these efforts directed the SAC to realize that there were two parallel tracks: the systems change strategies and program strategies. Welsh, the associate director, introduced the systems change strategies which were then explained by members of the SAC representing business, education, health and safety sectors. The importance of business involvement was stressed which was one of the unique elements of the Children's Initiative. It was pointed out that children grow up to be workers in businesses. Economic security is critical to family stability. The school to career focus area covered two perspectives: (a) student readiness for jobs; and (b) 
adequate career opportunities for youth who are graduating. Youth need mentors from the business community. The business interest in the collaboration stemmed from the knowledge that for a community to be attractive for business development it needs to be safe. secure, affordable--all of which are reflected the goals of the Initiative.

Sadler and leaders of the San Diego Community Foundation discussed the need for funding for the infrastructure of the Children's Initiative and for the systems and program strategies. Sadler requested multi-year funding commitments from the Funders. The Community Foundation renewed its multi-year funding pledge and urged the other funding groups to do the same. Sadler concluded the presentation with a few inspiring words and invited comments and questions. The presentation was inspiring because the collaborative players had never before agreed to work together. The magnitude of the commitment was apparent and inspiring to those in attendance.

By March of 1995 the SAC was ready to "roll out" the Children's Initiative to the Community if San Diego. The debate of "roll out" or "roll over" was still hotly discussed among the SAC members. But with the systems and program strategies in place and a plan for community engagement, the SAC had reason to celebrate. At the SAC meeting Sadler asked the group to think about and share three to five things that their respective organizations are doing differently based on the Children's Initiative. The responses demonstrated the potential impact of the collaborative process. The following are the responses of the SAC members off the top of their heads.

The Department of Health Services was participating in significant collaborations including: (a) the Polinsky Center collaboration with Department of 
Social Services, Probation Department, Children's Hospital, University of California at San Diego (UCSD), and Department of Health Services; (b) the Building Healthy Futures collaborative which became integrated into the Children's Initiative; and (c) violence prevention.

The Probation Department had integrated services and blending funding with Department of Social Services and Department of Health Services. They were seeking collaborative grants with Social Advocates for Youth and other grants with the County Office of Education.

The Sheriff's Department reported that it had created a team approach with probation and other law enforcement agencies and that changes were coming from within the department.

The Private Industry Council (PIC) was working with (a) Department of Social Services on joint deliver to put resources together to insure that youth get what they need. (b) community colleges developing a system for long-term follow-up for youth. (c) County Office of Education to provide additional training, and (d) using the New Beginnings data base.

The County Office of Education had worked with the PIC to expand the schoolto-career program. is seeking collaborative grants, places stronger emphasis on 0-3 and the preschool arena because of the 0-6 focus of the Children's Initiative.

The Department of Social Services' greatest effort was an in-house departmental approach to changing attitudes. Additionally they were collaborating with communitybased organizations in several areas of the city. 
The Navy representative reported that they were collaborating with law enforcement, San Diego schools and seeking to improve data bases.

The Academy of Pediatrics admitted that the Children's Initiative had not changed much in the relationships of the Academy thus far. The Academy was experiencing an identity crisis of sorts and needed to become lobbyists and more involved.

Children's Hospital representatives pointed to greater collaborative involvement, home visiting programs which involve Department of Social Services, Department of Health Services, schools and law enforcement and a significant change in internal thought processes and decision making.

The County Office of Education representatives cited collaborative grant seeking at all levels and collaborative health prevention efforts.

The community college representatives noted that they wove collaboration as part of their educational master plan. The Children's Initiative had demonstrated the importance of data exchange and collaborative work. The colleges were working better with the Offices of Education and the Navy. Additionally the relationships were more collegial and familiar and less formal.

The community based organizations, San Diego Youth and Community Services, Social Advocates for Youth and National Conference representatives each pointed out that their organizations had long been involved in collaborative efforts. San Diego Youth and Community Services was experiencing a greater level of friendship with the collaborative organizations and was taking the lead of the newly created Youth 
Congress. Social Advocates for Youth noted that the SAC gathered in the face of a trend and that they are steering the change.

Sadler concluded the conversation noting that he saw people viewing the world differently, making connections and experiencing a mind shift. He described the Children's Initiative effort as the little engine that could.

From the comments by the SAC members present on that evening it seemed clear that the members were reaching out of their separate silos. The Children's Initiative had influenced the largest organizations/bureaucracies most profoundly. There existed an extraordinary camaraderie among the SAC members. There was a level of comfort and warmth among people who had been strangers to one another only a year before. The SAC members were changing the face of services provided to children in San Diego as much through their building the collaborative and communal spirit among themselves as through the potential of their lofty vision, mission and goals.

The Roll Out--The Children's Summit, April 27, 1995

The weeks preceding the Children's Summit were filled witi anticipation and frustration. Because the attendance of elected city and county officials was deemed absolutely necessary the scheduling of the exact date was as challenging as any other task the SAC had taken on during the last 14 months. It was critical to the SAC to have the official blessing of the elected leaders.

The Summit was well publicized and SAC members were encouraged to invite not only their staff but leaders within the organizations with which they regularly 
network. It was hoped that the Summit would reach all organizations which provided services to youth and families. One of the purposes was to engage the extended San Diego Community, to extend the web of active stakeholders in the vision and mission of the Children's Initiative. One of the results was that the "folks" not participating in the SAC were keenly aware of their own absence at the SAC and didn't feel very folksy about the connections and relationships that had been built around them. For example, neither parent organizations nor religious organizations had been invited to participate in the initial phase of the SAC. In chapter 5 the SAC participants discuss the issues surrounding who was invited to sit at the collaborative table.

The Summit was carefully choreographed to present the image of camaraderie and collaboration among the SAC members that would be required to gain credibility for the collaborative's lofty goals. The presentation was short and to the point, much tighter than the Funders meeting the prior month. The brief program included introductions, the report of the SAC, remarks from the mayor and the head of the County Board of Supervisors and the SAC communal commitment. The program and system strategies were presented by pairs of SAC members. While the audience may not have fully appreciated the deliberate pairing, the message was clear. Each SAC member was paired with a SAC member who was at one time a stranger, with whom he or she had never worked or networked: business was paired with education, community based organizations with the chamber of commerce, probation with the academy of pediatricians. The meeting visibly demonstrated the commitment to compromise and collaboration. Those in attendance received both a document titled "A Proposal to 
Improve the Health and Well Being of San Diego's Children" and an executive summary prepared by Sadler. The document included a rational for the creation of the Children's Initiative and the work of the SAC, a justification for the three areas of focus. a presentation of the program and system strategies and a statement of commitment and intention.

The brief, but momentous morning of the Children's Summit represented the conclusion of the first phase of the work of the SAC. Sadler's eloquent commitment to action which concluded the meeting known as the Children's Summit, began the next phase of the work of the Children's Initiative. The proposal document concludes with a commitment to transition from the visioning phase to the phase of action. Within a few weeks there was significant change in staffing as well as change in focus of the work of the Children's Initiative.

This dissertation is concerned with the period of time that concluded with the Children's Summit. No matter what the later transitions or successes and failures, up to this moment, those individuals involved clearly demonstrated a commitment to stretch themselves and their institutions into new ways of thought and action. The individuals involved and perhaps their institutions will be forever changed for having attempted the process in this grandiose manner. The remainder of the dissertation will analyze and interpret the initial work of the SAC in order to investigate whether certain dynamics may have influenced the potential of the collaborative. 


\section{CHAPTER THREE \\ REVIEW OF THE LITERATURE}

Introduction

The issues involved in large-scale, multi-agency collaboration are extensive and complex. Several different threads of literature will frame this study. This presentation will review the most useful literature in formulating the theories that will emerge from the case study. They include five separate theoretical threads: (a) the history and development of multi-agency coordination and interagency collaborative efforts, (b) current theories about collaboration, (c) shared vision, (d) theories of action, and (e) stakeholder analysis. The learnings and results from studying the New Futures collaboratives, as they relate to the purposes of this investigation, will be presented at length, and finally, the still unpublished results of an initial study of the Children's Initiative will be included.

The History and Development of Collaboration

Perhaps in the 1980s Aharoni captured the essence of humanity's drive to improve the quality of life not only for oneself but for one's community. Aharoni noted the ability of humanity to rise to the task. "People are complex: they can be greedy and selfish, but they can also be part of a community for which they are sometimes willing to make sacrifices . . especially in times of crisis" $(1981$, p. 31$)$. Perhaps this is the reason that people are driven to be dissatisfied with a status quo that 
is not successfully accomplishing its purpose. With that assessment of human nature in mind a brief overview of the development of collaboration will be presented.

Already in 1946, Alinsky captured the critical need for collaborative problem solving. His words, almost poetic in their passion, written more than half a century ago, ring true in our own times.

There is none more important [lesson] than that no single people's institution, regardless of its strength or size, can resolve the issues facing mankind. The failure of the institutions of the people to solve basic issues is the result not only of their jealous isolation from each other but of the same mental isolationist policy concerning their objectives. They have forgotten that there is no such thing as a single problem, that all problems are inter-related, that all issues are part of a chain of human issues and that a chain is no stronger than its weakest link. (p. 216)

From that time forward, ideas about the need for and difficulty of democratic processes of problem solving and inter-agency cooperation were articulated by increasing numbers of scholars and educators (Lowi, 1979; Williams, 1982). Negandhi (1969) noted that the interdependencies between agencies were intuitively understood in the 1950s and 1960s. These interorganizational relationships became more formally studied in the late 1960s. Questions were put forth framed by a new understanding of systems theory and a challenge of traditionally held ideas about organizational boundaries. 
In Redesigning the Future, Ackoff described the Systems Age as one in which an interdisciplinary approach is required for finding solutions to complex problems.

In the past a complex problem was usually decomposed into simpler problems suitable for different disciplines. Then each discipline would solve its part of the problem and these solutions would be assembled into a solution of the whole. But contemporary interdisciplines do not work this way; a variety of disciplines work together on the problem as a whole. For example, experts in health, housing, transportation, education and other aspects of urban life work together on a city's problem taken as a whole rather than divide it into parts suitable for each to work on separately. $(1974$, p. 15)

According to Ackoff, the assumptions made in the past, that each societal problem may be adequately addressed by independent sectors and disciplines, proved inadequate to improve or solve the challenges facing an increasingly complex society. He suggested that "collective action directed at redeveloping society can arise only out of desperation and hope" (p. vii). The redevelopment he envisioned is one "in which a variety of disciplines work together" (p. 15) in solving problems as a whole. He was concerned with three central problems (p. 18): self-control, which he defined as designing and managing systems that can cope with the complexities of the tasks and relationships; humanization, which he defined as the work to be done within the various parts of the system; and environmentalization, which he defined as "putting into a system's mind its relationship to the whole of which it is a part" (p. 55). In other words, rather than approaching problem solving by simplifying the problem and dividing it into separate 
areas. Ackoff used a systems approach to broaden the scope of the problem and approach problem solving looking at the complexities and opportunities of the bigger picture.

Mason and Mitroff (1981) described required transformations in the field of policy making in order to deal with problems of organized complexity that they label "wicked problems." Wicked problems exhibit characteristics of interconnectedness, complicatedness, uncertainty, ambiguity, conflict, and societal constraints (pp. 13-14). Wicked problems "require new methods of real world problem solving to guide their policy-making activities. Otherwise, they run the risk of setting their social systems adrift" (p. 13). According to the authors there are two major implications for policy making:

1. There must be a broader participation of affected parties, directly and indirectly, in the policy-making process.

2 Policy making must be based on a wider spectrum of information gathered from a larger number of diverse sources. (p. 13)

Policy making and implementation affect a broad spectrum in agencies and individuals. The scholar's implications were pointing toward a paradigm shift more directly addressed by other social scientists.

Scholars (Emery \& Trist, 1965, 1973; Guba \& Lincoln, 1989; Harman, 1989; Morgan \& Ramirez, 1984; Perlmutter \& Trist, 1986; Williams, 1982; and others) refer to the 1960 s, 1970 s and early 1980 s as a period of continuing turbulence. In addition to the trauma reflected in these turbulent times these scholars pointed toward a global 
change. which can be described as a paradigm shift. This paradigm shifi moves toward a more constructivist, collaborative, and interconnected society.

Even assuming the greatest active adaptive capability and best intentions, single organizations do not possess the ability to contain and control the trends that are exerting the most critical influences on societal directions in the future. ... New social designs are required at levels intermediate between the single stakeholders and the government to enable societies' members to become actively involved in managing the changes affecting them. (Williams, 1982. pp. 173-174)

Throughout his work, Williams described several innovative sociological designs. From these studies he concluded:

The innovating organizations have broadly based local support and are outside of official administrative hierarchies. They seek to cooperate with government agencies, but they attempt to deal with the issues affecting their futures holistically rather than in piecemeal fashion according to fragmented functional responsibilities as defined by government bureaucracies. They establish the possibility, at the local level, of active adaptation through participation and collaboration. (p. 175)

The shift can be simply stated as a transition on all levels, macro, meso and micro, from either/or to both/and (Perlmutter \& Trist, 1986). The either/or paradigm implied an absolute right and wrong. It was an essentially black and white world view. Redford contended that "there is an inherent loss of humanity when super stances are 
taken--when two opposing sides push to be right rather than work toward a blend of common interests" (1987, p. 107). The effort to work toward a blend of common interests represents the shift toward an either/or world view. For example, Gray noted that

public-private partnerships that have sprung up to address deteriorating conditions in U.S. cities are illustrative of collaborative efforts across sectors to advance shared visions. In these partnerships, public and private interests pool their resources and undertake joint planing to tackle economic redevelopment, education, housing and other protracted problems that have plagued their communities. $(1989$, p. 8$)$

The structure of the interorganizational relationship became important and was studied by scholars. Van de Ven, Walker, and Liston (1979) proposed that it was critical to determine the different reasons for interorganizational relationships and to understand their structure. Structure was the main concern for Frombrun (1986), who argued for understanding structuring as having societal consequence. Horwitch and Prahalad, spoke of the new kind of institution as the Multi-Organizational Enterprise (MOE) which was "being used to respond to large-scale societal concerns" $(1981, p .3)$. They identified five major structural characteristics of MOEs:

1. They are established to accomplish a mission.

2. They often contain participating groups that demonstrate different cultures, assumptions, priorities and goals.

3. They can be both public and private organizations. 
4. Usually only a small part of each of the various organizations that participate in an MOE is actually involved in that effort, and the component organizations continue to maintain their separate identities.

5. MOEs are usually large. They require significant funds and employ thousands of employees from several organizations. (p. 3)

Meyer and Scott analyzed early efforts of interagency problem solving. When analyzing these kinds of interorganizational relationships, Meyer and Scott theorized that "with few exceptions, these field models have concentrated on horizontal linkages among organizations--that is, linkages among organizations lacking formal authority or fiscal control over one another" $(1983$, p. 131). They noted that the efforts connected by these horizontal linkages in the 1960 s and 1970 s failed to achieve their desired changes in the delivery of human services. Their observations and criticisms found that there was: (a) a disparity between client needs and services provided, (b) inaccessibility of programs, (c) duplication of effort, (d) absence of services, and (e) cooperation was constrained and restricted (p. 135). By the early 1980s they reported accounts of increasingly elaborate implementation and coordination systems which provided "important evidence of the growing interconnectedness of organizational systems--both public and private--in American society" (p. 138). The scholars noted a trend toward what they called societal sectoralization.

The concept of societal sector is broader than that of industry or industry group, for we wish to include also those organizations comprising the set of the focal industry group--namely, those organizations that contribute to or regulate their 
activities. For example, the "housing sector" might be said to consist of all the public and private organizational units, relations, and flows relevant to maintaining and adding to the supply of housing in a society. Such a definition would encompass units from many different industries and industry groups--for example. components of the construction, banking, public administration and insurance industries. (pp. 138-139)

What Meyer and Scott (1983) have called societal sectoralization in today's terms might be considered the collaborative and the stakeholder approach. They postulated three types of decision making: programmatic, instrumental, and funding (p. 143); and three types of sector controls: structural, process, and outcome (performance) (p. 148). They created a series of hypotheses which suggested how the three areas of decision making and the three types of sector control may be interrelated in societal sectoralization. Their groundbreaking hypotheses led later theorists and practitioners toward interagency and inter-sector collaboration involving a wide variety of stakeholders.

\section{Current Theories Relating to Collaboration}

The collaborative process is studied as a new phenomenon resulting from turbulent environments and the recent paradigm shift. The surge in collaborative ventures caused Gray to theorize about the "contextual" incentives to collaborate. The following contextual incentives may be more prevalent in turbulent environments:

1. rapid economic and technological change

2. declining productivity growth and increasing competitive pressures 
3. global interdependence

4. blurring of boundaries between business, government and labor

5. shrinking federal revenues for social programs

6. dissatisfaction with the judicial process for solving problems. (1989, p. 29)

These factors, or a combination of them, may influence or inspire interorganizational interactions. A case must be made for the benefits of the collaborative process and the futility of that which has been done until now. The example of collaborative efforts directed to youth at-risk is most illuminating.

The need for interagency collaboration may be most significant in the field of providing services to youth and particularly at-risk youth. Numerous articles which argue the need for interagency collaboration of services begin by presenting a dismal picture of youth at-risk, either a heart-wrenchingly true story or a composite picture of the breakdown of the bulky, cumbersome, unwieldy system designed, with best of intentions, to attempt to help and improve the lives of their designated population (Edelman \& Radin, 1991; Gardner, 1989). Gardner noted, "the headlines chronicling the youth problem are familiar: high rates of school dropout, unemployment, gang membership, juvenile incarceration, drug abuse, delinquency and teen pregnancy" (1989. p. 19). He argued that it is an obligation of a community to provide services to those who are powerless and that the obligation requires a community to provide effective services which achieve the purpose for which they were designed. He claimed that it is not "ethical behavior to provide an inferior service that we know will fail to achieve its purpose" (Gardner, 1993, p. 2) and that the maintenance of the status quo 
which is a fragmentation of services is unethical. He subsequently argues for and defines collaboration, suggesting that:

It is difficult to define ideal collaboration since no community has yet fully linked, counted and evaluated its youth services. But basically, genuine collaboration entails the creation of a community process to plan a service system for children. youth and families in which no new programs are started without participation by existing programs: schools and public and private agencies are linked horizontally in partnerships, rather than stacked vertically or allowed to float separately; funding is "pooled" rather than categorized to avoid turf protection; the many services needed by a child . . . are "brokered" by one agency or a cross-agency "case manager"; employers are important players; and publicized annual indicators of youth "outcomes" allow citizens to hold political and agency leaders accountable for results. (pp. 21-22)

Much of the literature echoes Gardner's ideas (Edelman \& Radin, 1991 ; The National Assembly of National Voluntary Health and Social Welfare Organizations, 1991). A study sponsored by the Amherst H. Wilder Foundation noted that "collaborative partnerships among human service agencies offer the ability to deliver services based on the total needs of clients--and the possibility of a truly integrated service system" (cited in Mattessich \& Monsey, 1992, p. 6). According to the authors, the collaborative relationship "includes a commitment to: a definition of mutual relationships and goals; a jointly developed structure and shared responsibility; mutual authority and accountability for success; and sharing of resources and rewards" (p. 7). 
Gardner (1994) suggested that the projects and joint projects mentality maintains a strong hold on agencies, yet collaboration requires a reallocation mentality which is defined as the difference between new grant funding and the serious reallocation of base funding (p. 190).

Gardner asserted that: "The emergence of 'children's policy' signifies an effort to unify the various levels of government and agencies which provide services for children. If school-linked social services are widely adopted it will reverse the policy trend toward fragmentation and categorical programs" (1994, p. 5). Yet she cautioned that "organizations can constrain or enable interorganizational efforts, but collaboration is a person-to-person activity" (p. 10). She further noted that time is a critical element to allow the collaborative interpersonal ties. "It takes time for professionals to learn the language and customs of their colleagues from other disciplines. Time is also required to forge the trusting, cross-institutional personal relationships that are crucial to overcoming organizational inertia and resistance" (p. 11).

Gray (1989) presented in detail the complexity of collaboration and suggested that there are two primary opportunities offered by collaboration: (a) conflict resolution, and (b) advancing a shared vision. She noted, "realistically collaboration involves difficult issues that have often eluded simple solutions in the past. Many multiparty problems are political in nature because they involve 'distributional' issues" (p. 24). Gray (1989; Gray \& Hay, 1986) emphasized that the allocations of gains and losses may be perceived very differently by the various stakeholders. Gray theorized that there were three distinct phases in the collaborative process: problem setting, 
direction setting and implementation (p. 57). Problem setting includes several issues: "defining the problem, identifying stakeholders and gaining their commitment to collaborate, ensuring the legitimacy of the stakeholders, identifying a skilled convener and possibly a third party, and securing resources" (p. 74). The direction setting phase includes the following important components: "establishing ground rules, agenda setting. organizing subgroups, joint fact finding, exploring options, and reaching agreements" (p. 74). Gray noted that:

Carefully forged agreements can fall apart after agreement is reached unless deliberate attention is given to several issues during the implementation phase of collaboration. These issues are dealing with constituencies, building external support, structuring, and monitoring the agreement and ensuring compliance. (p. 86)

These phases parallel the guidelines for social problem-solving interventions, labeled social problem solving processes, identified by McCann (1983). They included: problem setting, direction setting and structuring (p. 178). He suggested that "social problem solving poses significant conceptual and control difficulties that make it highly episodic and prone to setbacks" (p. 177).

Garvin and Young (1994) researched the New Orleans collaboration which began in 1991 and attempted to link public schools and social services. The collaborative partners included: The Orleans Parish School System, Principals of schools, the City of New Orleans, the Mayor, the Citizens Advisory Committee, the 
University of New Orleans, the Office of Family Services and its JOB component, Department of Agriculture, Louisiana Literacy Foundation and the United Way.

The authors identified that several elements are critical to the collaborative process. Resource issues were among the most important. Their findings departed from what they would have expected to be their most critical resource issues.

Instead of money and personnel being our major resource issues, we found the following to be most important:

1. identifying one person with the vision and energy to pull the elements of the program together and to keep them together;

2. creating the time necessary for effective planning and implementation to occur (many programs, especially collaborative ones, need longer periods of time for the elements to gel sufficiently);

3. creating opportunities for effective communication among partners who had historically kept away from each other, thus lessening the felt need to protect turf from each other. (Garvin \& Young, 1994, p. 98)

Related to these issues were concerns about: blended resource streams (p. 100.), sponsorship (p. 102), time (p. 102) and responsibility (p. 103).

According to the writers, somebody has to agree to sponsor the process in which all the diverse partners can gather and discuss what problems confront the agencies and the community. Additionally, someone needs to provide a neutral place for meetings. . . . 
Whoever acts as sponsor must know that sponsorship will require a sustained commitment to fostering the collaboration over an extended period of time. (p. 100)

They insightfully pointed out the complexity of the issue of responsibility:

One of the biggest obstacles that came up in the meetings over and over again was who was going to be responsible--not if things went right, but if something went wrong. It was the fear of being the responsible party that was the biggest concern. More often than not it was the perfect rationale for why things should not and could not be changed. (p. 103)

The profundity of this insight will be demonstrated in later chapters.

Kadel and Routh (1994) also presented recommendations and concerns to be addressed by the collaborative process. They focused on the significant issues of scale. conflict of interest, changes in attitude, and an understanding of the complexity of systemic change. They cautioned:

one of the most commonly mentioned characteristics of successful implementation is a small-scale project with a limited number of participants involved in the planning process. ... This is obviously a problem for collaboration efforts which necessarily involve many people with differing values and priorities, and which are large scale by definition since they require policy and strategy changes within many organizations while seeking agreements on new approaches that involve all agencies ... truly comprehensive service 
delivery cannot avoid extensive involvement during the planning process.

(p. 130)

The issues of scale are complicated by the difficulties of reaching consensus in multi-party collaboratives. The tendency toward conflict can create an anticipation of the "failure factor" (p. 131) which needs to be overcome by the collaborative partners. The authors noted that collaboration requires changes in attitude and development of trusting relationships. "Just bringing people together and telling them to 'do collaboration' is not enough at the outset; council members will have to believe (or be convinced) that working with others is necessary for improved service delivery and effectiveness" (p. 131). They suggested that building trusting relationships and trusting attitudes may assist the systemic change process, including creative problem solving. According to Neu (1988), certain elements are critical to the development of a strategic governance process, including several which illuminate this study:

1. Developing a vision of the community's desired future.

2. Setting community direction and goals for the attainment of that vision.

3. Anticipating and addressing issues which may affect the community's efforts to attain that vision.

4. Mobilizing community support and commitment to its long-term vision and goals. (p. 134)

He added to these the extreme importance of understanding the changing nature and complexities of the challenges and the issues, which he suggested would be well suited to be taken on by inter-governmental, public-private collaboration. Gray further 
noted that the "outcome of collaboration is a weaving together of multiple and diverse viewpoints into a mosaic replete with new insights and directions for action agreed on by all the stakeholders" (1989, p. 14).

Gray's ideas were supported by the recent findings of the Annie E. Casey Foundation, who in 1989 granted five mid-sized American cities approximately $\$ 10$ million each to create collaborative comprehensive system-reform efforts. "The Foundation asked the cities to create collaborative decision-making bodies that represented a broad cross section of local leadership. These collaboratives were to have the authority to pool funding and programs in order to allow categorical institutions and staff to cross boundaries, blend their work, at the very least coordinate better (Annie E. Casey Foundation, 1995, p. xi). In The Path of Most Resistance: Reflections on Lessons Learned from New Futures (Annie E. Casey Foundation, 1995), foundation staff summarize various lessons learned from the 5 years. Several of their findings shed practical light onto the theories of collaboration. The first and primary lesson learned was that comprehensive reforms are very difficult. The changes needed by existing institutions and systems were profound and pervasive. The impulse to provide direct programs and add new programs had to be recognized and resisted.

By challenging communities to design comprehensive system reforms rather than to add programs, New Futures had embarked on the path of most resistance. . . Vested interests in current practice, fiscal constraints. and political risks created a constant force capable of minimizing system change. Some parts of the reform agenda threatened the stability of the current system, 
and others seemed to discount the importance of the good aspects of the system that already existed. Based on their experience with previous reform efforts. often described as initially exciting but later lacking in follow-through, local participants in New Futures were sometimes drawn to improving or expanding good programs rather than challenging fundamental arrangements and attitudes and seeking basic reforms. (pp. 1-2)

Because of the extreme importance of the New Futures Collaboratives, the findings will be presented in greater detail further in this chapter.

\section{Shared Vision}

Chynoweth noted that "a good vision captures and directs people's discretionary energy" (1994, p. 23). Yet she cautions that the vision must pass what she has called the "ho-hum" test, or what others have called "so what. now what." or "apple pie and motherhood." The Amherst H. Wilder Foundation study suggested that "collaborating partners have the same vision, with clearly agreed upon mission, objectives and strategy. The shared vision may exist at the outset of the collaboration; or partners may develop a vision as they work together" (cited in Mattessich \& Monsey, 1992 , p. 14). In this dissertation, the vision, mission and goals of the SAC will be taken as a whole since together they create the kind of poignant vision that passes the ho-hum test.

Galaskiewicz (1979) noted that the distribution of power in interorganizational networks may be determined by an organization's resources. It is critical that the collaborative process advance a vision shared by each organization with cognition of the gains and losses it may require. 
Successfully advancing a shared vision. whether in the public or the private sector, requires identification and coordination of a diverse set of stakeholders, each of whom holds some but not all of the necessary resources. To be successful, coordination must be accomplished laterally without the hierarchical authority. (p. 9)

According to Gray (1989), the shared vision is a critical component of the formative phase of collaboration. Studies on collaboration concur with the importance of advancing a shared vision (Habana-Hafner, Reed, \& Associates, 1989). What is this shared vision and what does it mean?

Senge did not create the idea of shared vision, yet, it may be fair to suggest, that his work has popularized the idea. Much of the literature subsequent to his book The Fifth Discipline (1990) refers to his ideas. He presented the idea of shared vision as a collective passion. He described it as a force. Senge emphasized, "Today, 'vision' is a familiar concept in corporate leadership. But when you look carefully you find that most 'visions' are one person's (or one group's) vision imposed on an organization. Such vision, at best, commands compliance--not commitment" (p. 206). This traditional perception of the common vision as an imposed vision as described by Senge is exemplified by the SANNO Management Development Research Center.

In order to unify diversified work and workers, it is essential to have a common vision. A common vision leads even workers with temporary involvement to feel enthusiastic about the work, while permanent workers follow this vision as if it were their own. (1992, p. 20) 
According to this perspective the visioning task belongs to management and is a tool for communal compliance.

Scholars had defined vision as "a leader-conceptualized view of the future. When shared with others, the vision is the primary responsibility of the transformational leader" (Roueche, Baker, \& Rose, 1989, p. 270). This transfornational leader can "create a vision for change, communicate it to others, and then help those others to accomplish that vision through their own commitment to it" (p. 35). This CEO driven vision for the future can serve as a "a catalyst for action in the present" (p. 270). The writers concluded that "the key to the achievements that we strive for is the ability to share our vision and thus earn the acceptance and assistance necessary for turning them into reality" (p. 289).

This top-down philosophy about the common vision is contrasted with the kind of vision described by Senge a shared vision. "A shared vision is a vision that many people are truly committed to, because it reflects their own personal vision" (Senge, 1990, p. 206). Senge suggested that a shared vision creates an environment that:

1. allows people who mistrusted each other to begin to work together,

2. creates a common identity,

3. compels courage,

4. fosters risk taking and experimentation, and

5. fosters a commitment to the long term and strategic planning process (pp. 208-210) 
He further suggested that there are three possible attitudes toward a vision. They are: commitment, enrollment and compliance (genuine, formal and grudging) (p. 219), and that real commitment is rare.

Gray addressed the importance of advancing a shared vision for successful collaboration and stressed that:

advancing a shared vision, whether in the public or the private sector, requires identification and coordination of a diverse set of stakeholders, each of whom holds some but not all of the necessary resources...Even when parties agree initially on a shared vision, collaboration among them is not necessarily free of conflict. . . Overcoming the barriers created by different institutional cultures is frequently a formidable task. (1989, p. 9)

Therefore in creating a shared vision it is important to overcome the barriers. These barriers may have a great deal to do with the myths, cultures, and symbolism of the individual organizations and the myth, cultures, and symbolism that are being created about the collaborative effort, both consciously and unconsciously. Pondy (1983) wrote about the role of metaphors and myth in organizations as they influence the change process. His work was directed toward organizational entities and did not directly anticipate the larger collaborative organization. The work addressed the profundity of organizational myth and symbolism as it relates to the organization's culture. The ideas are equally important to the collaborative organization. Pondy stated: 
The use of metaphors in organizational dialogue plays a necessary role in helping organization participants to in-fuse their organizational experiences with meaning and to resolve apparent paradoxes and contradictions, and that this infusion of meaning or resolution of paradox is a form of organizing. . . . Metaphors help to organize the objective facts of the situation in the minds of the participants. $(1983$, p. 157)

The function of myth and metaphors is twofold: (a) they place explanation beyond the possibility of doubt or argumentation, the organization can get on with its work rather than question its legitimacy; and (b) they can facilitate and shape change and simultaneously reinforce traditional values. The beauty of metaphor is that it can express both change and familiarity. The caution is that metaphor can also preserve tradition and block change. Therefore deliberate attention to myth and metaphor are required in creating a shared organizational vision.

An understanding of organizational symbolism is equally important. According to scholars symbolism may be conscious or unconscious, simple or complex. The simple symbols are "consciously constituted to create a particular image or effect" (Morgan, Frost, \& Pondy, 1983, p. 8). The writers noted that:

Organizational life is rich in various forms of ritual activity, tradition, patterns or humor, story-telling and various kinds of metaphorical imagery which contribute to the development of distinctive kinds of cultural milieu within the organization. Such activities may be consciously contrived to produce certain effects within the organization, or may arise spontaneously to give shape and 
form to significant patterns of meaning. . . Thus organizational traditions and stories may be consciously developed. (p. 10)

Consciously created symbolism and ritual may facilitate the purpose of the organization. And conversely, those symbols and rituals that occur unconsciously may prove more difficult to deal with. "The unconscious modes of symbolism that permeate organization may well in the end prove to be one of the most challenging realms" ( $p$. 12). Understanding and developing organizational symbolism is crucial for the change process particularly because the symbolism may be neither conscious nor shared. Creating symbolism, myth and culture may enhance the possibility that the vision be genuinely shared. What can be certain is that these often ignored dynamics will influence the vision and the commitment of individuals to it. What inspires commitment to a vision? How is that commitment demonstrated? The literature about theories in action and the stakeholder approach add insight and help to formulate theory.

\section{Theories of Action}

The collaborative process requires a rethinking and restructuring of how organizations function and their relationship to one another. Creating the shared vision may be the clearest defining statement of the collaborative endeavor. It must be remembered that the collaboration is a collection of people who are attempting to dramatically reframe their ideas about how organizations work together.

For many years Argyris has been observing the behavior of people in organizations and how they attempt to change. Argyris did not refer to the word vision 
itself. yet he proposed theories of action that may help to explain the level of commitment to the shared vision by individual stakeholders. Argyris described two kinds of theories of action. "One was the theory that individuals espoused and that comprised their beliefs, attitudes, and values. The second was their theory-in-use--the theory that they actually employed" (1993, p. 51). Early in his research, Argyris and his colleagues encountered an unanticipated discrepancy between the theory espoused and theory-in-use. Further he discovered that individuals may be unaware of the discrepancy.

Perlmutter and Trist (1986) in their discussion of paradigms referred to Argyris' work in such a way as to give broader significance to the mental model of the individual:

Paradigms can be seen at the societal level where they involve a great variety of institutions, or at the level of the individual where they influence his key actions. They are to be inferred from behavior rather than from what is professed; they are "theories in use" rather that "espoused theories." (p. 18) Argyris' work began in the 1970s and from that time forward, together with his colleagues he has advanced and enhanced his work on theories of action (Argyris, 1976. 1980, 1982; Argyris, Putnam, \& Smith, 1985: Argyris \& Schon, 1974, 1978): Theories of action are governed by a set of values that provide the framework for the action strategies chosen. Thus, human beings are designing beings. They create, store and retrieve designs that advise them how to act if they are to 
achieve their intentions and act consistently with their governing values. (Argyris, 1993, p. 50)

The question arises, to what degree is there a discrepancy between the theories espoused and the theories-in-use? Through international research projects, he attempted to understand the implications of this discrepancy.

He concluded:

We have created a model of theory-in-use that most individuals appear to use. A model I theory-in-use has four governing variables, or values for the actor to "satisfice": (1) strive to be in unilateral control, (2) minimize losing and maximize winning, (3) minimize the expression of negative feelings, and (4) be rational. Along with the governing variables is a set of behavioral strategies such as (1) advocate your views without encouraging inquiry (hence, remain in unilateral control and hopefully win), and (2) unilaterally save face--your own and other people's (hence, minimize upsetting others or making them defensive). (Argyris, 1992, p. 26)

His scholarship reflects a severe indictment of human nature.

The thrust of the analysis above is that people's theories-in-use make it likely that they will sabotage their own opportunity for change what he has labeled doubleloop learning, what might also be thought of as transformational learning--learning to do business differently. According to the scholar:

Human beings have theories in use that will inhibit their own and others' double-loop learning; that they are largely unaware of their theories-in-use and 
that both the unawareness and the counterproductive actions are due to highly skilled, internalized, and hence, tacit, automatic reactions. If individuals reflected on their actions correctly (which is unlikely because of their theoriesin-use), they would become aware of the counter productive aspects of their action. . . They are not unaware of the inconsistencies in others' behavior, but they are programmed to withhold feedback on this lest the be held responsible for upsetting others. (Argyris, 1992, p. 27)

Recently (1993) he concluded that changing the action strategies of the "governing variables themselves" may help close the gap with what he has labeled double-loop learning (p. 218). Single- and double-loop learning are required by all organizations. "Single-loop learning is appropriate for the routine, repetitive issue--it helps get the everyday job done. Double-loop learning is more relevant for the complex, non-programmable issues--it assures that there will be another day in the future of the organization" (Argyris, 1992, p. 9). Double-loop learning is a concept that Argyris developed which is helpful when dealing with complex and wide ranging change. He described single- and double-loop learning as the following:

Organizational learning involves the detection and correction of error. When the error detected and corrected permits the organization to carry on its present policies or achieve its present objectives, then that error-detectioncorrection process is a single-loop learning. Single-loop learning is like a thermostat that learns when it is too hot or too cold and turns the heat on or off. The thermostat can perform this talk because it can receive information and take 
corrective action. Double-loop learning occurs when error is detected and corrected in ways that involve the modification of an organization's underlying norms, policies, and objectives. ... One of our major assertions will be that organizations tend to create learning systems that inhibit double-loop learning that calls into questions their norms, objectives, and basic policies. (Argyris \& Schon, 1978, pp. 3-4)

This idea of double-loop learning is essential to the prospect of collaboration. It explains how it may be possible for individual organizations to begin to modify their norms, objectives and basic policies in order to facilitate those of the newly formed collaborative. According to the scholars a situation which requires double-loop learning arises when organizational executives or managers find themselves confronted by changing and conflicting requirements for which the current norms, objectives and policies are not salient. A conflict arises and this conflict can be resolved a myriad of ways. The scholars suggest that double-loop learning can allow for inquiries, new strategies, or analysis, which gets 'underneath the members' starting perceptions of the incompatible requirements" (p. 24). Double-loop learning is described as those types of organizational inquiry which seek to resolve "incompatible organizational norms by setting new priorities and weightings of norms, or by restructuring the norms themselves together with associated strategies and assumptions" (p. 24).

In these cases, individual members resolve the interpersonal and intergroup conflicts which express incompatible requirements by creating new understandings of the conflicting requirements, their sources, conditions and 
consequences--understandings which then become embedded in the images and maps of organization. By doing so, they make the new, more nearly compatible requirements susceptible to effective realization. (Argyris \& Schon, 1978, p. 24)

Creating these new understandings is essential for the collaborative process and these are created through double-loop learning. Actions that promote double-loop learning involve "sharing control with those who have competence and who are relevant to designing or implementing action" (p. 220). The actions strategies should "include minimally defensive interpersonal and group relationships, high freedom of choice, and high risk-taking" (p. 220). Argyris and Schon (1978) noted two implicit criteria to enhance organizational double-loop learning: (a) the individuals have enough power and autonomy to assure themselves and others, that they are not kidding themselves or others when they strive to learn new theories-in-use and create new learning systems; and (b) learning must begin at the individual level and then spread to the organizational level (p. 35).

Finally, double-loop learning "must also deal with undiscussability, the undiscussability of the undiscussable, and the puzzling fact that most individuals are unaware of their own causal contribution to these organizational features, yet are aware of the causal contributions of others" (p. 36). Argyris contrasts defensive reasoning with productive reasoning. Defensive reasoning includes: (a) soft data; (b) tacit, private inferences; and (c) conclusions not publicly testable (p. 221). Whereas productive reasoning includes: (a) hard data; (b) explicit inferences; and (c) premises 
explicit. conclusions publicly testable (p. 221). Defensive reasoning is often undiscussable and influences the learning possibilities or the individual and the organization. While difficult to grasp these issues may help illuminate the potential success of a new collaborative venture as the theories espoused and in use profoundly influence the process. The research section of this project will be focused toward understanding the degree of discrepancy between the espoused vision and the vision in use.

These issues have been addressed by other scholars in different terms. Freeman labeled the discrepancy more pejoratively by suggesting that it represented selfdeception. "Self deception occurs when we do not honestly ask the tough questions and do not accurately assess our own values and the stakeholder picture that we face. It involves saying one thing and acting on another. Self-deception is the difference between those values that we espouse and those that are really in force" $(1984$, p. 108$)$. Gray suggested that stakeholders involved in the collaborative effort may be stuck in their stereotyped images of one another and past interactions. She noted that: Frequently the parties have had a long history of interaction, fighting out their differences in legislative and judicial arenas. Working on opposite sides in these arenas allows the parties to continually reconfirm their stereotypic impressions with hard evidence (about the other side's motives, values, and willingness to react accommodation). Collaboration operates on the premise that the assumptions that disputants have about the other side and about the nature of the issues themselves are worth testing. The premise is that testing these 
assumptions and allowing a constructive confrontation of differences may unlock heretofore disguised creative potential. (1989, p. 13)

Testing the assumptions involves the processes identified by double-loop learning and bridging the gap between espoused theory and theory in use. The task is complex and formidable. It influences every level and layer of interaction and every stakeholder in the collaborative process.

Stakeholder Analysis

In attempting to understand the collaborative process and creating a shared vision. it is critical to take the stakeholders into consideration. By stakeholders I mean any group our individual who has a stake in the outcome. According to Gray, "Local initiatives may hold for greater promise because the problems now touch multiple stakeholders" (1989, p. 47). Freeman wrote about the concept of the stakeholder in relation to the corporate organization. According to Freeman:

The actual word "stakeholder" first appeared in the management literature in an internal memorandum at the Stanford Research Institute in 1963. The term was meant to generalize the notion of stockholder as the only group to whom management need be responsive. Thus, the stakeholder concept was originally defined as "those groups without whose support the organization would cease to exist." . . . The SRI researchers argued that unless executives understood the needs and concerns of these stakeholder groups, they could not formulate corporate objectives which would receive the necessary support for the continued survival of the firm. (1984, p. 32). 
In 1974. Ackoff referred to stakeholder theory and credited it to those who identified the need to include in consensus making a broader view of those participating in the organization (p. 62). Freeman (1984) suggested that the stakeholder approach created theories and strategies for "dealing with particular groups and issues, and the need for processes for integration across issues and groups" (p. 27). He emphasized the importance of understanding the expectations of the stakeholders on a variety of levels, including social, political, economic, and technological, in setting the strategic direction of the enterprise. Although Freeman's work addressed a corporate setting his theories present significant insight into the collaborative process. The collaborative process involves a much wider range of stakeholder groups.

The most immediate group of stakeholders are those organizations invited to sit at the collaborative table. Mattessich and Monsey (1992) studied collaborative efforts. They noted the importance of stakeholders to the collaborative process. The largest number of their respondents identified the category of membership characteristics as having great importance. "Thus, in developing a collaborative effort, the greatest weight should be placed on bringing the right partners together and building the right attitudes and spirit among them" (p. 34). These partners are the most immediate set of stakeholders. The large interdisciplinary, public/private collaborative effort involves collaborative policy making and implementing efforts. The collaborative stakeholders include a wider range of groups and individuals. Mason and Mitroff (1981) asserted the importance of generating stakeholders in the policy making process. "The reason is that stakeholders are the concrete entities that affect and in turn are affected by a 
policy" (p. 95). They identified six categories to characterize the properties of stakeholders:

1. The purposes and motivations of a stakeholder.

2 Beliefs.

3. Resources: a. material, b. symbolic, c. physical, d. positional, e. informational, f. skill.

4. Special knowledge and opinions.

5. Commitments.

6. Relationships to the other stakeholders in the system: a. power, b. authority, c. responsibility, d. accountability. (pp. 97-98)

Perspectives of the stakeholders will vary and even cause disagreement depending upon the characteristic of the stakeholders.

The writers noted that assumptions of stakeholders and about stakeholders must be posited as a premise to creating policy. "Assumptions and facts, or so-called true statements, about the world of stakeholders bear a close relationship to one another...a fact is an assumption in which our confidence is justified or warranted, whereas an assumption is a doubtful fact" (Mason \& Mitroff, 1981, p. 103). The risk of positing assumptions increases as the complexity of the task at hand increases.

Williams, whose ideas about turbulent social conditions were reviewed earlier in this chapter, noted the changing needs and roles of stakeholders under the turbulent social conditions: 
Single stakeholders in extended social fields that have become turbulent cannot by their independent efforts, control change and uncertainty. To continue with the pursuit of narrow self-interest and reliance on bureaucratic government would leave the direction and outcomes of these change forces very much to chance. . . Given change in the environment, the most probable response by stakeholders is to change their behavior independently on one another in the pursuit of their various goals and objectives. In doing so, they help to produce a new environmental state that is more threatening than the initial change. If they recognize this, it is possible for them to collaborate in their responses to change with the intention of producing a future state favorable to attaining the goals of two or more stakeholders. In turn, it is possible to enlarge the basis of collaboration to coproduce desired future states by identifying still other stakeholders with whom the initial partners are potentially directively correlated by such a process. It is possible for the field itself to be transformed into a social environment that is more manageable and conducive to the survival and development of all. (Williams, 1982, pp. 177-178)

Williams' strategy optimistically identifies the potentially transformational role of the collaborative stakeholders. He suggested that stakeholders must participate in creating "the designs that are appropriate for active adaptive collaboration among them" (p. 178). Williams described a shift in stakeholder priorities from competition to cooperation. "It is a shift from a more or less exclusive preoccupation with getting as 
much as one can toward attempting to identify and pursue courses of action to increase the active adaptive potential of all concerned" (p. 20).

Gray (1989) discussed the particular challenge of problem setting by identifying five judgments made by stakeholders in deciding whether or not to collaborate.

1. Does the present situation fail to serve my interests?

2. Will collaboration produce positive outcomes?

3. Is it possible to reach a fair agreement?

4. Is there parity among the stakeholders?

5 Will the other side agree to collaborate? (p. 59)

Through these questions and throughout her work, Gray noted the importance of using a stakeholder analysis in understanding the motivation to collaborate. Williams wrote that stakeholders may collaborate in their responses to change when the external environment is more threatening than the proposed internal change. By collaborating stakeholders may "coproduce desired future states" (1982, p. 177).

Freeman made explicit the implied notion that "Stakeholder" connotes 'legitimacy'" (1984, p. 45). Gray articulated concern over the legitimacy of stakeholders. "Often stakeholders will disagree about the legitimacy of other stakeholders. Perceptions of legitimacy will undoubtedly be colored by historical relationships among the stakeholders" (1989, p. 67). "There is, of course, a broader notion of legitimacy which is at issue here. Do all stakeholders have an equally 'legitimate' claim to the resources" (Freeman, 1984, p. 45). 
Nanus suggested that "by its very nature, a public-sector organization is responsive to a much wider array of influences and interests" $(1992$, p. 195). He proposed questions regarding stakeholder involvement to be answered in the creation of the vision. They include:

1. Who are the most critical stakeholders?

2. What are the major interests and expectations of the most important stakeholders regarding the future of the organization?

3. What threats and opportunities emanate from these critical stakeholders?

Certainly the layers of stakeholder involvement increase with the collaborative effort. "Collaboration establishes a give and take among the stakeholders that is designed to produce solutions that none of them working independently could achieve" (Gray. 1989, p. 11). Adler and Gardner addressed these issues while discussing community empowerment.

All of the advocates for linking schools and social services have at least paid "lip-service" to the notions that families who will be the recipients of such services should be part of the planning process. Prior efforts at community involvement, such as those of the War on Poverty programs, raise a caution about the difficulties of these efforts. Who decides what is defined as a need: the community, the professionals, or the polities? How is community participation structured? Critical theorists suggest that unless institutions change how they conceptualize the role of community members, government action will 
result in replicating the current social structure which empowers some and disenfranchises others. $(1994$, p. 8)

This relates directly to the concerns about assumptions posited by Mason and Mitroff (1981) whose ideas were reviewed earlier in this chapter. They recommended broader participation by of those who are affected by the issues and concerns. The stakeholder approach will greatly illuminate the research which follows. In the following chapters when the Children's Initiative will be studied, direct observations will be made regarding the assumptions, perspectives, attitudes, and perceptions of the various stakeholders.

\section{Learnings and Results from New Futures}

Very few collaborative efforts have been studied at length. Recently the New Futures collaborative effort has been analyzed by its initiator the Anne E. Casey Foundation and in more scientific depth by the Center for the Study of Social Policy in Washington, DC. Annie E. Casey published The Path of Most Resistance: Reflections on Lessons Learned from New Futures (1995) and The Eye of the Storm: Ten Years on the Front Lines of New Futures (Walsh, 1995), an interview with Otis Johnson and Don Crary. The Center for the Study of Social Policy published Building New Futures for At-Risk Youth: Findings from a Five-Year Multi-Site Evaluation (1995). Together, these publications present a relatively comprehensive analysis of large-scale collaborative efforts and are exceedingly helpful to this study. 


\section{The New Futures Story}

The Annie E. Casey Foundation set out in 1987 to improve the present circumstances and future opportunities of at-risk youth in five low-income communities. Called New Futures, the ambitious social experiment provided a total of $\$ 50$ million to five cities over five years. Its goals were for each city to measurably improve school achievement, reduce adolescent pregnancy and school dropout rates, and increase young people's gainful employment after high school.

Driving New Futures was an unswerving commitment to a single core strategy: broad institutional change in the way services and supports are provided to at-risk youth as determined by a newly constituted body called a collaborative. A collaborative was to be the means by which a community would restructure its youth-serving institutions and hold them accountable for improving the life chances of disadvantaged youth...Thus, New Futures was essentially a "political" agenda aimed at rectifying a fundamental and long-standing ailment. . . . New Futures, then, was an experiment in using private money to leverage public policy and public financing on a major social issue of the day. . . New Futures was a high-risk proposition. (Annie E. Casey Foundation. 1995, pp. i-ii) With broad systems change as its lofty agenda, the Casey Foundation concluded:

That premise turned out to be wrong. None of the New Futures cities made such measurable improvements in five years. Just assembling the New 
Futures leadership collaborative proved an enormous political task. "Systems reform" was tougher still. New Futures projects got busy putting case managers in schools, setting up health clinics, promoting education reform and developing school-to-work initiatives. But by getting involved with new services, however innovative, they left the public systems they were designed to change mostly intact. . . At the end of the five-year project, while none of the sites achieved their original goals, evaluators found that all five had created respected "mediating structures to help break down the fragmented, categorical system of services," a necessary first step to renewed public systems that would truly strengthen at-risk children, families and communities. (Walsh, 1995, p. ix-x) The Casey Foundation applauded their visionary work even as they acknowledged their naiveté and unrealistic expectations.

Even when these efforts fall short of their greatest ambitions, they can help guide a community's long-term planning for youth development and ultimately produce real change in the lives of young people. (Annie E. Casey Foundation, 1995, p. vii)

As the following pages will reveal, prior to the New Futures efforts, only one decade ago, there was no blueprint, no model, no example of large, multi-agency collaborative efforts. The writings and reviews of New Futures suggest that there is still too little known about collaboration, and that the process is too complex to lend itself to cookie cutter recipes or prescriptive models of success. Yet in every New Futures city, there were in fact measurable differences and improvements in the ways 
that business gets done and particularly, in the interest of the city in the fate of its youth. In the following pages New Futures will be analyzed according to the theoretical threads of this literature review.

\section{Development of New Futures}

The Annie E. Casey Foundation was able to coin many poignant phrases describing the texture of the collaborative efforts. In The Path of Most Resistance, they noted:

By challenging communities to design comprehensive system reforms rather than to add programs, New Futures had embarked on the path of most resistance. Although reform always encounters resistance, the comprehensive reform agenda envisioned by the Casey Foundation would require simultaneous changes in many youth-serving systems as well as changes in relationships among these systems. Vested interests in current practice, fiscal constraints, and political risks created a constant force capable of minimizing system change. Some parts of the reform agenda threatened the stability of the current system, and others seemed to discount the importance of the good aspects of the system that already existed. Based on their experience with previous reform efforts, often described as initially exciting but later lacking follow-through, local participants in New Future were sometimes drawn to improving or expanding good programs rather than challenging fundamental arrangements and attitudes and seeking basic reforms. (Annie E. Casey Foundation, 1995, pp. 1-2) 
Perhaps the defining statement about the effort to both design and do collaboration is the idea that it is "the path of most resistance" because it threatens the status quo and requires honest observation and evaluation and clear planning. Collaboration requires a forum for dialogue. That forum did not exist prior to New Futures.

The Casey Foundation said: "We want a table created in which the school superintendent and the child welfare administrator and the mayor and the business leaders all sit down regularly and look at what's going on with kids and take ownership to design new systems and reconfigure the way dollars are spent. There wasn't a city in the country with a table where this was happening. (Walsh, 1995, p. 2)

Creating that table where a "broad cross-section of people that meets regularly with youth and families as the subject" (p. 30) is seen as one of the collaboratives ${ }^{*}$ greatest achievements. "Certainly that did not exist, and to have it sustained over that much time is really significant, and probably the basis for a lot of positive changes in the community" (p. 30).

At the end of the 5 years, the creators of New Futures concluded:

While the outcomes of the New Futures cities to date have by no means proven the validity of our underlying system change paradigm or theory, there is nothing in our experience with this initiative that disproves or erodes it. Indeed, our confidence has grown that these initiatives reflect the only plausible strategy available to improve aggregate outcomes for large numbers of American youth. ... We are convinced that efforts like New Futures can be the 
impetus toward the creation of effective partnerships among institutions.

community leaders, and the general public. (Annie E. Casey Foundation, 1995, p. 28)

The evaluation team at the Center for the Study of Social policy (1995) confirmed the conclusions of the Annie E. Casey Foundation. The evaluators noted that

they were successful in building some of the interim steps that may in the longer term lead to improved outcomes for children. For example, they collaboratives in every city (1) raised the awareness about the problems of at-risk youth:

(2) started a new dialogue among leaders and community representatives who had not previously sat down together; (3) developed rich school-based information systems; (4) created a new body of knowledge around collaboration and local governance that did not exist before; (5) demonstrated how to build substantive relationships between the public and private sectors by combining money and leadership; and (6) launched ongoing community structures for addressing youth problems that outlasted the initial five-year period. (Center for the Study of Social Policy, 1995, p. 8)

New Futures significantly expanded the field and possibility of large-scale multiagency collaborations. Perhaps it would be fair to suggest that New Futures created the possibility of collaboration and became the model for later collaborative efforts.

The findings from the Center for the Study of Social Policy concluded: 
Perhaps the single biggest lesson from New Futures is how little is known about the nuts and bolts of restructuring service systems in a way that cuts across single programs and individual agencies. This was uncharted territory in 1987 when New Futures began, and still is to a large extent today. . . . The next generation of community based initiatives should aim to increase the capacity of local collaboratives so they are better prepared to tackle cross-agency, intergovernmental social problems. (p. xiii)

The findings suggested that greater time and structure for strategic planning with key stakeholders would better prepare future collaboratives for the daunting task ahead.

\section{New Futures Learnings Building the Collaborative Process}

New Futures began with a theory of change which believed that "you bring powerful people to the table and they will push the systems to change" (Walsh, 1995, p. 1). They did not anticipate that "with all the big leaders there's a culture of 'you scratch my back and I'll scratch yours.' Part of the flaw was expecting them to hold each other accountablen (p. 3). However, although the leaders tended to rally around one another they concluded that it was the correct place to begin the effort of systems change. "Systems reform is about changing relationships" (p. 6).

The effort toward capacity building is an important aspect of changing and expanding relationships. Capacity building was the effort to increase the reach, influence and potential of the collaborative. The collaboratives "began to see their goal as 'capacity building,' an agenda that required just as much trial-and-error experimentation as the previous goal of 'systems reform'-but with a bigger potential 
payoff" (p. 11). The staff at the Annie E. Casey Foundation found that capacitybuilding leadership was essential to the process. Capacity-building leaders were the "keeper of the flame, the standard bearer. But you also have to be able to be the bridge between groups and ideas" (p. 15).

Building capacity requires dealing with discomfort, emerging conflict, and community anger. Don Crary from the Annie E. Casey Foundation noted that: Who are the potential leaders in different sectors? Who can take this new message and spread it in an effective way, and be heard in the business community, among nonprofit providers, in the various neighborhoods, in city government and state government? . . . I am convinced that the key leadership skill we need is the ability to recognize leadership in all those sectors, and to facilitate it and empower it and build it. The best leaders are really translators-taking the same message to different groups in ways that they can understand it... But I don't want to underestimate the importance of risk-taking, either. (quoted in Walsh, 1995, p. 15)

Capacity building is essential to the collaborative effort. But the activity itself, as well as the other complexities of the collaborative effort, proved to be time consuming.

According to New Futures publications, the creators and participants underestimated the time required for planning and for "broadly based collaborative decision-making bodies to gel" (Annie E. Casey Foundation, 1995, p. vi). Because of the diversity of the stakeholders and the complexity of the issues everything took longer and required more review that they had anticipated. 
The best original plans from states or local communities for complex multi-year change will require repair, revision, reassessment, and recommitment. This should not be an excuse for tentativeness in original plans. In fact, the more developed the original plan, the more likely the implementation will be successful. But review and revision must be permitted and significant modification cannot be a sign of failure. (Annie E. Casey Foundation, 1995, p. 19)

Review and revision needed to be based in part upon evaluation. Yet the Center for the Study of Social Policies, who had been named as the official evaluators, noted again and again the difficulty in creating measures for evaluation.

Nobody had a ready-made design. There simply were no proven evaluation methodologies that fit the parameters of an initiative like New Futures.

Recognizing this fact led to a choice: either the nature of the New Futures initiative could be changed so it was simpler and more prescriptive--and thus easier to evaluate--or a more complex, multifaceted evaluation design that was consistent with a complex and ambitious set of community-wide interventions would gave to be designed. (Center for the Study of Social Policy, 1995, p. ii)

The Center chose to honor and support the complexity of the collaborative effort and developed quantitative as well as qualitative methods of evaluation. Nonetheless, those methods are inadequate and primitive since the effort of collaboration is yet so new. 


\section{Shared Vision}

The Annie E. Casey Foundation staff noted the importance of a vision. New Futures demonstrated that "reform efforts characterized by a comprehensive vision can inspire tremendous energy in communities" (Annie E. Casey Foundation, 1995, p. vii). The Foundation approached the New Futures ventures with the vision that shaped the initiative. The vision included: "better outcomes for youth, restructuring community decision making, greater local awareness of the needs of at-risk children, and improvement of service delivery" (p. 3). "Project designers also believed that collecting and publicizing good data from schools, health and service agencies would create a shared picture of problems and lead to a common vision about what to do about them" (Walsh, 1995, p. 1). However, there did not seem to be a solid and common vision. "Part of the problem was that the functions of the collaborative were not yet clear in the early years" (Center for the Study of Social Policy, 1995. p. 22) .

The level of commitment to the vision became an important dynamic. The three attitudes identified by Senge (1990), commitment, enrollment and compliance (or graphically rephrased: genuine, formal and grudging), were found to have a more important influence on the process than might have been anticipated. In 1991 the New Futures sites developed a "Second Half Plan" to continue guiding their work. "This review provided the sites with an opportunity to revisit their decisions about collaborative membership, focus, approach and priorities" (Annie E. Casey Foundation, 1995, p. xiii). It appeared that the sites themselves required greater ownership of the vision. 


\section{Theories of Action}

For many reasons including naiveté, and lack of experience, there were many gaps between the collaborators intentions and familiar ways of interacting. The framers of the collaboratives were not prepared for the discrepancies between the theories in use and espoused theories. They discovered:

Communication gaps created by the historical isolation of participants from one another were formidable. The sheer lack of experience that most people have in dealing across racial, class and cultural lines areas was pervasive on most of the collaborative governing boards as in the communities at large. The diversity of language, style beliefs, and interests--at least in the early stages of the collaborative processes--were considerable and needed to be addressed. (Annie E. Casey Foundation, 1995, p. 4)

Although the participants may have declared their support of the collaborative. a great deal of double-loop learning would have been required to make that a reality. Significant gaps between the desired new behaviors and the status quo existed in relation to the funding as well.

Operational knowledge of how to turn lofty reform rhetoric into concrete activities was lacking. Moreover, there was a tension between funding programs--the easiest way to spend large amounts of money quickly--and reconfiguring existing delivery structures. (Center for the Study of Social Policy, 1995, p. 16) 
Even with the best of intentions, at times agencies reneged or only "half-heartedly fulfilled their obligations" (p. 16) or commitments to the collaborative process. There needed to be more attention and awareness given to the dynamics created by the theories in use and espoused theories. Perhaps had these been more explicit or even examined, the learnings (double-loop learnings) required to create true systems change might have assisted the process and enhanced it's possibility for greater success.

The Foundation found that the collaboratives did move toward more consistency between their theories in use and espoused theories. The Foundation proudly concluded that "people who work hard together and in good faith on problems of enormous importance to the community can provide, in time. the impetus for taking risks. for talking about things most often not raised directly, and ultimately for building mutual respect" (Annie E. Casey Foundation, 1995, p. 5).

\section{Stakeholder Analysis}

Who sits at the table was among the most important issues.

Further, we learned that a truly diverse array of local stakeholders must be involved early, and that this expectation must be communicated early and as clearly and consistently as possible. (Annie E. Casey Foundation, 1995, p. 5) The answers to the questions who is left in and who is left out, who is part of the planning process, who's brought in later proved important to the effort. Stakeholders who were left out of key stages and decisions believed that "they owed no allegiance to the specific commitments or vision embodied in the original plans" (p. 7). Further. "because system change ultimately requires the political reassignment of local public 
dollars and public functions, it absolutely demands local ownership" (p. 15). Therefore collecting the diverse set of stakeholders necessary to create systems change is an important challenge of the collaborative.

The New Futures collaboratives dealt with the top-down, bottom-up challenge. These strategies define the kind of stakeholder invited to the table. The collaboratives tended to choose people "who could control resources" (Walsh, 1995, p. 3) to participate in the initial phases. It was noted that "unless high level local leaders who represent the city and/or county are at the helm. it is unlikely that state and federal officials will pay as much attention to a local collaborative" (Center for the Study of Social Policy, 1995, p. 21). The cities were successful in bringing the influential leaders to their table, "but initially neglected grassroots representatives" (p. 22). Yet, when analyzing the role of the key stakeholders in Lawrence, one of the original New Futures cities, the evaluators noted there was no consistent support from top-level decision makers. Instead, there were only tension and mistrust, negative blame-laying, defensiveness and personal confrontations between the school superintendent, the mayor and other community representatives. The collaborative could not function in this climate, either as a forum to give greater visibility to problems of at-risk youth or to create a shared community agenda. (Center for the Study of Social Policy, 1995, p. 20)

Partly due to the discordance among stakeholders, Lawrence was replaced as a New Futures city at the half way point. It was clearly not enough to put the key stakeholders 
around the table. Even the key stakeholders need to identify and structure a planning process with "the time and information to spin out various models, asking whether a particular intervention will work for a given end, how various programs can be packaged together and financed toward that end, and so on" (p. 98). Time and planning were some of the critical elements necessary to create trust among stakeholders. Over time those involved began not only to work together but to formally and informally network with one another.

The recognition that multiple entities needed to address these problems, simple as it now sounds, was new to many in 1988 . It led to a whole new perspective on how to tackle the intertwining problems that were inhibiting positive youth behavior. Mental health directors, many for the first time, called their social service counterparts, school leadership, and the probation department, for example, when they wanted to start a new therapeutic group counseling session for troubled adolescents. (Center for the Study of Social Policy, 1995, p. 96)

The good news was that in the New Futures cities, "turf protection diminished, to some extent, lines of communication opened up, and the spirit of working together on complex problems sparked the zeal of professionals and lay persons alike" (p. 26). Perhaps this was an unanticipated benefit of working with the key stakeholder groups. This benefit may well prove enduring over time.

\section{Summary of New Futures Findings}

The Center for the Study of Social Policy concluded that: 
The New Futures experience taught us that "institutional change" is much easier to write about than to actually accomplish. The collaboratives did not know how to radically alter the way existing institutions served at-risk youth and their families. . . The difficulty was two fold: on the one hand, most collaborative members simply did not know what changes were needed in their current institutions, and the collaboratives were not staffed to provide this kind of information. ... The collaboratives could not give the agencies any alternatives to the way there were already doing business. At the same time, some of the leaders of existing organizations simply did not see a need to change the way they had been operating and openly resisted specific attempts. (1995, p. 97) It is no wonder that the Foundation labeled the collaborative process as the path of most resistance. No doubt that this process involving so many interwoven dynamics and a critical case for coming into existence deserves such study, analysis and respect.

\section{Initial Study of the Children's Initiative}

Anita Harbert, director of the School of Social Work at San Diego State University, and her research team studied the San Diego Children's Initiative and reported their findings in two unpublished papers (Harbert, Finnegan, \& Reynolds. 1995; Harbert, Finnegan, \& Tyler, 1995). Their work "focused on the formative phase of the children's Initiative Collaboration. It attempted to identify those dimensions which influenced the collaborative development of a strategic action plan which would be used to implement a Children's Initiative" (Harbert, Finnegan, \& Tyler, 1995, p. 7). 
Harbert's research team used Gray`s (1989) theoretical framework to guide their own scholarship of the collaborative process. In their work, the researchers adopted the three collaborative phases promoted by Gray (1989) and noted that:

Collaborations induced by shared visions are intended to advance the collective good of the stakeholders involved. . . The shared vision is the glue that binds agencies together in a collaborative venture. A true collaboration is governed by a set of contractual or formal agreements which delineates how authority, interventions, and resources are to be shared by the agencies involved in the collaborative as they seek to solve a specified problem(s). (p. 11)

As has been noted previously (Center for the Study of Social Policy, 1985) in this chapter, there is little work available on how to evaluate the collaborative, Harbert and her colleagues developed a framework for evaluation which incorporates a "conceptual theme that uses interrelated components" (p. 11). Two questionnaires were administered to the Strategic Action Committee. The first in June 1994, approximately 5 months after the group began to meet, and the second 11 months later. The research team was attempting to ascertain whether the SAC was moving toward the implementation phase of the collaborative process (p. 18).

The team asserted that "collaboration will not produce successful outcomes unless the context in which it is attempted is conducive to collaboration and the collaborative process is skillfully orchestrated. Understanding the context in which the collaboration occurs is especially critical in the formative stage of the collaboration" (Harbert, Finnegan, \& Reynolds, 1995, p. 22). They defined context as "those factors 
that assist or impede successful collaboration" (p. 23). The research team tested six broad areas of context which they deemed to be important to successful collaborations: "environmental, membership, process and structure. communication, purpose, and resources" (Harbert, Finnegan, \& Tyler, 1995, p. 20). Their findings are summarized as follows.

Environmental: While the respondents perceived themselves as leaders in the community and many had a history of participating in collaborative efforts, the majority did not find the political/social climate favorable to collaboration (p. 20).

Membership: There was a perception that collaboration was in the self-interest of the respondents and that they had developed increasing levels of trust, mutual respect and understanding (p. 21). Yet the results "suggest that there is not a high level of mutual respect, understanding, and trust among group members" (p. 29). There was not agreement regarding the appropriate representation on the SAC (p. 21).

Process and structure: Participants agreed that the members shared a stake in both the process and the outcome of the collaboration. They were less inclined to agree that the decision making processes involved enough of the participant organizations, or agree upon other process and structure issues (p. 21).

Communication: The respondents found that the quality of communication among members had increased (p. 22).

Purpose: Into this area the researchers grouped several topics which are of great interest to this study. 
Concrete, attainable goals and objectives, a shared vision. and a unique purpose were areas that tend to relate to successful collaborations. The results clearly showed that members tended to modify their views over time regarding the purpose of the SAC. By the second administration, most members agreed that the goals and objectives were clear and realistically attainable and that members of the SAC shared a common vision. There was less agreement, however, about the uniqueness of SAC's vision and goals. Only a sizable minority perceived the goals and visions of the collaboration to be different from their own organization. (Harbert, Finnegan, \& Tyler, 1995. p. 23)

Resources: The members responded that the convener was highly skilled but there wasn't consensus about the availability of adequate funding resources (p. 23). The researchers used these findings and the archival materials of the SAC to make the following conclusions. Although the SAC had achieved most of the work identified for a successful formative phase of collaboration including articulating a shared vision, mission, and goals. they had been unable to create the specific objectives that would allow them to move into the next phase of collaboration. The dynamics between the SAC members was among the factors that they concluded had inhibited the success of the collaboration:

Without a high level of mutual respect, understanding, and trust, it is highly unlikely that members of a collaborative will move easily into the development phases of the collaborative process. It is in the development phase 
that they develop formalized agreements in which authority, resources, and reputation are surrendered to a true collaborative effort. (p. 29)

Another factor is a diminishing level of confidence by the members that the "process and structure are flexible enough to all for needed changes to occur" (p. 30).

The researchers conclude that "given that it takes several years for a

collaborative to implement and achieve its objectives, it would be necessary to continue the study of the Children's Initiative into the developmental and implementation phases to access the outcomes of the Initiative" (p. 32). Therefore while their conclusions point toward certain outcomes, those outcomes may be influenced by other factors over time. It will be interesting to note how these finding relate to the findings of the current study.

\section{Conclusion}

The summaries of the New Futures collaborative efforts and the research already completed on the Children's Initiative should add depth and insight to the findings of this study. The theoretical threads of this literature review can assist with the analysis of the findings of this study. Each of the separate threads of this literature review have long been woven into the fabric of organizational life. With the phenomenon of collaboration, these threads may be woven into new designs that help to create new patterns for the successful delivery of services in a collaborative arena. The Center for the Study of Social policies who were the official evaluators of the New Futures collaboratives noted that thus far, there are no proven evaluation methodologies that address the parameters of collaborative efforts. From the presentation of the 
literature, it may well be that the culmination of this study draws similar conclusions, since clearly the variables in the review of the literature itself may cover issues which are not traditionally linked and may prove to be too confounding. Yet perhaps a key to structuring the collaborative effort can be found in understanding how to create a truly shared vision, how to collect the most advantageous set of stakeholders and how to make explicit their theories in use so that they have a greater chance of achieving the vision to which they are committed. 


\section{CHAPTER FOUR}

\section{RESEARCH METHODOLOGY}

\section{The Descriptive Case Study}

The purpose of this study was to gain a better understanding of the field of large scale collaboration and the dynamics that influence the potential success of such an endeavor. As a formal social process, the collaborative effort is a relatively new phenomenon. It is becoming a critical component of the organizational menu because of the social, political and economic tenor of our times. The Children's Initiative Collaborative was rich with potential and lent itself to a variety of potential inquiries both quantitative and qualitative. Because this study strove to understand the perceptions of the participants it was decided that a qualitative naturalistic approach would best serve the purposes of this research since "the paramount objective is to understand the meaning of an experience" (Merriam, 1988, p. 16).

Qualitative research accepts, in fact encourages, the understanding that there exits multiple realities, that every situation and experience is enormously subjective and that the same phenomenon may be experienced differently at the same moment by different participants. These phenomena are in need of interpretation and the research that leads toward interpretation is subjective, exploratory, and emphasizes process rather than outcomes (Guba \& Lincoln, 1989; Merriam, 1988; Miles \& Huberman, 1984; Patton, 1982, 1987a, 1987b). According to Merriam: "In this paradigm there are 
no predetermined hypotheses, no treatments, and no restrictions on the end product ... What one does do is observe, intuit sense what is occurring in a natural settinghence the term naturalistic inquiry" (1988, p. 17).

This study of the Strategic Action Committee offered the opportunity to work with individuals who are among the most influential people in the county. Because the SAC represented such a high level of local leadership, the opportunity to study the phenomenon of their attempted collaboration was unique and fortuitous. To quantify their perceptions and reduce their experience of the initial phase of this collaborative adventure into a series of numbers would have been a great disservice to the teaching potential of these individuals. It was a privilege to attempt to understand the phenomenon and the rich and varied experiences of the SAC participants in the naturalistic setting of the SAC. The qualitative methodology allowed the researcher to explore and interpret the words and ideas of this unique collection of individuals. It was hoped that the perceptions of the participants would be of great benefit to other collaboratives that work with the same kind of executive and high profile community leaders.

The first phase of the work of the Strategic Action Committee, as this investigation was designed to study, fit well the methodological criteria required of the case study methodology. Merriam defined the qualitative case study as "an intensive, holistic description and analysis of a single entity; phenomenon, or social unit. Case studies are particularistic, descriptive and heuristic and rely heavily on inductive handling multiple data resources" (1988, p. 16). The SAC fit exactly those loose 
parameters. It was a single entity that was attempting to create phenomenon which could be studied in a particular and discrete period of time. Patton advised:

Case studies become particularly useful where one needs to understand some particular problem or situation in great depth, and where one can identify cases rich in information--rich in the sense that a great deal can be learned from a few exemplars of the phenomenon in question. . . Regardless of the unit of analysis, a qualitative case study seeks to describe that unit in depth, in detail, in context, and holistically. (1987b, p. 19)

The SAC fits perfectly into the parameters described by Patton. Yin noted that "the distinctive need for case studies arises out of the desire to understand complex social phenomena" (1984, p. 14). The Children's Initiative qualified as an extremely complex social phenomena. The individuals involved held a wealth of knowledge, experience, insights and wisdom. In discussing the qualitative paradigm, Merriam (1988) added, "in this paradigm, there are no predetermined hypotheses, no treatments, and no restrictions on the end product" (p. 17). Since this inquiry began without predetermined hypotheses, the descriptive case study seemed to be the most effective methodology to fulfill the goals of this study.

By using a holistic approach, by trying to understand the experience through the eyes of the participants, the case study methodology enabled the researcher to create a discrete phenomenon out of the experience of the Children's Initiative and to investigate the dynamics identified through the tools of the research interview. Yin described the case study as "an empirical inquiry that investigates a contemporary phenomenon within 
its real life context; when the boundaries between phenomenon and context are not clearly evident; and in which multiple sources of evidence are used" (1984, p. 23). He further stated that the case study methodology was best used when "a 'how' or 'why' question is being asked about a contemporary set of events, over which the investigator has little or no control" (p. 20). The research questions of this inquiry include a variety of "how" questions: how important is shared vision, how is that vision influenced by stakeholder theory and theories-in-use, and how do these dynamics affect the success of the large scale collaborative process. Patton (1990) suggested that the focus on "how" is a process focus. "Qualitative inquiry is highly appropriate in studying process because depicting process requires detailed description; the experience of process typically varies for different people; process is fluid and dynamic; and participants' perceptions are a key process consideration" (p. 94). For this study, the participants' perceptions gave life to the theoretical dynamics which affect the collaborative process.

Patton (1990) continued to suggest that the case study approach may be preferred by a researcher for a variety of reasons. These reasons include studying a program that is highly individualized, that uses a systems approach process, that is process oriented, and that is a relatively new entity (p. 101). Each of these reasons applies directly to the Children's Initiative Collaborative. Merriam concluded that these very concerns are best investigated through a case study approach where the research is "exploratory, inductive and emphasizes processes rather than ends" (1988, p. 17). The end results of the Children's Initiative Collaboration were not the focus of this investigation. Rather the researcher was concerned with the initial phase of the 
collaboration and the processes by which the phenomenon was understood and pursued. Under these circumstances, experts in the field, Patton, Guba and Lincoln, Merriam. Strauss and Corbin, suggest that the case study narrative illuminates the phenomenon being investigated.

The case study is a readable, descriptive picture of a persona or program making accessible to the reader all the information necessary to understand that person or program. The case study presents a holistic portrayal of a person or program. . . The descriptions of the case should be holistic and comprehensive, given the focus of evaluation, and will include myriad dimensions, factors, variables, and categories woven together into an ideographic framework. (Patton, 1990, pp. 387-388)

The procedures followed will be described in the subsequent pages.

\section{Research Design}

This study had four specific questions focused on the attempt to enhance the current research regarding the formative stage of multi-agency, public-private collaborative efforts. The interview questions sought to solicit information and perceptions about the following four research questions:

1. What implications could be articulated about the relationship between perceived gains and losses by members of the SAC and whether these perceptions influence the degree to which the vision is shared?

2. Was it possible to establish a relationship between shared vision, theories in use and the differences among stakeholders? 
3. What inferences could be drawn about the collaborative process?

4. What insight could be provided into the process of large-scale multi-agency collaboration which is a relatively new field of study and practical endeavor? Additionally, the interviews were designed to solicit information, perceptions and opinions in the areas of theoretical interest that were discussed in the review of the literature. The questions were designed around the following concerns: the visioning process, the perceptions of gains and losses, theories-in-use and espoused theories, stakeholder issues, and characteristics of collaboration.

\section{Role of the Researcher-The Participant Observer}

The time frame of this study extended from November 1993 through April 1995. These 17 months were formally labeled Phase 1 of the Children's Initiative by the SAC. I joined the SAC as a doctoral intern in July of 1994 . In that capacity I worked closely with the staff and the committee members. I attended SAC meetings and participated actively at preparatory and brainstorming meetings that took place once or twice weekly with the Chairman, the Children's Initiative staff, various members of the SAC and consultants. These planning meetings were described in detail in Chapter two of this dissertation. I participated on the SAC as an intern from July 1994 through January 1995 and I continued to be informally involved through April of that year. During that time. I decided to focus my dissertation studies on the Children's Initiative.

\section{Data Collection}

Merriam (1988) noted that in the case study, "the researcher will be the primary instrument for data gathering and analysis" (p. 19). As the researcher and participant 
observer. I collected data using a variety of sources. Three major categories of data were collected: interviews with the SAC members as described below, archival data and observational notes. Evidence was gathered from archival documents of the Children's Initiative, beginning from November of 1993, including: organizational notes, papers, agendas, minutes, publicity material, internally published materials and other materials distributed by the organization. Additional evidence included notes taken by the researcher during the SAC meetings and the additional planning meetings. The archival data and observational notes were primarily used to create the narrative in Chapter two. Patton accurately noted that "observational data, especially participant observation, permits the evaluation researcher to understand a program or treatment to an extent not entirely possible using only the insights of others obtained through interviews" (1990, p. 25). It has further been argued that "participant observation is the most comprehensive types of research strategies" (p. 25). According to Merriam, "the ideal in qualitative case studies is to get inside the perspective of the participants" (1988, p. 95). I was able to reap the benefits of understanding the collaborative as an insider. This greatly enhanced my ability to immerse myself in the phenomena and the data. At the same time it created a strong bias that will be discussed further in the section of limitations found later in this chapter.

The research design called for 10 interviews of SAC members. The interviews were conducted during the spring of 1997. At the time of the interview, the participant received a copy of the vision, mission and goals of the Children's Initiative for review. The interview took place after the consent form had been read and signed. The 
received a copy of the vision, mission and goals of the Children's Initiative for review. The interview took place after the consent form had been read and signed. The interview questions are contained in Appendix $\mathrm{F}$ in the order in which they were used during interviews. The questions are presented below organized by subject to demonstrate their connection to the topics of research. Some of the questions fit more than one of the research questions and are listed here twice. For example, the questions about the vision being risk-taking or courageous relate to both the question of shared vision and the question of theories-in-use. Each question was asked only once during the interview itself. These questions help to formulate responses to the research questions presented earlier in this chapter.

The questions relating to the vision of the Children's Initiative are the following:

1. What is the vision of the Children's Initiative?

2. What is your vision for the Children's Initiative?

3. Do others share your vision?

4. How important do you think it is for there to exist a shared vision by the members of the collaborative? Can you tell me why/more?

5. Would you describe the vision as risk taking? If so, it what ways?

6. Do you find the vision courageous? If so, in what ways?

The questions relating to espoused theory and theories-in-use are the following:

7. Is there any discrepancy between your vision and the existing vision?

8. How important do you think it is for there to exist a shared vision by the members of the collaborative? Can you tell me why/more? 
9. Would you describe the vision as risk taking? If so, in what ways?

10. Do you find the vision courageous? If so, in what ways?

11. What kinds of sacrifices, organizationally and professionally, are you prepared to make in support of the vision?

The questions that deal with collaborative issues and perceived gains and losses in particular are the following

12. Blair Sadler, president and CEO of Children's Hospital and chair of the SAC, was recently quoted in the San Diego Union Tribune as saying, "The jury is still out on whether the initiative is a well-meaning ideal that went nowhere, or something that will really change children's lives." What do you think?

13. What do you perceive are the ways in which the SAC members can gain from the collaboration, organizationally and/or professionally?

14. What are the losses, organizationally and/or professionally?

15. What are the potential gains and losses for your organization?

16. What are the potential gains and losses for you personally and professionally?

17. Do you think that the Children's Initiative can impact a positive change or is it just another committee?

18. How many other collaborative groups are part of your work right now?

The questions related to stakeholder issues are the following:

19. Are the right people sitting at the table? 
The responses to these questions will enable the researcher to formulate answers to the research questions presented earlier in this chapter.

\section{Participant Selection}

Participants of the SAC were identified according to methodological criteria suggested by experts in the field of research and evaluation. Guba and Lincoln stressed that in the constructivist paradigm, "sampling is not carried out for the sake of drawing a group that is representative of some population to which the findings are to be generalized. Nor is the sample selected in ways that satisfy statistical requirements of randomness" (1989, p. 178). Guba and Lincoln adopt Patton's description of purposive sampling. Purposeful takes on the meaning of having other uses than randomness and representativeness. "The logic and power of purposeful sampling lies in selecting information rich cases for study in depth" (Patton, 1990, p. 169). Patton identified several different strategies for purposeful selection, each with a different purpose or variation of a purpose. The strategy used for this research study can be labeled maximum variation sampling.

This strategy for purposeful sampling aims at capturing and describing the central themes or principal outcomes that cut across a great deal of participant or program variation. For small samples a great deal of heterogeneity can be a problem because individual cases are so different from each other. The maximum variation sampling strategy turns that apparent weakness into a strength by applying the following logic: Any common patterns that emerge from great variation are of particular interest and value in capturing the core 
experiences and central, shared aspects or impacts of a program. (Patton, 1990, p. 172)

The writer identified a methodology for maximizing variation within a small group. He suggested that an effort be made to identify varied criteria for selecting participants (p. 172).

This researcher wanted to maximize variation in the sampling that was taken of the SAC. Maximizing the variation would yield the broadest responses to the research questions. The design of the study required that 10 members of the SAC be interviewed. Although the population of the SAC was homogeneous in that each SAC member was the highest executive in her or his respective organization there were, in fact. some significant variations among the SAC members. Their personalities, characteristics and life experiences were extremely varied. Their career paths and life histories were remarkably varied. The size, type, style, environment, and philosophies of the organizations that the SAC members represented were quite different. The SAC included representatives from five different targeted fields which provide services to youth and families: health, education, safety, economic security and ad hoc communitybased organizations (Harbert, Finnegan, \& Tyler, 1995, p. 6). At least one participant representing each of these targeted fields was interviewed. The original intention of the study was to interview the most active member of the target group and the least active member of the target group. This goal became unfeasible as a research design for two reasons. First, the concerns of this study required that the participants had been part of the Strategic Action Committee from the beginning of Phase 1, late 1993 or in early 
1994. There was a significant amount of turnover, of both staff and participants in the Strategic Action Committee. In some cases, there were no longer two members of the SAC that fit the original criteria. Second, to achieve maximum variation required that the chairman of the SAC be interviewed because of his unique level of involvement. Therefore in addition to the chairman, nine other participants were selected for eligibility from the five targeted groups. The participants were selected based on consensus of the former Director, Sammy Moon, the Acting Director Liz Shear, and the researcher and the selections were based on the following parameters. The goal was to chose eligible participants who had been the most and least active on the SAC. In order to achieve maximum variation the research was designed with the belief that those who were most involved would bring particular perspectives and those who were least involved would bring different perspectives. This researcher was seeking the widest range of experiences by the SAC members. The level of activity was based on attendance at the SAC committee meetings, involvement at SAC meetings, involvement with the planning group, involvement with the consultants and involvement with the staff.

From those eligible, the participants were chosen by target group and degree of participation on the SAC. In some of the target group categories there were only two eligible participants and they both were chosen. When there were more than two potential participants they were chosen by consensus of the individuals indicated above and their choice was based on the participant's level of activity. For example, the head of the Probation Department, the Chief of Police, the Sheriff, and the Superior Court 
Judge were eligible in the category of safety. The Sheriff had joined the SAC nearly a year after the work began; therefore, he was not eligible. In this category, the Police Chief who subsequently took over the chairmanship (in 1997) was chosen because of his high level of activity with the SAC, planning group, staff. and consultants, and the Judge was chosen because he had discontinued his participation in 1996 because he was disappointed in the results.

The purposive maximum variation sampling yielded the following facts about those who composed the sample. Most of the participants who were interviewed for this study were still involved with the SAC at the time that their interviews took place. Two were no longer directly involved at the time that the interviews were administered. In the category of Economic Security two of the three potential participants had left the field entirely and were unavailable to participate. The titles of the SAC members who were interviewed are listed below by target category.

\section{Chairman}

1. President and CEO of Children's Hospital

Health

1. Director of the County Department of Health Services

2. Director of the County Department of Social Services

Education

1. Superintendent of City Schools

2. Chancellor City College System 
Safety

1. Chief of Police

2. Superior Court Judge

Economic Security

1. Associate Director of the Greater Chamber of Commerce

Community Based Organization

1. Director of Social Advocates for Youth

2. Director of San Diego Organizing Project

\section{Pilot Interviews}

Two pilot interviews were administered to two members of the SAC who were not directly eligible to be part of the participant pool. Both participants had been part of the SAC from the beginning of the first phase.

1. Assistant Dean of Education, San Diego State University (Education Target Group).

2. Former Director of San Diego Youth and Community Services/Acting Director of SAC (Community Based Organization Target Group).

The pilot interviews were particularly helpful to the researcher in that she found that she had been too active and too involved in these interviews. This experience allowed her to take a more passive role in the interviews used for the study itself. The interviewer spoke less and engaged in less back and forth conversation than in the pilot interviews. This allowed the interviews to be more completely focused on the ideas of the participants. 


\section{The Interviews}

The interviews were 45 minutes to 1 hour in duration and took place at a location specified by the participant. With the exception of one, all interviews took place in the private offices of each individual. The other interview took place in a private home. No interviews were canceled or postponed. With the position and demands of each of the participants the interviews could have been tossed aside by any one of them for much more important activities. Their eagerness to participate indicated their continued enthusiasm for the Children's Initiative. Each participant was thanked and a thank you note was attached to the transcript of their interview that was sent to them shortly thereafter. This letter can be found in Appendix K. A stamped envelope. addressed to the researcher, to be used by the participants for returning their edited interviews was included.

The interviews were tape recorded and transcribed. Each participant was given the opportunity to fully review and edit her or his interview. Eight out of 10 participants returned their edited interviews. Two participants did not choose to edit their interviews nor did they respond by email or phone. Ten interviews were used for this study.

The final chapter of the case study contains a discussion of the current state of the Children's Initiative. In order to answer the last research question and truly provide insight into the large-scale multi-agency collaborative process, after consultation with members of this dissertation committee, I decided to confer with individuals currently active with the Children's Initiative. I spoke with the chairman of the Board of 
Directors of the Children's Initiative, and a member of the funders group and the Board of Directors, and the current Executive Director of the Children's Initiative.

The purpose of my conversations with three individuals currently involved with the work of the Children's Initiative was to investigate what happened during the implementation phase of the Initiative. I brought to these individuals the vision, mission, and goals that were created by the SAC from 1993 to 1995 , during the initial phase of the SAC and presented at the Children's Summit on April 27, 1995. These are the same vision, mission, and goals that were used by the SAC participants at the time that each was interviewed. They are included here as Appendices D and F. Each one was asked to review these documents and to share the extent to which they were implemented, and the role that these original goals played in the agenda of the Initiative as it has evolved over time.

Two of these conversations took place in person at a location chosen by the participant. One of these conversations took place over the telephone with both the Executive Director of the Children's Initiative and her secretary. The participants were given and signed a participant consent form. The conversations were not taped. The researcher took notes and subsequently sent a copy of the notes to each of the participants in order that they might be edited. Additionally, I collected current official literature of the Children's Initiative in order to compare the current literature with that of the first phase of the Children's Initiative. 


\section{Protection of Human Subjects}

The benefits of studying a little-understood social phenomenon outweighed any perceived risks. I adhered strictly to the University of San Diego's Protection of Human Subjects Guidelines. Because the participants were SAC members, the interviews were conducted in a location of their choice and the interview questions themselves all suggested that the potential risks to the SAC participants would be minimal.

Prior to beginning each interview, the SAC participants signed a consent form in which they were advised that information gained from the interviews would be used in the written document resulting from the study and that following the completion of the dissertation, the interviews would be destroyed to preserve the privacy of the participants. While the identity of the San Diego Children's Initiative has been disclosed throughout this study, the names of the participants are not directly disclosed. During the reporting of the results it was sometimes necessary to disclose the kind of organization a participant represented. Since there was more than one participant representing the various types of organizations, this disclosure did not necessarily identify the participant.

Participants understood that because of their positions and the high profile nature of the collaborative, it would not be possible to assure them confidentiality. The participants were given the opportunity to review and edit their interviews. Only the edited portions of the interviews were used as data. In chapter five, a few comments are attributed to the chairman of the SAC because the data could only be understood 
within the context of the chairman's point of view. Other than that, the names of the SAC members are not disclosed. When in the course of the interviews the participants used the names of their colleagues, they were designated by a blank in the narrative thereby not identifying individuals.

\section{Data Analysis}

Miles and Huberman defined analysis broadly. They included data reduction and data display as steps in the data analysis process $(1984$, p. 17).

Data reduction refers to the process of selecting focusing, simplifying, abstracting, and transforming the "raw" data that appear in written-up field notes. . . The researcher's choices of which data chunks to code, which to pull out, which patterns summarize a number of chunks, what the evolving story is, are all analytic choices. Data reduction is a form of analysis that sharpens, sorts, focuses, discards, and organizes data in such a way that "final" conclusions can be drawn and verified. (p. 21)

These insights are significant because, as with the effort to document any experience, the "facts" of the event are chosen and shaped by the perspective of the documentor (and in this case the researcher). Perhaps the most apt description of the data analysis activity is mining. The interviews were indeed a veritable gold mine of information, wisdom, ideas, suggestions, opinions, inspirations, theories and so much more. The challenge lay in how to mine the great wealth of material and particularly how to reduce and code the data. 
Coding was a critical component to the data reduction process. According to Coffey and Atkinson, "Coding can be thought of as a range of approaches that aid the organization, retrieval, and interpretation of data" (1996, p. 27). These scholars conclude that the "process of coding is about asking oneself questions about the data. Those questions help to develop lines of speculation and hypothesis formation" (p. 46). Miles and Huberman argued that words allow for a rich description, yet they are less convenient than numbers for the coding process. They write: "words are fatter than numbers, and usually have multiple meanings" (1984, p. 54). Despite the disadvantages, the social scientists endorse the use of words for the entire coding process. Coffey and Atkinson noted that "the establishment of ordered relationships between codes and concepts is a significant starting point for reflection and for theory building from qualitative data" (1996, p. 48). Strauss and Corbin frame this activity as conceptualizing the data: "By breaking down and conceptualizing we mean taking apart an observation, a sentence, a paragraph, and giving each discrete incident, idea, or even a name, something that stands for or represents a phenomenon" $(1990$, p. 63). In this study the codes are linked both to the questions discussed earlier in this chapter and to recurrent themes that have emerged from the richness of the interview data. The codes are directly linked to the themes that were investigated at length in the review of the literature presented in chapter three of this dissertation.

These methods of analysis necessitated repeated readings of the interviews. My goal in writing the analysis of data was to present the results of the participants' perception of the dynamics that were being investigated through the vehicle of the oral 
interview. The inquiry sought to understand how the three dynamics, shared vision, stakeholder concerns and theories-in-use, affected the properties of the collaborative process. Thus, to begin with, I read each interview twice prior to coding them in any way. Then I read the interviews a third time making observational notes.

Subsequently, I read the data again and coded them with color-coded Post-it flags. Each color represented the theoretical dynamics of vision, stakeholder issues, theoriesin-use, and properties of collaboration. Additionally the data was coded and flagged for each participant's definition of collaboration and the number of collaboratives in which each participant is involved at the time that the interview took place. The data was then further analyzed to code the subthemes that emerged within each of the four main theoretical dynamics. These subthemes had been identified from the theoretical presentation in the literature review.

"The second major flow of analysis activity," according to Miles and Huberman. "is data display." "We define a 'display' as an organized assembly of information that permits conclusion drawing and action taking" (1984, p. 21). They go on to assert that: "In the course of our work, we have become convinced that better displays are a major avenue to valid qualitative analysis" (1984, p. 21). They suggested that other displays such as matrices, graphs and charts "are designed to assemble organized information in an immediately accessible compact form, so that the analyst can see what is happening and either draw justified conclusions or move on to the next-step analysis the display suggests may be useful" (1984, p. 22). Therefore, following the coding and flagging of the interviews the data from this case study were used to create four working matrix 
charts which became the blueprints for the narrative analysis. Each of the four matrices were labeled with the particular dynamic being studied. These dynamics included: shared vision, stakeholder analysis, theories-in-use, and properties of collaboration. The matrices were then labeled with the various subthemes that were salient to the dynamic being studied. The subthemes of each dynamic corresponded to components which had been investigated in the review of the literature. For example, the matrix on vision, included the following subthemes: shared, individual, metaphors, symbolism, commitment, enrollment, compliance, and barriers. The matrices were created by numbering each grid of the graph horizontally from 1 to 10 in order to correspond with the interviews which had been randomly numbered from 1 to 10 . Each grid was labeled vertically with a reference word for the subtheme being investigated. Each box in the grid was used to note whether or not a particular interview referred to that issue. In the box itself, the researched noted a few key words of its content and the page number of the particular interview being referenced. In this way it was possible to graphically observe which of the subthemes emerged as being salient to a greater number of participants. These charts are included as Appendices G-J.

Chapter five will be written in narrative form by presenting the results of the matrices and the references to the interviews themselves. The presentation of the data was organized according to the investigated dynamics and divided into three sections: shared vision. theories-in-use and stakeholder analysis. The dynamic that related to the properties of collaboration was utilized according to how they affected the three themes which address the overall research questions of this dissertation. The words of the 
interviews were presented at length to allow the participants to speak for themselves on the subjects of concern. There was a meaningful disparity among the ideas of the participants and these differences in opinion were presented in detail. The case study methodology allowed for a rich presentation of the data which created a multidimensional picture of how the dynamics influenced the collaborative process.

\section{Limitations}

There were several concerns which arose during the process of preparing this dissertation; they included issues of the passage of time, transition of leadership, candor of the interview participants, and bias of the researcher.

The materials used which comprised the field notes and evidence were documents that had been created during the initial phase of the SAC from November of 1994 through April of 1996 . The interviews that were used for this study were taken in the spring of 1997 , almost 2 years after the conclusion of the initial phase of the collaborative. The consequences to this lapse in time include: possible changes (either conscious or unconscious) in the perspectives of the participants, attrition of people from the original SAC causing a smaller participant pool, and a bit of difficulty of in recollecting the initial work of the SAC by participants.

By the spring of 1997 , there had been significant changes in leadership of the Initiative on two levels. Both the professional staff and the lay/volunteer leadership had changed. Blair Sadler, who had been the Chairperson of the SAC, had passed the baton to another member of the SAC. Sammy Moon and Veronica Welsh, who had been the Director and Assistant Director, had both resigned their positions, an interim director 
held the position for several months, and a new director had been brought on board. The transition of the professional staff was both challenging and trying for all those involved in that process. The transition of the lay/volunteer leadership, which took place after that of the professionals, was more celebratory in nature. The transition of lay leadership indicated the beginning of another phase in the development of the collaborative.

The participants were eager to share their ideas and opinions. Because I had worked closely with each of them on the SAC they seemed to be quite comfortable during the interviews. In fact, most spoke quite frankly, more so than I would have anticipated. It was not unusual for a participant to speak for several minutes without a break. This was a great advantage to me as a researcher. It was unnecessary to create rapport because rapport had already been established. It may also have been a disadvantage as well. When the transcripts were sent to the participants for review a few of them closely edited their own comments, removing the most candid and reflective sections because they may have been too candid and forthcoming for use in a public document. Additionally, a researcher less involved with the actual collaborative work might find it difficult to replicate the findings of this study through the same or similar methodology.

Merriam cautioned that:

There may be problems with the data one collects. Most acute are the biases an investigator brings to the situation. These biases, inherent in all investigations, affect how data are seen, recorded, and interpreted. An observer cannot help 
but affect and be affected by the setting, and this interaction may lead to a distortion of the real situation. (1988, p. 103)

This investigator was biased through having been involved with the Collaborative during its initial phase. I got to know the SAC members and the participants so that I was predisposed toward admiring their work, style and characters. Although the SAC members spoke candidly, even those who had negative things to say about the effort, all expressed their admiration for the folks involved and in some ways sugar coated their comments. It is unlikely that they would have spoken negatively to me about their colleagues since that would have constituted gossip as I was part of the inner group as well. Perhaps they might have been more candid with a stranger who would have had little or no reaction to words of dislike or an apparent lack of respect of one person for another.

Finally, a case study is simply and fully that, a study of one particular phenomenon which occurred at one particular moment in time. The data is anecdotal and may or may not represent a common experience of those participating in a large scale collaborative effort. It can be used to point toward the necessity for further research into the collaborative experience, but not as an end to those means.

\section{Conclusion}

Guba and Lincoln asserted that "the nature of a construction that can be held about anything depends on two things: the range or scope of information available to a constructor, and the constructor's sophistication in dealing with that information" (1989, p. 71). I have attempted to use the wealth of information provided by the data 
and particularly the interviews taken from members of the SAC to construct ideas about the collaborative process. If I have been at all successful, then it is be a tribute to the quality of information with which I was given the opportunity to work. There is little question that a deep understanding of the collaborative process requires a level of sophistication. I hope that I have brought that to this project and that I have added, in some small way, to what is known about trying to make this enormous and complex process work. 


\section{CHAPTER FIVE}

\section{RESULTS}

Introduction

The purpose of this case study was to better understand particular dynamics that may influence the outcome of a large scale multi-agency collaborative effort. This investigation focused on attempting to determine the relationship among specific dynamics which influence the success of the large scale multi-agency collaborative effort. In this chapter the results of the investigation will be presented through presentation of the qualitative data collected by the researcher. As such, the researcher designed an interview instrument based on the fourth and fifth research objectives outlined in the first chapter of this dissertation. They are the following:

1. To articulate implications about the relationship between perceived gains and losses by members of the SAC and whether these perceptions influence the degree to which the vision is shared.

2. To identify the possible relationship between shared vision, theories in use and stakeholder analysis in the attempt to enhance the current research regarding the formative stage of multi-agency, public-private collaborative efforts.

The interviews were then administered to ten members of the SAC who were selected according to criteria outlined in the fourth chapter. 
The purpose of this chapter is to present the results and findings of the interviews with the 10 SAC participants. The chapter is organized according to the theoretical threads presented through the literature review as they related to the purposes of the research reviewed in the above paragraph. These dynamics included shared vision, theories-of-action and stakeholder analysis. In this chapter the members of the SAC speak for themselves about how these dynamics influenced the collaborative process. Because so many of the words in this chapter come directly from the mouths of the participants, the chapter presents a lively debate of the collaborative effort as well as the feelings, insights and perceptions of the SAC participants.

The first question that will be addressed in this chapter is: whether the degree to which the vision was shared by SAC members is influenced by their perceived gains and losses from participating in the collaborative. In order to ascertain the answer to the first question, the interviews with SAC members were analyzed using three lenses: the degree to which each member ascribed to the shared vision, each member's personal articulation of that vision and the each participant's perception of gains and loses that resulted from participating on the SAC.

The second research question sought to establish a possible relationship between the shared vision, the theories-in-use and espoused by the SAC participants and the influence of stakeholder issues. In order to answer this complex question many lenses needed to be used in analyzing the data. From the first research question it will have been determined whether or not the vision was shared. The interviews were analyzed as to which theories-in-use and which espoused theories where operating conscious and 
unconsciously among the SAC participants. That is to say, what did the researcher discover about which theories-in-use were motivating the SAC participants and what did the SAC participants say about one another. Then the interviews were mined for information as to whether the discrepancy significantly influenced the effort through the eyes of the SAC participants. Subsequently the interviews were analyzed for the SAC members' perceptions of whether the appropriate stakeholders were sitting at the collaborative table as perceived by the SAC participants.

All of the data presented in this chapter was gathered during 10 interviews with SAC participants. Each of the interviews is identified by the words "PARTICIPANT $X$." Of course the $X$ represents a number 1-10. Therefore a quote from Participant 4 is identified by "PARTICIPANT 4" at the end of the quote. Each time that an interview has been noted means that a direct quote from that interview had been presented. The data presented from the interviews are coded in this manner so that the reader can scan through the chapter for continuity in outlook and perception by each participant.

Several times it became important to identify the chairman of the SAC as having made particular statements and insights. When this became necessary, after that quote, the researcher has noted that this comment came from the Chairman and there is no other identification of the interview so as to preserve the identity of the interview number of the Chairman. Other than that, the individuals are not readily identified through the presentation of the data.

Before presenting the data, I would like to present an editorial note about the data. I request that the reader keep in mind the kinds of individuals who composed the 
SAC because they have been reduced in this chapter to an interview number. Recall that each SAC member was the highest ranking person of the particular organization. Take a moment to imagine the career paths of the individuals represented on the SAC; for example, Chief of the Police, Sheriff, or Probation, Social Services and Health Services Departments. As another example consider the career path of the School Superintendent, a CEO of the Chamber of Commerce, Children's Hospital and the like. Reflect on the career path of a director of a community based organization. Imagine how varied are the experiences of the individuals who composed the SAC. As you read the results of the data two dimensionally, remember that SAC participants are multidimensional. Each has successfully made significant investments into a life and a career to the point where she or he leads a significant urban organization.

The first research question will be addressed in four sections: the degree of commitment to the shared vision, the personal articulation of the vision, perceived gains and perceived losses.

Question One: Degree of Commitment to the Shared Vision

Although the concept of shared vision was critical to this exploration of the collaborative process, of all the dynamics investigated, the vision was the least interesting to the participants. Perhaps this stems from the fact that the vision and mission was created by a variety of groups and adopted by the SAC at the beginning of their work together. The Chairman explained:

At the first meeting we had one debate, which is, you've received this vision and mission statement, which was done by the first group, which I will call the 
Idea Group. And we made a strategic call, that I think was the right one, but some didn't later, which was, do you want to start with a clean blackboard and spend " $\mathrm{X}$ " number of meetings writing a vision and mission statement or do you, can you sign up with this? Because it was sort of discussed with you when so and so met with you on a Tuesday afternoon. Now you're here. And the group was, hey, let's get on with it. We all salute this. (THE CHAIRMAN)

One of the SAC members remembers it the following way:

What we were given was a binder and then we went through the charge. It was all war language. We got our charge through the Strategic Action Committee. The SAC was to charge ahead and with this vision and this mission to create then some goals for collaboration that people could make happen. (PARTICIPANT 10)

The vision and mission were formally adopted at the first meeting. However, the program and systems strategies which are taken here as part of the vision, were created by the work of the SAC over the entire period about which this study is concerned. As has been noted previously, the program strategies and systems strategies were given to each participant to review prior to each interview. The degree of commitment to the vision can be inferred from the different statements made by SAC participants regarding the vision and from the SAC participants reframing of the vision into their own words.

The following comments demonstrate a strong commitment to the vision and all it entails. 
The concept was an idea, actually, that I had tried in some manner, shape or form in Philadelphia, and it didn't go well. . . . But I felt that, for some reason, the sprit of collaboration felt different here. . . . It was fortuitous. . . I was willing to more readily commit resources and invest time in strategic, you know, goal setting, envisioning, in committing resources. I think when you have a collaborative like that, the best way a collaborative works is when you see people actually committing resources to the effort. (PARTICIPANT 8) It's an important vision. . . . It's a real important priority because as an educator, I see the amount of preparation that is needed to be able to succeed, to be competitive in the job market. I see the importance of helping young people establish early on a good, strong value for learning, for community service, and I think this vision encompasses all of that. . . . So the vision is important because it looks at helping young people, helping their families at least to give them an important fighting chance. (PARTICIPANT 9)

The above levels of commitment to the vision are contrasted to the comments presented below. Some of the members accepted it without much enthusiasm. For them the vision was a fine idea but not as earthshaking as it was being made out to be. The vision statement that I just read here, as then, and as I read again now, still is a nice apple pie statement that says, gee whiz that's why we showed up. But I don't think that most of the people there viewed this vision statement as anything particularly new or different. Nothing wrong with platitudes.... We 
don't need a meeting of community leaders to come to that vision.

\section{(PARTICIPANT 2)}

This SAC member clearly appreciated the intention of the vision but did not demonstrate a high level of commitment to it. Which is similar to the attitude expressed by the following two participants.

I remember seeing this and using it a lot, but I thought that ... this was created prior to the Strategic Action Committee. ... I still think it holds a lot of value. (PARTICIPANT 6)

Gosh, I can't remember how this vision came. . . . I think there was some working before and after, and I think that's how we got the vision and the mission statement. . . I think it's fine, but I think the actual "doing" of something like this is still going to be different that what you've put down on paper. (PARTICIPANT 7)

\section{Personal Articulation of the Vision}

Although the SAC participants generally didn't seem overly enthusiastic about the vision as it was presented to them, when asked to articulate the vision in their own words each and every one of them created a vision statement that reflected the intention of the one adopted by the SAC. This indicates that each SAC participant understood and enrolled into the vision. This will become more important later in this chapter when we examine the espoused theories and theories in use. The vision as articulated by the SAC participants represents each participant's espoused theory. This connection is key to the effort, so at the risk of being redundant, the vision that each SAC 
participant described as the vision for the Children's Initiative is the place where he or she wanted the collaboration to go. The following are the espoused words of the SAC participants.

My vision for the Children's Initiative is that we focus very strongly on families with the children in the center and that we break down the barriers that occur as we function in our silos. (PARTICIPANT 1)

What is it about the way we are doing business that we ought to change, and how do we change it? . . Do we have shared idea, vision, goal of a new paradigm for how to approach children's issues? We came to agree that collaboration was important and valuable. (PARTICIPANT 2)

I thought the vision was that we needed to find a way to do better in San Diego about children, youth and families, and that we needed to think of how we could collaborate and make better use of our resources in an integrated way. . . Collectively, by using our collective expertise and our monetary resources, we had a better chance to go ahead. (PARTICIPANT 3)

The idea of putting the child in the center of the circle and in this case these four quadrants all relating (health, education, safety and security). Let's see how we can help kids rather than help health and help education and help safety. (PARTICIPANT 5)

An opportunity for every child in San Diego to have a healthy start and to have a healthy education and to have opportunities for growth in a safe and nurturing environment. (PARTICIPANT 6) 
I thought the key thing was the integration of how you are caring for these families. (PARTICIPANT 9)

Here we had a collaborative that already existed [referring to the Children's Initiative], the mission being the well-being of children.

\section{(PARTICIPANT 8)}

To change systems so that we can all collaborate and contribute. Not on a one-time basis, but on an ongoing, systematic basis, our resources. Not bring in new resources, but shift resources so that all of us at some point or another, when we interact with these families, would make a contribution.

\section{(PARTICIPANT 9)}

From the above comments you can note that the SAC participants demonstrated in their own words that they were committed to the greater vision of the Children's Initiative. Each of the definitions focused on family and children, all but one mentioned collaboration or integration of services. We can interpret that the espoused theory of the SAC participants adhered to the vision of the Children's Initiative. Several of the participants underscored this point in the following reflections that they made about the vision.

Part of the whole thing in the Strategic Action Committee and the Children's Initiative has been dealing with the long term goal. So it literally is a vision that we have all had and have all bought into. So it wasn't to create one program or to create one piece it was really a long term piece that fits all the different pieces that we have been putting together over the years. So I think that's where the 
value was. I think it keeps us really focused on what we are trying to do. (PARTICIPANT 6)

It's become some kind of a vehicle for people to cooperate together in delivering certain things . . . and because there is a shared commitment at that level, you know there would be resources invested. (PARTICIPANT 4)

It's a job that is never going to end. I think that the idea is good. the vision is good, but I think that only obstacle that I'm concerned about is the ability to maintain the passion, the drive, and continuing to find people that are creative and willing to maintain that amount of work that it takes at least to carry this concept through. (PARTICIPANT 9)

The participants were reciting the vision as their masthead. Only the last comment reflected the acceptance of the vision tempered by a dose of reality. Two of the participants were actually critical about the vision and the process of accepting it. These comments begin to point to a discrepancy between the espoused theory of the vision and the theories-in-use by organizations as they have entered into the process.

The SAC was never as a group part of a visioning process or designing the mission of the Children's Initiative. I think that was a flaw. That's why I believe that the group never really jelled. . . . So I don't know how you can expect a group to give up some of their turf or whatever when they are not in a climate of trust to begin with. (PARTICIPANT 10)

The problem that we see is a problem that evolves from the things we've created, and so this is very, this has to be a very self critical process to say 
we ve been on the wrong track. And that's a challenging thing to do.

\section{(PARTICIPANT 2)}

The indictment by the two SAC members quoted above begins to point toward deeper difficulties in the collaborative process that existed from the beginning. The vast majority of the SAC members interviewed, $80 \%$ of the SAC participants, were committed enough to the vision to reflect the intention of the stated vision in their own words as the guiding vision of the Children's Initiative.

\section{Perceived Gains}

Participants were much more interested in talking about the advantages of participating in the SAC both personally and organizationally. Participants spoke at length about the value of participating: the opportunity to network, get to know one another, and lobby on behalf of one another's organizations. Nine out of 10 participants actually mentioned networking as a personal and organizational gain. It was the place to be or as one of the participants put it

Our primary motivation, to be honest, was to stay close to some of the folks that were going to be at the table. (PARTICIPANT 4)

The Chairman reflected upon how the SAC members might have benefited by being part of the SAC. He said:

I think most of them, because it was an extraordinary group of people, extraordinarily caring and I would actually say there was love in the room. . . What resonated for me when I made these pastoral visits initially, the sales calls. was the extraordinary "ah ha" reaction people were having. And people I think 
felt it was good networking and contacts and getting close to the people who were there. So I think those are probably the twin expectations for us, both of those. Good people were there, I'd better be there too. I don't want to be left out. And a kind of hedging their bets, but much less optimistic about anything major. . . And it was enjoyable as possible. (THE CHAIRMAN)

SAC participants reflected that they felt understood and gained understanding from the other members of the SAC:

I think a personal benefit is you don't feel quite so lonely when you are dealing with a particular issue, and other people take an interest and those kinds of things and are able to comment on it and talk about it with you, and you know they have some sense of understanding. (PARTICIPANT 3)

I think it brings about a new perspective, a way of looking at the business we're in and relationships with our co-partners. (PARTICIPANT 1)

A few of the participants referred to the SAC as a lobbying group for their separate and communal concerns. One participant spoke of an intervention that the SAC members made on behalf of a policy that her organization wished to initiate with the Board of Supervisors. Members of the SAC built support for the initiative

Not just for the purpose of support but for the purpose of showing the comprehensive impact of something like that on the quality of life throughout this city. And I see that more of that kind of thing is beginning to happen as you have different groups coming together under this umbrella, talking about those things we have in common. (PARTICIPANT 3) 
According to the SAC participants, the SAC members created a dialogue between themselves and their organizations. This SAC participant commented upon the relationships that were built between the SAC members.

What really happened was important to have happen was people out of some different agencies began to connect around common agendas. So you saw a kind of dialogue that apparently was refreshing between the probation and the schools, or with the health department, police department. You know, that kind of cross dialogue. (PARTICIPANT 4)

The following statement perfectly demonstrates that dialogue.

Well. I think that for the first couple of years I think that the primary benefit was that it linked a lot of people in San Diego who were providing different things to the community on different levels, whether it was CBOs, or whether it was governmental agencies or whether it was United Way or some of the others. We had never really worked that closely together. I mean, we all saw each other on the circuit, as you call it, but there was not a lot of relationships there. Through the Strategic Action Committee, I think that we all became aware of the different things. I mean, I had no idea who SAY was, and I've been a cop for 24 years . . . same with SDYCS. I mean, I didn't know what they did, and I was really impressed. I've talked to him (the director of SDYCS) several times because of that relationship, where we've developed things. . . . I think that's been a really beneficial part of it. I even talk more with people that are in the law enforcement side. We work real closely with the sheriffs, but we haven't 
worked that closely with probation in the past. Certainly we haven't worked that closely with courts in the past, so the relationships that we built in the SAC have really helped out in terms of calling up and trying new things and developing solutions to problems. (PARTICIPANT 6)

This participant explicitly identified the benefits of being part of the SAC. He clearly perceived that he was better able to do his job, fulfill the mission of his institution because of the relationships built on through being a member of the SAC.

Another SAC participant describes the benefit of networking as building trust and relationships.

I think that people at the table maybe knew each other, but didn't really know each other so that is a nice little spin off that's come. I think any one there could pick up the phone. And before, you'd go, who is this harebrained liberal out there in Mid-City driving me nuts saying they need $X, Y$, and $Z$ ? So that core group, that are power players in San Diego, even if they can't get their own large bureaucracies to move, probably still can be very helpful to these other constituencies if it's something that they alone can give input on or make a decision on or pass on a name or two. Do you know what I mean? Give it validation from the top, which many times down in the trenches helps a lot. (PARTICIPANT 7)

This participant was able to better understand the needs of what she called those harebrained liberals, who were in fact the heads of the community based organizations, from building a relationship of trust and understanding. Additionally, she perceived 
that the power held by the larger bureaucracies could be of great benefit to the smaller organizations. It is interesting to note that the statement just above this one commented upon the value that the community based organizations bring to the larger bureaucracies.

Another benefit perceived by the SAC participants was the value of having the collaborative in place when state and national opportunities came up for funding collaborative and innovative programming on local levels.

It has served as a sort of ready-made collaborative for other things that pop up on the radar screen that you can't necessarily anticipate. In other words, most collaboratives are built around a particular issue, they are issue based collaboratives, or you put together a collaborative to get a grant proposal. Here we had a collaborative that already existed. the mission being the well-being of children. And so for example when the federal Office of Juvenile Justice and Delinquency Prevention (OJJDP) said they were trying to identify a community to test their comprehensive juvenile justice reform package, when they came and visited San Diego as one of several cities that they visited and began to get educated about this thing called the Children's Initiative where once a month public and private sector leadership get in a room and talk about issues, they were floored. And I think that was the issue that kind of put us over the top in having OJJDP feds designate San Diego as the site where they wanted to test this new reform effort, because they knew it would require that kind of collaborative effort. (PARTICIPANT 8) 
This benefit of having the SAC in place when other opportunities became available, like the OJJDP opportunity, was a great benefit to the SAC members, their organizations and the greater community. The same SAC member mentioned another grant that was made possible through participation on the Children's Initiative.

This grant did not come out of the Children's Initiative. The Children's Initiative helped grease the skids, and reduced the friction through which there's about a time we started talking about this concept called HeartBeat, and probation was here, health services was here, I was here, school superintendent was there, and the judges were there, and it was well, can we get this done. Yeah, we can get this done. Still a struggle, but we've got a grant that's moving, and we expect it to be operational in a year. (PARTICIPANT 8) Other SAC participants perceived that being part of the SAC was an advantage for their organization and its mission.

I think we have gained a lot as a community college. ... We in education. especially higher education may be critical of students that are coming to us that lack so many skills, basic skills, poor preparation, but yet we may be critical. I think that we also need to be part of a community wide solution. And in our interest is that if you can get all the public agencies working together to understand where we fit. We are a member of this community. We have to be, in addition to being involved primarily in the teaching/learning process, we also have to be able to provide some public service and that public service is very, very, important. Again, the credibility and the validity because if everyone else 
is a player, we have to be a player as well. We have to be part of this team that's willing to work for many years to come to begin to solve some of the social problems and pathology we face. (PARTICIPANT 9)

As an educator the SAC participant was willing to acknowledge that the schools needed to look at the whole child "so we want to make a little contribution to the long term success of a child and improving the quality environment for that family" (PARTICIPANT 9).

Two SAC participants noted that the vision of the SAC was similar to the vision of their respective organizations and participating on the SAC affirmed the value of their organization's purpose.

I think that is part of the system that subscribes to that vision by doing the work that we did and maybe by doing it better. We had been doing integrated service delivery since 1970 . Look at the guiding principles of our organization. We are about establishing collaborating partnerships and creating healthy alternatives, that's prevention. We were all about measurable outcomes and we worked in health, education, safety and economics. I mean, so there was certainly a congruence. I thought it was sort of hot. . . The opportunity was for other people to start thinking together and maybe something new would emerge. (PARTICIPANT 10)

Another SAC participant proudly asserted that:

The vision and mission of the Initiative was completely in synch with the mission of the Department. (PARTICIPANT 8) 
Nine out of the 10 SAC participants interviewed found that their participation on the SAC was beneficial to their organizations and to each of them personally. The benefits or gains to them included: (a) the opportunity to network, the SAC was the place to be; (b) increased understanding about one another's organizations and companionship at that high level of leadership; (c) a group that created a powerful local lobby; (d) building relationships that lead to other joint and collaborative projects, (e) building trust where there had been mistrust; (f) validating one another's efforts; (g) a group ready to take advantage of federal, state, local and private opportunities funding and programmatic; (h) the opportunity to see one's organization and own efforts as part of a bigger whole; (i) the opportunity to participate in an effort that mirrors the vision of one's own organization.

The one SAC participant who did not perceive that he gained from being a member of the SAC later resigned from the SAC. He reflected:

I pissed off some people. Not because they disagreed. I pissed them off because I, I think because I challenged them. And I held them accountable, and I don't think they liked it. ... At one meeting I said "the difficulty with the process that we were in right now is that we are trying to change the problem and we are the problem. The problem that we see is a problem that evolves from the things we've created, and so this is a very, you know, has to be this, a very self critical process to say; we've been on the wrong track." And that's a challenging thing to do. (PARTICIPANT 2) 
Further into this chapter other SAC participants discuss this idea of a self-critical process, but this participant was clearly seeking gains in the degree to which organizations were willing to be self-examining and ready for change. He was not in sync with the his colleagues and subsequently resigned his position on the SAC. Perceived Losses

The SAC participants were much less concerned about losses or sacrifices that they perceived to themselves or their organizations. Four (PARTICIPANT 5, PARTICIPANT 6, PARTICIPANT 7, PARTICIPANT 8) of the 10 participants interviewed mentioned the loss of time as being a real loss to them. One participant summed it up by saying:

Disadvantages of anything like this, I think, is the time that it takes and I haven't found any great solution for that. (PARTICIPANT 3)

Another SAC member said it more forcefully and added the loss of resources as well.

If we're going to commit to certain things, then we're going to try to do it. So the question is, how much time and resources get invested. And if it's not going anywhere, does this become a real drain? . . . And so two hours invested here is two hours not invested somewhere else. (PARTICIPANT 4)

Another SAC participant spoke about the discomfort "because it's not the way we've always done stuff" (PARTICIPANT 6).

Two of the SAC participants focused on a sacrifice that had more to do with the dynamics of the SAC. 
It was often fun to talk about how we could work together for a healthier and more productive community for kids. There was built-in frustration between the two camps; which were the do-ers and the processors. And the do-ers were, "I don't get it, we're sitting in a room for three hours a month, and I don't see us doing anything for kids, when are we going to do something the touches the lives of a kid. What are we waiting for. We need a project." And the processors, who said, "we're moving too fast, this needs to be more anchored in grass roots in community, we shouldn't come out with any projects, programs, agenda items, until we've gotten more of the community invested in what we are doing." So there was this constant and very frustrating tension between the doers and the processors. (PARTICIPANT 8)

This tension will be addressed at length later in this chapter; for now, it should be noted that it made at least one SAC participant uncomfortable enough as to call it a sacrifice for him to participate in the process.

The participants didn't dwell on their perceived losses nor did the losses seem to significantly influence their commitment to the vision of the collaborative. This concludes the data presented to ascertain the answer to the first research question presented in this chapter.

The answer to the question, of whether the degree to which the vision was shared by SAC members was influenced by their perceived gains and losses from participating in the collaborative, seems to be that vast majority of the SAC participants both shared the vision and perceived significant gains for themselves and their 
institutions. The participants were able to articulate and discuss both the vision and the measurable gains they received from their activity on the SAC. SAC participants' perceptions of losses appeared to pale before their perceptions of significant gains through participation in the Children's Initiative. There appears to be a positive correlation between perceived gains and the degree to which the SAC participants were committed to the vision of the Collaborative.

\section{Question Two: Relationship Among Dynamics}

The second question investigated through the course of the study involves the relationship among dynamics that influence the collaborative process. Is there a relationship between the shared vision, the theories-in-use and espoused by the SAC participants and whether the appropriate stakeholders are sitting at the collaborative table. This complex question will be presented in six sections: is the vision shared, espoused theory, theories-in-use, tensions derived from the discrepancy, the doers versus the processors, and stakeholder concerns.

\section{Is the Vision Shared?}

The above data demonstrate that indeed the vision was shared by those SAC members who were interviewed for this study. While the degree of commitment or enthusiasm varied, every participant supported the vision, and, with the exception of one, the participants perceived significant gains for themselves and their organizations. The vision then represents the espoused theory for the SAC participants. That is to say, that the vision is the theory that the SAC participants claim is their raison d'être. 
It was important then to determine whether or not there existed a discrepancy between this espoused theory and the theories-in-use by the SAC participants.

The participants had the most to say and the most interesting insights to reveal in the area of theories-in-use. The interviews revealed their espoused theories, the participant's theory and use and some of the dynamics that were created by the discrepancy between them.

Espoused Theory

Since it has been established that the vision was shared. this vision then was the espoused theory for members of the SAC. Over half of the participants expressed only genuine excitement and optimism about the espoused theory.

I think all of that translates into age, prior experience, new experience, a spiritual awakening within me, that simply says, why can't we begin to do something different? How can we begin to move from the way we function now to a position where we all function in the best interest of the communities and our agencies? And here was an opportunity to do so. I went to each of those meetings with a very open mind, a very inquisitive piece of me. . . And I began equating my thinking pattern as a bureaucrat over a long period of time to some of the thinking that I was hearing here. And I feel very fortunate that I was able to say there were several "ah ha" moments for me. And I've never been bashful about those "ah ha" moments. (PARTICIPANT 1) 
Two of the SAC participants expressed hope that the effort would be contagious and, as one SAC member put it, "take the whole country to a different level of awareness" (PARTICIPANT 5). Another said:

I think that if we can maintain that eftort, that struggle, that fight, I think eventually this is going to be such an important component of the core value of this city, that we hopefully will be able to expand it to other locations. (PARTICIPANT 9)

Another SAC participant was so enthusiastic about the effort that he suggested that even the political culture in San Diego supported the effort:

The notion of a public/private collaborative spirit was something that was very rich here. (PARTICIPANT 8)

Still another SAC participant described the SAC as an umbrella:

It obviously is more challenging when you're trying to carry the big umbrella forward to accomplish your overall mission. But if you really are going to touch and carry the umbrella theme, I guess, for all of the children and families in San Diego, and I see it as a great advocacy for that whole group. (PARTICIPANT 3)

Generally the SAC participants supported the espoused theory. However, even those who were enthusiastic at times expressed concern. Two of the participants expressed only pessimism about the espoused theory.

I used to come from the meeting, back to the office and cry . . there wasn't any fresh look at their own work. Nothing. I mean, you were expected to come 
in and talk about all your weaknesses, but there is no look at your work. I don't mean going over people's work like saying, you nasty person, you should do this, but there wasn't any way to look at all of our work and say were we really coming to this, and the answer is no. So if we are not, what will we want to do? You would never even look at what they were doing now, you would simply say what would it take to get to this kind of a vision. (PARTICIPANT 10)

These sentiments were echoed by another SAC member who suggested that the SAC ask similar kinds of questions of itself:

What is it about the way we are doing business that we ought to change, and how are we to change it? And instead, what I saw over time was a lot of reports about things that were happening that were kind of business as usual, which were fostered by this coming together, just by the fact that we were meeting . . but we never did go back to what the initial problem was, is: do we have a shared idea, vision, goal of a new paradigm for how to approach children's issues? (PARTICIPANT 2)

One of the participants expressed both optimism and pessimism.

The people representing those entities are well meaning and committed. The problem is, they represent huge bureaucracies that aren't always willing to change in the ways that they are espousing, or that we are all agreeing to, because they are not hearing the same information, the same trust the same buyin, and one person at the top is not going to be able to move the " $\mathrm{X}$ " thousands 
of employees to think and act differently to their client constituency. So while this is good, I think that the attempting to live it out has probably been a much bigger struggle. (PARTICIPANT 7)

Three other SAC participants directly mentioned concern about the trickle down into the respective organizations that the SAC members represent. Although this study is not concerned about that particular issue, the concern or worry about it by SAC participants is important to the degree of commitment to the vision. The member of the SAC who resigned from the SAC expressed the concern in this way. In this quote the SAC participant is describing another SAC member.

You know, here's a guy who got a heart as big as all outdoors, and yet he's also a survivor and a bureaucrat in a bureaucracy that's his. And so he's in to the art of compromise and concession and all the games that are played to allow you to survive in that world. None of that game playing is designed to accomplish our vision. Bureaucracies are first designed for their preservation.

\section{(PARTICIPANT 2)}

Interestingly, the man to which this statement was referring himself saw the challenge and had this to say about it:

That old story about you can take a horse to water but you can't make him drink? I began my management belief that my job was to make those around me thirsty. A thirsty horse will drink; they will find the water. And so I began sending other people to a whole variety of places, let them get excited, and all I 
had to do is say, well. yeah, let's go to it. And it began to have a life of its own. (PARTICIPANT 1)

To summarize, the SAC members were for the most part optimistic about the espoused theory and the reality of carrying it out. One SAC participant referred to the document by the Annie E. Casey Foundation, The Path of Most Resistance, which was reviewed earlier in chapter three. He commented:

Once I kind of read that and they talk about their lessons learned from collaborative efforts of New Futures. It was "of course!" You know, this is why this stuff is hard. There are a number of stops that the train kind of has to go through that are called growth. And there are very good reasons why institutionalized collaboration is very difficult to sustain beyond a project. And I think there are a lot of good examples of successful collaborations for projects, but not for systems change. On the project part, I would give us an A-. On the systems change piece, I think we're at about a $\mathrm{C}+$. (PARTICIPANT 8)

The SAC participants knew the drill. They were aware that they had been invited to participate in an entity that would require change at profound levels of their organizations. By sitting around the collaborative table they agreed to buy into the espoused theory that collaboration was the desired goal. Clearly the data demonstrates that their commitment was more than lip services or just the desire to be part of the in crowd. The evidence shows that the SAC participants took their commitment seriously and that it represented a contract of intention. In the next section we will be able to 
look at a different layer of intention. Perhaps the reality of their respective professional lives didn't provide a path to achieve the intended goals.

\section{Theories-in-Use}

There were a wide variety of theories-in-use operating within the SAC. These theories-in-use that might be thought of as the SAC participants' personal agendas or survival agendas. Some of the theories-in-use came directly from the mouths of the SAC participants about themselves, others came as reflections or indictments from other SAC participants. Examining the theories-in-use can illuminate the process and path toward fulfilling the vision.

Some of these personal agendas supported the espoused theory and vision. Those have already been documented in the previous section which demonstrated support for the vision. One participant asserted:

I was willing to more readily commit resources and invest time in strategic goal setting. envisioning, in committing resources and I think when you have a collaborative like that, the best way a collaborative works is when you see people actually committing resources to the effort. (PARTICIPANT 8) Other members of the SAC identified theories-in-use that may not have facilitated the fulfillment of the espoused theory. That is to say that they expressed ideas and attitudes that were present that may have presented a significant discrepancy. Those included: protecting turf, business as usual, patronizing of certain kinds of SAC members, accommodating, and lack of commitment of resources. 
Half of the SAC participants referred to protecting turf as operating among the SAC members. One SAC participant noted that:

People are still protecting their turf, they're still funding issues. everybody is going after the same amount of money, or the same pots of money, and it's hard to give up some of your power to somebody else who you may not have a real strong relationship with. Or even who you have a strong relationship with. (PARTICIPANT 6)

I think that many of the SAC members spent a lot of time covering their butts and protecting their turf. (PARTICIPANT 10)

Another SAC participant asserted "most of these organizations spend a lot of time preserving the organization" (PARTICIPANT 2). These sentiments indicate that getting to the espoused theory would still take some effort.

Another theory-in-use came up in looking at attitudes of SAC members toward one another. The entire SAC was made up of large bureaucracies both public and private and several community based organizations. Some of the SAC participants noted particular attitudes toward the community based organizations.

I liked all the people and I even liked our differences, even though I would get so God damn frustrated with these altruistic, if we can't help everybody, we'll help no one. Well, that's not the way society is. Not everyone benefits the same, not everyone succeeds the same. So I'm not hung up on that, but some of these people that are nicer that me are rightfully hung up on it. But I thought it was good, they are just so concerned about the entire 
group and the empowerment at the lowest level. where I'm lazier and I'm more get the top dogs in the room and they'll give the marching orders and we'll do it. Now, the community people, probably rightfully, because I haven't worked as much in the community as they have, say if you don't get the real buy-in at the grass roots level ... it's not going to work. (PARTICIPANT 7)

That participant expressed frustration but respect toward the community people. Others were not as respectful.

The community type people were coming up with some very dynamic, real world things that could be done that would impact kids and even that was kind of being pushed off very subtlety. They were being tolerated, in my judgment by people who had larger and more important things to do. I mean, they had bigger picture visions. . . . I got patted on the head a few times and told how passionate I was and after a while I got real annoyed with that.

\section{(PARTICIPANT 2)}

Three participants mentioned that the theories-in-use were those which maintained business as usual. One participant said directly:

I saw it as a careful disguise to continue the status quo. (PARTICIPANT 10) Another asserted that

The Children's Initiative quickly became an agency driven initiative. And so there were bureaucratic kinds of agendas that perhaps became more cooperative. ... It is in a sense represents the self interest of those various departments or agencies, and the question of whether the self interest of those various agencies 
and departments represent the best interest of the public was not the question. (PARTICIPANT 4)

Another SAC participant offered a more generous interpretation:

The problem is, they represent huge bureaucracies that aren't always willing to change in the ways that they are espousing, or that we are all agreeing to. (PARTICIPANT 7)

Two SAC participants spoke about committing resources. One participant described it as the litmus test of the espoused theory.

Maybe it's a question of, how do you get it done? How do you change? And everything is fine until you start talking about giving up money. That's when the rubber meets the road and different arguments. They are still in silos. (PARTICIPANT 1)

The other SAC participant described it as justification for slow advancement: Things evolve slowly. and as they evolve slowly, hopefully they will be evolving on the basis of the, of a success and as a result of those successes and long term benefits they will then become part of the fiscal priority of our operations. (PARTICIPANT 9)

Another SAC participant suggested that the theory-in-use was how to keep the stakeholders at the table:

The priority of the Children's Initiative became keeping the diverse players at the table, and accommodating the variety of interests that they represented. 
... The priority value became how do we accommodate the diverging opinions of what needs to happen? That forced the lowest common denominator to be that which was operating. "You don't get into A if my focus is, I'm at this table because I want to move A, B, and C forward. I'm not going to sit at the table to look at D. E and F. Okay?". . That's why I think at the time the chairman was interested in protecting the table. By that I mean protect the involvement of people. The measuring stick of success became are these same people still sitting around the table. (PARTICIPANT 4)

This particularly sharp assertion about the theory-in-use further demonstrates the discrepancy between the espoused theory and the theories-in-use. One SAC participant hypothesized about the reason why the espoused theory departed from the theory-inuse.

The problem is that the notion of broad and sweeping systemic change for children is, unless you're kind of in this business, can be very abstract. . . So, I guess, if you asked every member of the Children's Initiative about systemic change and systems change, you would probably still get a lot of different answers. . . I I think you probably get some eyes glazing over.

\section{(PARTICIPANT 8)}

His thoughts suggest that it was difficult for the SAC members to grasp the meaning of systemic change and that was reflected in the dynamic of the group.

Results of the discrepancy between the espoused theory and the theories-in-use pointed toward an enormous tension that developed in the SAC. Eight out of the 10 
SAC members interviewed discussed this tension directly. The SAC members themselves raised the issue of the tension and they focused in two areas. Six of the eight suggested that the tension was centered between the organizations that were bureaucratic in nature and those that were community based. That is to say that the theories-in-use and the perceptions about the theories-in-use about the way business is done varied so greatly between the bureaucratic organizations and the community based organizations that a tension developed that wounded the success of the Initiative. Three of the SAC members suggested that the tension was a result of the differences between the go getters and the processors. Which is to suggest that the there was a significant discrepancy between theories-in-use regarding the process of change. The variety of theories-in-use operating among the SAC members created a discrepancy and a tension that became overwhelming to the process.

\section{Tension Derived from Discrepancy}

The tension was presented by the majority of SAC participants without being asked specifically about tension created in the SAC. It was crippling to the process and presented itself in the form of several rifts within the committee. This is not to say that philosophical disagreement would not have potentially strengthened the effort; however, the SAC participants presented these issues as divisive and creating enough tension to be damaging. Three categories of tension will be presented here, bureaucracy vs. grass roots, doers vs. the processors, and self-critical vs. take it from here. 
Bureaucracy vs. grass roots. The vast majority of SAC members represented large bureaucracies with a minority representing the community based organization. Those representing the large bureaucracies held a variety of opinions regarding the place of the individuals who represented the smaller more grass roots community based service providers. One participant framed the discrepancy well. He said:

And the issue was, health, social services, then they listened to probation, and it was, why are we focusing just on the big organizations? When are we going to get to the community based organizations to really begin to talk? And that was the beginning of what I think was an educational component, and a trip that takes us to where we are now. That has been good. It is, are we going to be neighborhood and community focused, or are we simply going to be what large agencies and governmental entities have always done, and that would be create programs and tell neighborhoods and communities and those individual recipients to conform to our desires, because we supposedly are better equipped to make decisions on programs. (PARTICIPANT 1)

That SAC participant viewed the tension as a challenging force. Other SAC participants saw it differently.

I originally thought the Children's Initiative was viewing itself as a catalytic agent to create a capacity within the county for a lot of folks to begin to think a bit about some of the problems that youth were facing and to work together on it. I think what it moved to is some agencies deciding that they knew what the answers would be, but they needed to pool resources in order to implement 
those strategies. . . It became "we versus they." And somehow I got lumped in with [the other community representatives]. The four of us would have radically different views of the same question. Just because we "come out of the community." I think brought a certain kind of ideological perspective that got laid on the rest of us. So that was one of the battles within the battles. But there was tension between those perspectives. It got raised and not taken seriously. (PARTICIPANT 4)

The above comment by a representative of the community based organizations reflects the struggle within even that small group. The following articulates the attitude of the large bureaucracies toward the community based organizations.

The consensus that there was a new paradigm, a different way of doing it. The closest we came frankly, is when we go into the breakouts with committees, and then there was a group of, the group I just talked about that was made up mostly of $\mathrm{CBOs}$ and the community type people, and they were coming up with some very dynamic, real world things that could be done that would impact kids and even that was kind of being pushed off very subtlety. There was tremendous tension, because they were not being welcomed with open arms. They were being tolerated, in my judgment, by people who had larger and more important things to do. I mean, they had bigger picture visions. The typical global government administrative approach to things that never really gets down to anything. (PARTICIPANT 2) 
One SAC participant noted that the discrepancy and tension may be derived from the very vision of the Children's Initiative:

I think there is a discrepancy between the vision statement of the Initiative, and the mission statement of the Initiative. The vision statement talks about the people in San Diego and the mission statement talks about an integrated service delivery system. Those are two very different things. The vision statement is a community development statement, the mission statement is a human service delivery system statement. Sometimes those things match. But in this instance they are very different. I think that subtly caused ambiguity and a kind of cognitive dissonance. It certainly did for me, because I was with the vision and I'm not much with the mission. I think some people saw the discrepancy.

Certainly the community reps saw the discrepancy. (PARTICIPANT 10) Another SAC participant pointed toward the difficulty created by the varying perspectives.

It's not an easy process: it's extremely difficult, and both sides depending on who you have at the table, but with us specifically, neither side has an easy time with it. The community doesn't have an easy side, easy time with it and neither does the department. (PARTICIPANT 6)

Another SAC participant was quoted earlier referring to the tension between the bureaucratic agencies and the CBOs. Her comments colorfully identify the tension:

I'm lazier and I'm more get the top dogs in the room and they'll give the marching orders and we'll do it. Not, the community people, probably 
rightfully, because I haven't worked as much in the community as they have, say if you don't get the real buy-in at the grass roots level, these communities are tired of the next program, the next fix, so it's really not going to work. Now I think the majority of the group bought that argument. so I think it's become much more tedious in trying to maybe do some of these implementing of these thrust areas, if that's the way you're going to do it. And I'm not saying it's right or wrong; it just sounds like more work to me. But maybe in the long haul, it's more work for a longer, real buy-in. (PARTICIPANT 7)

Clearly the data show that the tension was present and articulated by a significant number of SAC participants. The ways in which this tension may have affected the collaborative will be discussed and analyzed in the next chapter. This tension was not the only inhibitor creating discrepancy between the espoused theories and the theoriesin-use.

The doers vs. the processors. Three of the SAC participants identified the tension as being a matter of style. Regardless of whether the SAC member represented a bureaucratic organization or a CBO each individual's theory-in-use varied along the continuum from a slow processing orientation to an action oriented style. The Chairman noted:

The hardest part of chairing the SAC was, being in the absolute untenable position of, which made it fun, about a third of the people were real go-getters, let's roll up our sleeves, we've been talking too long, let's get going. The 
opposite third wanted to study it forever, and the other third was sort of in the middle and changed depending on how they felt. (THE CHAIRMAN)

Another SAC participant confirmed the Chairman's analysis.

There was built-in frustration between the two camps; which were the doers and the processors. And the doers were "I don't get it, we're sitting in a room for three hours a month, and I don't see us doing anything for kids, when are we going to do something that touches the lives of a kid. What are we waiting for? We need a project. And the processors, who said, "we're moving too fast, this needs to be more anchored in grass roots in community, we shouldn't come out with any projects, programs, agenda items, until we've gotten more of the community invested in what we are doing." So there was this constant and very frustrating tension between the doers and the processors. The doers thinking we're moving too slow, the processors thinking we were moving too fast. . . I actually felt that we needed to do both. I felt comfortable with that ambiguity. Others couldn't get comfortable with it because, probably two things. One is, as someone who is a manager, I understand that nothing succeeds like success. And nothing prepares an organization for achieving success like victory. To use a sports metaphor, you've got to win some games and get through the Super Bowl. I mean you have to build a tradition of winning and achieving something. And I felt very comfortable that we could pick off some "low hanging fruit" and get some stuff done; at the same time that we were building the, vision of having the community ultimately taking ownership of the 
Children's Initiative and exerting the leadership: parents. youth, grass roots organizations. And that we didn't need to stop the whole train to wait for everyone to get on board before the train left the next station. So I'm not sure why, I think there was a number of us who felt that way. And then there were the other two camps. I think that perhaps we should have anticipated that a little bit better. And if I had to do it all over again I would have that, everyone kind of understand that that was an issue, that that was a tension, that we could recognize it, acknowledge it, but move on, knowing that the tension was there. And perhaps even use some of that tension positively to fuel the engine. . . It seemed to have caught us by surprise and it shouldn't have. And we stayed in it for too long. (PARTICIPANT 8)

This SAC participant poignantly described the tension and the paralysis which resulted from it. One SAC participant suggested that more attention needed to be given to creating a trusting environment.

But that is very specific process in terms of how do you make people who come from very different places, how do you create conditions in which they might trust each other. It might take a longer time. (PARTICIPANT 10) Self-critical vs, take it from here. Seven of the 10 SAC participants referred to the necessity of creating a self-critical process in order to move from the theories-in-use toward the espoused theory. The most serious indictments came from those SAC participants who would be considered the community folks. 
And then there was early on in the development of the Children's Initiative, there were divergent paths that were constantly being held up. One that kind of took a more critical look at what's not happening and tried to examine it. And the other was let's just figure out one thing we can do and do it together so that we've got a something that gives us a track record. And it was those two points of view that were tension with one another and it kind of provoked a middle ground. One that was not highly critical; one that eventually moved us toward programmatic articulation. (PARTICIPANT 4)

This participant noted that the middle ground was to move forward with the status quo which could ultimately allow for programmatic rather than systemic collaborative works. The following participant identified what it might take in order to achieve the vision. In many ways the following statement represents the criticism of representatives of the community based organizations directed toward the bureaucracies.

The reality was that if we really got into doing the groundwork, you would end up with a whole different kind of accountability system and funding system even on integrated service delivery stuff. You could perceive that as a loss or you could perceive it as a change. I would rather perceive it as a change... There wasn't any fresh look at their own work. Nothing . . . there wasn't any way to look at all of our work and say were we really coming to this and the answer is no. So if we are not, what will we want to do? And that, you would never look at what they were doing not, you would simply say what it would take to get to 
this kind of vision. . . You really start believing in this vision or some other vision that you are creating together and that would have been, I mean, can you imagine? (PARTICIPANT 10)

One SAC participant theorized as to why this was not possible. What would it take to do the work?

The people who created the problem are not attitudes that are going to solve it. So when you bring in the leaders of the agencies, they're either going to have to become suddenly very self aware or self critical, or honest in a way that most of us are challenged to be honest. Or they're not going to be able to solve the problem. Because they, you know, they are the problem. They are good, decent, caring, hard working people, but they are bought into the systems and working for ten years to make those systems work better and to ask them to say. "hey, all this stuff I've been doing for ten years isn't very good" is really, really, tough. And they're just not likely to say that, because what you automatically say is, "well hey, I'm doing the best I can." And they are. All of that is what makes efforts like this difficult. . . I guess I'm skeptical that you can get people who are that bought into the existing process to sit down together and make that kind of change when you consider the risks. (PARTICIPANT 2) AT the same time, some of the SAC participants who represented larger bureaucracies were more optimistic about the potential for self-examination and change.

This is the largest organization I've ever seen in my life. It has so many rules and regulations, and I marvel at how my staff have been able to keep up with 
the ever changing, because whatever else I am, we as a department are a creature of the state and federal government. When I look at $\$ 960$ million worth of a budget, at this point in our lives. only $\$ 23$ million of that is county money. So when you take somebody else's money, you take their rules. . . I think also with the Children's Initiative, my eyes began to open up to all the new possibilities as we began with each entity, large and small, public and nonprofit, began talking about what they do. See, and I've always had a good working relationship with people like [head of a CBO]. And then [head of a different CBO], I began to have a real delightful understanding of how he thinks. And I began equating my thinking pattern as a bureaucrat over a long period of time, to some of the thinking that I was hearing here. (PARTICIPANT 1)

The above comment represented a participant who was more introspective and keenly aware of the boundaries surrounding his responsibilities. He was invigorated by the challenge. Another SAC participant who represented a large bureaucracy didn't see the necessity in being self-critical, rather asserted that the task is best approached by building on what is there and making changes.

I think it's going to take small steps for people to build trust and to see how the system works, and to kind of look at the systems that they build instead of looking at the systems that they are from. Because if you look at the systems you are from, you know how that works and you know how difficult that is. If you look at the system as you build, in small ways you can see what you are 
doing. I think that's what we're hoping. I don't think that you have to be self critical of your organization that you've built in order to try something new. I mean we have changed, we have made a lot of changes and it hasn't been by being critical of what we were doing previously. (PARTICIPANT 6)

The CBOs had a much more rigorous demand for self-evaluation and critique as demonstrated by the quotes presented above in this section. The larger bureaucratic organizations were more focused toward improvement with less of a critical component. It should be recalled that the purpose of the Children's Initiative was to distinguish itself as a collaborative rather than a group of organizations joining to create joint programs. The Children's Initiative saw itself as changing the paradigm, the foundation, of how services were delivered to children. That was the raison d'être for the commitment by the individuals involved. The struggles and the way that they were managed, resolved, and used had important implications for the success of the collaboration.

\section{Stakeholder Concerns}

The SAC participants weren't terribly concerned about whether or not the best set of stakeholders were invited to the SAC table. Their stakeholder concerns focused in only two areas, who's there and who's missing. Eight of the 10 participants mentioned the value of who was at the table. One put it simply: "There are good people represented" (PARTICIPANT 7). The Chairman describes his effort to organize the SAC. He had been inspired from other collaborative efforts and had the idea of combining the fields of health, education, safety and security. He noted that: 
Almost no one was bringing in the business sector and community based organizations. So then another pie chart would have three groups: one was public non profit; one was business; and one was private non profit which was institutions like mine and more importantly, the community, the neighborhood based organizations. That led to this group of about 15 or $16 \ldots$ So no one systematically went out and built this " $A$ " team. It just showed up. (THE CHAIRMAN)

Another SAC participant described the collection of SAC members as serendipitous. I think what you had were people who almost serendipitously shared the same concern for the welfare of young people and families who were in need. We shared the same core value about solutions to making our communities better so that children would have an environment where they felt safe, where they felt secure, where there were support systems, a safety net if you will, and I think that without exception whether there was a change in leadership or not, these institutions have continued to support that philosophy. (PARTICIPANT 9) One SAC participant described the stakeholders involved in the following way. He uses this idea when he gives speeches to local groups "from the Rotary to Kiwanis." And I'll talk to them about the fact that we convene people from all over San Diego. We're not program developers; we're really people who are bringing other programs in to collaborate, to focus, to provide a variety of services. We're there to kind of lay out a matrix and try to fill in holes by bringing other people to the table. (PARTICIPANT 6) 
A different SAC participant noted that the stakeholders involved were critical to larger arenas than the Children's Initiative.

I think it helps everyone to be on the same page, and you're getting the benefit of the data as shared by all the various important entities. If there's something happening in welfare reform. then I'm going to hear it there from those who are working closely with that. If there's something happening in terms of the city's mission, Renaissance Commission, all of those things, you hear it there. And then you're able to take that information and reflect upon it in terms of your own individual agency's mission. (PARTICIPANT 3)

Yet another SAC participant reflected on the breadth of the SAC differently.

It was a very painful beginning because we were a broad spectrum of people: public, private, non profit. (PARTICIPANT 1)

The SAC participants appreciated the breath of the SAC as it was composed and understood the challenge presented by a gathering of such diverse stakeholders. They acknowledged the challenges by creating a group as large and diverse as the SAC. Eight out of 10 SAC participants also noted that there were stakeholders missing from the SAC. One SAC participant justified limiting the number of SAC members by saying.

If we bring in everybody that has a legitimate case, many of them as strong as the people that were on that list, we'll be needing Jack Murphy Stadium. (PARTICIPANT 6) 
One SAC participant "wondered at the lack of religious participation" (PARTICIPANT

4). Another SAC participant noted that in time the stakeholder base would need to expand.

I think with time it'll get a bit more play, a role that's a bit more proactive. And the keys to that, I think, are getting youth participation and leadership and community and parental participation and leadership. Because until we get that, it's still a bunch of us kind of talking heads and executives kind of sharing information about what we're doing without a lot of sort of grass roots from the bottom up you know, leadership. (PARTICIPANT 8)

SAC participants noted the necessity to bring in other significant stakeholders like the PTA, the Urban League, youth leadership organizations, religious leadership and other community based agencies, yet they understood the constraints of working in such large numbers.

And I see that more of that kind of thing is beginning to happen as you have different groups coming together under this umbrella, talking about those things we have in common. Because we are all working with the same families and children, and the same life in San Diego that we are trying to maintain.

\section{(PARTICIPANT 3)}

All of the SAC participants understood that the work of the collaborative extended to stakeholder groups beyond the scope of the SAC.

This concludes the presentation of the data regarding the second research question that sought to determine whether or not there existed a relationship between 
several important dynamics involved with the collaborative work of the SAC. The data demonstrates an important relationship between the articulated vision, the chasm between the espoused theory and the varied theories in use and the importance of who was sitting at the table. The SAC participants suggested that SAC members brought to the table briefcases packed to the brim with theories-in-use. Some of these included: protecting their turf, preserving business as usual, patronizing of certain kinds of SAC members, accommodating and lack of commitment of resources. According to the SAC participants, the chasms created by these theories-in-use were not dealt with in ways that would build bridges and roadways toward reconciling with the espoused theories. Although many of the appropriate stakeholders were represented the tension created by the discrepancies may have been more crippling than was anticipated. The data establish a strong relationship between the dynamics and one that needs further analysis toward the potential for greater success.

\section{Summary}

This chapter has presented the data pertaining to the two research questions addressed at the beginning of the chapter. The following chapter will answer the four research questions and in the process analyze, discuss and recommend further areas of study. 


\section{CHAPTER SIX \\ DISCUSSIONS AND CONCLUSIONS}

Introduction

This case study investigation attempted to determine the relationship among specific dynamics which influence the success of the large-scale multi-agency collaborative effort. Chapter one offered a brief overview and background of the collaboration, and the four research questions that would be explored in order to better understand the phenomenon being studied. Chapter two provided a context for this case study by documenting the beginning phase of the San Diego Children's Initiative. That chapter began and concluded with the Children's Summit in April of 1995. It provided an in-depth view of the workings of the SAC and the planning team which assisted and charted the course of the SAC. Chapter three covered the review of the literature by investigating the theoretical breadth of the issues involved in large-scale, multi-agency collaboration. In the fourth chapter, the research design, rationale, and methodology used in the descriptive case study were presented. The fifth chapter presented the findings and results of the interviews with the 10 SAC participants.

This chapter will include a discussion on the subject of each of the four questions of the research, comments regarding the implications and limitations of this case study, and reflections of the researcher. The four research questions were the following: 
1. What implications could be articulated about the relationship between perceived gains and losses by members of the SAC and whether these perceptions influence the degree to which the vision is shared?

2. Was it possible to establish a relationship between shared vision, theories in use and the differences among stakeholders?

3. What inferences could be drawn about the collaborative process?

4. What insight could be provided into the process of large-scale multi-agency collaboration, which is a relatively new field of study and practical endeavor?

In addressing the four research questions, the data which is required for responding to the questions has been presented and analyzed in the previous chapter. The third and fourth question are more open-ended than the first two. The third question regarding inferences that may be drawn about the collaborative process will include discussions drawn from the review of the literature and inferences drawn from the data presented in chapters two and five about the unintended consequences, initial actions of collaboration, and the systemic change effort. Finally, in order to answer the last research question and truly provide insight into the large-scale multi-agency collaborative process, after consultation with members of this dissertation committee, I decided to confer with individuals currently active with the Children's Initiative. I spoke with the chairman of the Board of Directors of the Children's Initiative, and a member of the funders group and the Board of Directors, and the current Executive Director of the Children's Initiative. 
The purpose of my conversations with three individuals currently involved with the work of the Children's Initiative was to investigate what happened during the implementation phase of the Initiative. I brought to these individuals the vision, mission, and goals that were created by the SAC from 1993 to 1995, during the initial Phase of the SAC and presented at the Children's Summit on April 27, 1995. These are the same vision, mission, and goals that were used by the SAC participants at the time that each was interviewed. They are included here as Appendices D and F. Each one was asked to review these documents and to share the extent to which they were implemented, and the role that these original goals played in the agenda of the Initiative as it has evolved over time. I came to believe that unless we knew something about what happened next as it related to the vision, mission, and goals of the collaborative, it would be difficult to offer insights, perceive implications or suggest learnings.

\section{Purpose 1: Vision, Gains and Losses}

If Senge is correct that a shared vision reflects the personal vision of the stakeholders then, in fact, the vision of the Children's Initiative was shared by the SAC participants. Furthermore, according to Cheynoweth (1994), Galaskiewicz (1979) and Gray (1989) it is essential for a collaborative to have a vision, mission and goals that is shared by the collaborating partners, regardless of whether that vision exists at the outset as was the case with the Children's Initiative or whether it evolves from the collaborating partners. The vision of the Children's Initiative may have been what Senge called an imposed vision. But this imposed vision had a bit of a kick to it. Rather than being a creation of the elite, it was created by the Committee of 100 , as 
described in the second chapter of this dissertation. The vision was the result of many community forums which took place just prior to the creating of the Children's Initiative. Therefore, although it was not the creation of the SAC, neither was it the property of a single leader or even a few influential people. If anything, the vision belonged to the people of San Diego. The vision might have been called the "marching orders" in the parlance of the Strategic Action Committee, and the committee adopted them as their own. Overall, the SAC participants were warmly enthusiastic about the vision as it was presented to them, and when asked to articulate the vision in their own words, each and every one of them created a vision statement that reflected the intention of the one adopted by the SAC. The vast majority of the SAC participants both shared the vision and perceived significant gains for themselves and their institutions.

These results were confirmed by the learnings of the New Futures Collaboratives as they were presented in the third chapter. Through New Futures, it was demonstrated that "reform efforts characterized by a comprehensive vision can inspire tremendous energy in communities" (Annie E. Casey Foundation, 1995, p. vii). The vision was described by SAC participants in chapter five as keeping the SAC focused, a vehicle for people to cooperate, the inspiration for maintaining the passion, drive and creativity necessary to carry the concept through.

Scholarship noted that it was essential for the collaborative process to advance a vision shared by each organization with cognition of the gains and losses it may require. The participants in this case study were asked about their perceived gains and 
losses as they related to participation on the SAC. The participants were able to articulate and discuss both the vision and the measurable gains they received from their activity on the SAC. SAC participants' perceptions of losses appeared to pale before their perceptions of significant gains through participation in the Children's Initiative. The participants didn't dwell on their perceived losses nor did the losses seem to significantly influence their commitment to the vision of the collaborative. In fact, 9 out of the 10 SAC participants interviewed found that their participation on the SAC was beneficial to their organizations and to each of them personally. Participants were quite interested in talking about the advantages of taking part in the SAC both personally and organizationally.. Nine out of 10 participants actually mentioned networking as a personal and organizational gain. It was the place to be. In summary, the benefits or gains to them included: (a) the opportunity to network, the SAC was the place to be; (b) increased understanding about one another's organizations and companionship at that high level of leadership; (c) building trust where there had been mistrust: (d) the opportunity to see one's organization and own efforts as part of a bigger whole; (e) validating one another's efforts; (f) the opportunity to participate in an effort that mirrors the vision of one's own organization; (g) building relationships that lead to other joint and collaborative projects; (h) a group that created a powerful local lobby; and (i) a group ready to take advantage of federal, state, local and private opportunities funding and programmatic.

Clearly the SAC participants perceived advantages for themselves and their organizations. The question arises, to what extent do the reasons that taking part in the 
Children's Initiative address the stated vision, mission and goals of the Initiative? That is to say, do the perceived benefits promote the collaborative vision and mission of the Children's Initiative? In order to ascertain that answer the vision and mission of the initiative are presented here so that the reasons may be evaluated within their context. The vision of the Children's Initiative is to create a more nurturing, caring, and supportive community of people and organizations that places top priority on children and families and encourages them to reach their potential. The mission states that the Children`s Initiative is a collaborative effort among individuals and organizations representing the government, private nonprofit, and business sectors of San Diego County. It is dedicated to strengthening children and families by working for integrated service delivery systems that promote the values of collaboration. prevention, and measurable outcomes in the fields of health, education, safety and economic security. The SAC participants had the opportunity to familiarize themselves with the vision, mission and the systems and program strategies prior to their interview. They were given the these documents to review so that they were fresh in their memories.

The one-sentence vision statement does not mention collaboration among the community of people and organizations to which it refers. It does mention that these people and organizations become more nurturing, caring and supportive and place higher priority on the well being of children and families. The nine reasons why belonging to the SAC was beneficial to SAC participants as summarized above, can be divided into those reasons that relate to and promote the vision, and those reasons that promote the mission. Reasons one through five above fulfill the summons to create a 
more nurturing, caring and supportive community of individuals as called for in the vision. Reasons six through nine fulfill the call to work for integrated service delivery systems that promote the values of collaboration, prevention and measurable outcomes. The first two benefits listed were the most prevalent of those benefits identified by the data. While they are in fact related to the vision in the broadest sense, the purpose of the Children's Initiative was not intended to be a networking group concerned about children's and family issues. It was intended to have collaboration as its purpose and collaborative relationship building as its goal. The high value placed on participation on the SAC as a networking organization was the most important benefit perceived by the participants of this descriptive case study. This benefit will be discussed further in this chapter as one of the unintended consequences to arise from SAC participation. The strong networking relationships created a strong lobby which was also an unintended and beneficial consequence of belonging to the SAC. SAC members quickly learned to throw around their collective and considerable weight as with the example of the school boards described in the previous chapter. The concluding two reasons relating to building collaborative relationships and collaborative grant seeking reflect the direct intention of the vision, mission and goals of the Children's Initiative. Collaborative grant seeking is one of the seven systems strategies identified by the SAC.

What the participants did not mention as a benefit to them either professionally or personally was integrated service delivery systems, or measurable outcomes. This is where, as one SAC participant described it, the pedal meets the floor. Yet it was 
glaringly left out of the perceived gains by SAC participants. The benefits were not considered to be pooled funding, cross agency case management or outcome indicators by which to evaluate the success of services provided to youth and families. These are the very benefits and goals identified by Gardner and discussed in the third chapter of this study.

Clearly the SAC participants perceived significant gains for themselves personally and professionally. Yet these gains may not have been those necessary to facilitate the vision, mission, and goals of the Children's Initiative as it was designed during the first phase of its work.

This can be seen from the perception of losses both personally and organizationally. The losses articulated by the SAC participants focused on the degree to which participating on the SAC was time consuming and perhaps a bit frustrating because of the process of decision making. The vision, mission, and goals strategies identified actions that would have required redistribution of funding, authority, responsibility, and accountability. Cognizance of that is neither mentioned in perceived gains or perceived losses.

The results suggest that Senge correctly identified the function of the shared vision when he noted that the shared vision creates the opportunity to develop trusting relationships, create common identity, take risks, and make a commitment to the long term planning and implementation processes (1990, p. 206). The data suggested that the SAC participants did strongly enroll in the vision of the Children's Initiative and actively perceived gains to themselves and their organizations. The gains, however, 
were focused toward the relationship building sections of the vision and mission statements and less on the service delivery/implementation sections of the vision and mission statements. Based on this, one would expect that the gains identified by the SAC participants would endure and ensure the continuity of the SAC, but one would not expect that the strategic goals had been implemented in the next phase.

The answer to the first research question is that the SAC participants strongly enrolled in the vision to the extent that it became shared and they did perceive many greater gains than losses for themselves personally and organizationally.

Purpose 2: Vision, Theories-in-Use, and Stakeholder Concerns

The second research question seeks to determine whether a relationship exists between three distinct dynamics that influence the collaborative process. What is the relationship between the shared vision, the theories-in-use by SAC participants, and the stakeholders involved with the SAC? That question can be rephrased in a way that can clarify its intent. Is what the SAC participants are saying consistent with how they are behaving, and are the most appropriate people to walk the talk sitting at the table? Can a true collaboration take place? One would presume so, if the vision compels the behavior, and the best people are involved to implement the action. Was that the case in this unique case study?

The SAC participants knew their marching orders and the drill. They were able to articulate the vision which is the espoused theory, or raison d'être for the collaborative. The SAC was the place to be. The SAC was where they wanted to be. 
The mantra was the vision and the commitment to collaborate. Just how far did they have to go to get there and what were the impediments? As one SAC participant put it: "How can we begin to move from the way we function now to a position where we all function in the best interest of the communities and our agencies?" That's precisely the movement that fills the gap between the espoused theory and the theories in use. That's where the SAC participants had a great deal to say. It was a long way getting from their existing realities, systems, states of being, and ways of doing business to that portrayed by the vision. Closing the gap would require more than building bridges over it.

In chapter five, the discrepancies described by the SAC participants were centered in three areas: bureaucracy vs. grass roots, doers vs. processors, and selfcritical vs. take it from here. These discrepancies are the main discrepancies that emerged from the interview data. Because this study is a case study focused on the San Diego Children's Initiative, it is not possible to surmise whether these discrepancies would be consistent with the findings from studying other community collaborative initiatives. However, how they were experienced by the SAC participants may have further implications as to how discrepancies in general are perceived and dealt with. Therefore, it is worthwhile to examine them more closely.

The conversation surrounding the tension between the grass roots and the bureaucracies ranged from sympathetic, and encouraging to frustrated. Participants' comments included the following disparate ideas. This first participant views the community based organizations as a catalyst for positive change. 
When are we going to get to the community based organizations, to really begin to talk? And that was the beginning of what I think was an educational component, and a trip that takes us to where we are now. That has been good. It is, are we going to be neighborhood and community focused, or are we simply going to be what large agencies and governmental entities have always done, and that would be create programs and tell neighborhoods and communities and those individual recipients to conform to our desires, because we supposedly are better equipped to make decisions on programs.

\section{(PARTICIPANT 1)}

This next participant viewed the SAC members representing the community based organizations as a nuisance:

I'm lazier and I'm more get the top dogs in the room and they'll give the marching orders and we'll do it. Not the community people. probably rightfully, because I haven't worked as much in the community as they have. say if you don't get the real buy-in at the grass roots level, these communities are tired of the next program, the next fix, so it's really not going to work. . . I'm not saying it's right or wrong; it just sounds like more work to me.

\section{(PARTICIPANT 7)}

This participant refers to the bureaucratic organizations as the agencies and he or she perceived that the people representing community based organizations became lumped together and an obstacle toward implementing strategies that were decided upon by the big agencies: 
I think what it moved to is some agencies deciding that they knew what the answers would be, but they needed to pool resources in order to implement those strategies. . . . It became "we versus they." And somehow I got lumped in with the other community representatives. (PARTICIPANT 4)

The above quotes graphically demonstrate the tension that ensued. This tension was not directly addressed by the SAC. The tension in fact was a legitimate tension. The individuals involved with the SAC had a variety of ethnic, religious, cultural, educational, and national backgrounds. Since each of them held the highest position in their organization, they were experienced professionals. The organizations represented five different sectors of the community: health, education, safety, economic and community based organizations. Some of the organizations had similar structures even across the sectors. They may have received similar kinds of funding. The may have been accountable to similar board of governance. Some had extremely different structures, management philosophies and priorities. It might have been predicted that a tension, even conflict, would arise because of these very significant differences. It may not have been enough to believe that we were all there for kids and it would all go smoothly. The SAC had no formal system of tension or conflict resolution. This tension was therefore, left smoldering under the surface.

The tension between the doers and the processors was more formally acknowledged by the chairman who reflected that:

The hardest part of chairing the SAC was, being in the absolute untenable position of . . . about a third of the people were real go-getters, let's 
roll up our sleeves, we've been talking too long, let's get going. The opposite third wanted to study it forever, and the other third was sort of in the middle and changed depending on how they felt. (THE CHAIRMAN)

This dynamic built a strong tension, that while acknowledged, was not addressed in terms of moving forward. This tension hit the very nerve of the collaborative. It might have paralyzed the Initiative completely. This will be discussed further on in this chapter.

Finally, the tension between those who believed that in order to effect change on systemic levels the organizations needed to be more self-critical or self-reflective rather than those who believed that they could move forward without much self examination might have been divided along the community vs. bureaucracy lines as well. And once again this tension was not dealt with formally by the SAC.

These are the tensions referred to by Argyris in his work with organizations and theories-of-action. The review of the literature in chapter three summarized the work of Argyris relating to his concepts of theory-in-use. The collaborative would have needed to deliberately and forcefully engage in double-loop learning actions in order to work through and past the debilitating tensions created by the discrepancies between theories-in-use and espoused theories. Did the SAC seek to resolve the discrepancy between espoused theories and theories-in-use by setting new priorities, reconfiguring the weightings of norms, or by restructuring the norms themselves together with associated strategies and assumptions (Argyris \& Schon, 1978, p. 24)? The vision, mission and goals of the Initiative called for just this kind of double loop learning. 
Perhaps the success of the collaboration, as it was designed during this initial phase, required a greater understanding of the relationship between the dynamics involved in attempting such an effort. These findings were consistent with those presented by the evaluators of the New Futures collaboratives found in Chapter three. The evaluators of the New Futures referred to the gaps created by a variety of variables including culture, interests, style, and beliefs, and suggested that these needed to be addressed. Again, these results confirmed the necessity of deliberate double loop learning actions that would be transformative in nature and action.

Clearly there existed a strong relationship between the vision and the theories-in-use present among the SAC participants. This relationship might have been used as a more deliberate educational tool to move the effort forward.

The issue of stakeholder concerns was the third dynamic investigated as to its relationship with the shared vision and theories-in-use. In the review of the literature, Gray noted that "local initiatives may hold for greater promise because the problems now touch multiple stakeholders" $(1989$, p. 47$)$. These words certainly reflect the experience of the SAC participants. The Children's Initiative touched their lives, the lives of their organizations, their employees, their clients, their communities. The ripple of the Children's Initiative could be perceived throughout the county. Perhaps that is one of the reasons why the SAC was the place to be. While the SAC members knew that the circles of stakeholders would increase over time, by and large, they were satisfied with the breadth of individuals who composed the initial SAC. 
It is possible that more deliberate thinking about the initial stakeholder participants might have pre-empted the tensions that were subsequently created. Freeman (1984) emphasized the importance of understanding the expectations of the stakeholders on a variety of levels, including social, political, economic, and technological, in setting the strategic direction of an enterprise. Many scholars agreed that the perspectives (we can read that as theories-in-use) of the stakeholders will differ and that these differences may even cause disagreement depending upon the characteristics of the stakeholders. The Children's Initiative differed from other collaborative efforts because it represented five sectors within the community: health, education, safety, economic and community based organizations. The joining of these disparate sectors may have presented a greater challenge and increased turbulence to the collaborative process.

There was a sense among several of the SAC participants that the SAC represented a serendipitous or magical combination of individuals who at that moment in history. shared the same concern for the well-being of children and families. The commitment to the SAC and the vision, as discussed earlier in this chapter, demonstrated this sense of extraordinary commitment. At times the SAC participants express almost a sense of elation that together they have committed themselves to the Quixotic task. One SAC participant noted that the commitment extended beyond the passion of the individual leaders.

I think what you had were people who almost serendipitously shared the same concern for the welfare of young people and families who were in need. We 
shared the same core value about solutions to making our communities better so that children would have an environment where they felt safe, where they felt secure, where there were support systems, a safety net if you will, and I think that without exception, whether there was a change in leadership or not, these institutions have continued to support that philosophy. (PARTICIPANT 9) Only one SAC participant noted the difficulty of bringing together such a broad and diverse spectrum of people. And perhaps this participant's insights pointed toward the potential for difficulty in reconciling theories-in-use with espoused theories among such a broad group of stakeholders.

The stakeholders who became members of the SAC were well aware that they were the core group of stakeholders. It would be necessary to involve many other stakeholder groups to fulfill the vision of the SAC. The Bullet Diagram presented as Figure 4 in chapter two graphically depicted this understanding. The diagram demonstrated that as the Children's Initiative Collaborative moved into its implementation phases, the spheres of stakeholders continued to become larger and larger.

Once again these findings about the San Diego Children`s Initiative confirmed the findings from the New Futures Collaborative. When New Futures began, there wasn't a city in the country where the education, safety, social services, policy makers and business leaders sat down regularly to look at what was going on with children and families and create a collaborative vision and strategic plan. Creating that table where a diverse cross section of people met regularly was seen as one of the New Futures' 
Collaboratives greatest achievements. The results presented in chapter five certainly mirror this significant achievement.

Clearly there existed an important relationship between the vision and the stakeholders involved in the SAC. However, once again, the discrepancies identified by the data in chapter five, particularly between the perspectives of the community based organizations and the larger bureaucracies may have impeded the ability of the SAC to implement the action strategies that were presented at the Children's Summit in April of 1995.

Examining the triangle of dynamics, shared vision, stakeholder concerns, and theories-in-use, it is possible to imply that shared vision and stakeholder concerns were better understood and managed by the SAC. The vision was compelling enough to inspire commitment of SAC members! They were willing to endure some sacrifice in order to be part of the Children's Initiative's vision and they perceived significant advantages that would result from their of participation. The SAC members believed that the correct stakeholders composed the initial stakeholder group and demonstrated understanding that the spheres of stakeholders would increase over time. What appears to be misunderstood or less understood were the implications of the gaps created by the discrepancies between theories-in-use and espoused theories on many levels. The espoused theory was the stated vision. On that there was agreement and buy-in. The theories-in-use were left for the most part undiscussed. Differences among the stakeholders themselves, their organizations, their cultures, their philosophies, styles, 
backgrounds and more created both subtle and glaring discrepancies between what was espoused and what was done.

This gap was noted as well in connection with the New Futures Collaboratives and may be credited for the less than hoped for results of the New Futures Collaboratives. The gaps and discrepancies caused real frustrations among the SAC participants as presented in the previous chapter. It is possible that if deliberate proactive effort had been made in these areas, the process of the collaboration may have been smoother, less frustrating, and ultimately more successful. The Annie E. Casey Report framed it in the following manner: "One of the most pervasive influences is the culture or cultures of people who participate in the initiative" (Annie E. Casey Foundation, 1997, p. 2). Included in this idea of culture is the education, training, experiences, styles, beliefs and interests. It is an exceedingly complicated phenomenon that accounts for the variance between espoused theories and theories-in-use. The vast differences in culture regarding organizational turf, attitudes toward bureaucracies and bureaucrats, attitudes toward community based organizations and organizers, accommodating, committing resources, decision making, policy making, implementation, authority, consensus, organizational growth, and more, all served to widen the gaps created between the ideal of the vision and the reality of the individual SAC members, their organizations, the populations they served and to whom they answered. Perhaps it was miraculous that the vision, mission, and goals were completed in such intricate detail. The SAC received well deserved official recognition for the efforts in made in this area. 
The implications of the data suggest that there exists a strong and influential relationship between the vision, the stakeholder concerns and the theories-in-use. It would be of great service for this kind of large-scale, multi-agency collaborative effort to be cognizant of the issues raised by this triangle of interpersonal and interorganizational dynamics.

\section{Recommendations}

The data and the results pointed toward the necessity for greater understanding of the characteristics and cultures of the stakeholder group. Kadel and Routh (1994) were focused on the significant issues of scale, changes in attitude and understanding the complexity of the systemic change efforts. They noted that a small scale project with a limited number of participants more likely reaches a successful conclusion. Their work suggests that collaborative efforts that involve (a) many people with differing values and priorities, (b) attempt to make policy and strategic changes within many varied organizations, and (c) seek agreements on new approaches that involve the varied organizations, cannot avoid conflict and extensive involvement during the planning process. Therefore with all of the consultants and experts involved in the initial phase of the Children's Initiative, perhaps it may have been salient to create or select a process by which to deal with conflict, tensions and the discrepancy between what was espoused and what existed. The field of conflict resolutions offers many different theories for dealing with conflict within the organizational process. This descriptive case study was not focused toward theories of conflict resolution therefore none will be promoted here. It does appear, however, that the conflicts were not 
adequately anticipated either by the Children's Initiative or by the New Futures Collaboratives. Perhaps large-scale collaborative efforts in the future would do well to focus on anticipated discrepancies as well as those that arise during the collaborative process.

The early work of the Children's Initiative anticipated the barriers to collaboration, created pyramids that diagrammed transformational and systemic change, as well as the year 2000 planning and actions. In the initial phase of the Children's Initiative the SAC attempted to set forth a strategic plan designed to be implemented in its entirety. Chapter two of this dissertation documents this initial effort. What cannot be found is a methodology of how to get from planning to implementation: how to cross the barriers, fill in the gaps, reduce the discrepancies between what was espoused and what existed at the time. Further in this chapter, information is included about how the Children's Initiative has evolved from its original intent. It is in fact possible, that what the Children's Initiative has become may be the most positive outcome. At the same time, gaps, between the vision and what it would take to get there, would have made it difficult, if not impossible, to implement the system and program strategies that had been created during the initial phase of the Children's Initiative.

\section{Purpose 3: Inferences Drawn about the Children's Initiative Collaborative Effort}

The third question regarding inferences that may be drawn about the collaborative process will include discussions drawn from the review of the literature and inferences drawn from the data presented in chapters two and five about the 
unintended consequences, initial actions of collaboration, and the systemic change effort.

\section{Unintended Consequences}

Often the phrase unintended consequences refers to the negative fallout of strategic actions. In this context the unintended consequences of the Children's Initiative were resoundingly, overwhelmingly positive! Regardless of the vision, or raison d'être, the members of the SAC became a community. Virtual strangers became acquainted with one another. Individuals who theoretically should know and work together for a variety of common causes had, some for the first time in their careers, the opportunity to meet and get to know their colleagues. Above all, the SAC was a networking group where relationships and sometimes trusting relationships evolved among individuals who may have perceived themselves as competitors for common dollars, jobs, and service populations. Respectful relationships developed between people who in the data refer to one another as "hairbrained liberals" and "career bureaucrats." These were not just coincidental networking relationships, but formal relationships that, by their very existence, could change the way organizations work together for a very long time into the future.

The vision of the Children's Initiative was to create a more nurturing, caring, and supportive community of people and organizations that places top priority on children and families and encourages them to reach their potential. As has been discussed in detail, certainly and absolutely the Children's Initiative succeeded in creating a more nurturing, caring, and supportive community of people! These 
relationships would definitely benefit children and families, but also many others. When the sheriff, police, probation departments, social services, health services, private industry consortiums, community based organizations, departments of education and many other groups are connected to one another through positive ties, imagine the possibilities for the young and the old, the infirmed, the challenged, and the at-risk of any population. The purpose was to collaborate and place top priority on children and families. But in making that effort, the SAC changed the texture and fabric of an entire county through the relationships that they created.

Comments by SAC participants, presented throughout the fifth chapter demonstrate this consequence of their work together, and that they understood that magnitude of this phenomenon. Nine out of $10 \mathrm{SAC}$ participants mentioned the value of networking as one of the greatest advantages of participating on the SAC. SAC participants used vivid phrases that included the following:

It was the place to be.

I would actually say there was love in the room.

You don't feel quite so lonely.

People out of some different agencies began to connect around common goals.

The primary benefit was that it linked a lot of people in San Diego who were providing different things to the community. We had never really worked that closely together. 
The people at the table maybe knew each other, but didn't really know each other. I think anyone there could pick up the phone.

It has served as sort of a ready-made collaborative for other things that pop up on the radar screen that you can't necessarily anticipate.

The Children's Initiative helped grease the skids, and reduced the friction.

For the SAC members the value of networking with one another facilitated their abilities to: (a) understand one another's organizations, (b) share companionship at that collegial level, (c) create a powerful local lobby, (d) build relationships that lead to other collaborative projects, (e) validate and support one another's efforts, and (f) take advantage of collaborative, local, state, federal, and private, funding opportunities.

Chapter two documented the wide reach of this unintended consequence and includes a description of the SAC meeting in March of 1995. At that time, the Chairman asked the SAC members to share several things that their respective organizations did differentiy based on the impact of the Children's Initiative. Every SAC member reported significant improvements in collegial relationships, participation in new collaborations, and greater levels of friendships and trust.

This positive consequence was confirmed by Harbert (Harbert, Finnegan, \& Reynolds, 1995; Harbert, Finnegan, \& Tyler, 1995) in her earlier studies of the San Diego Children's Initiative. Harbert's studies, described in chapter three, sought to identify those dimensions which influenced the Children's Initiative's ability to develop and implement a strategic plan. Harbert concluded that SAC members perceived that 
collaboration was in the self-interest of the participants and that they had developed increasing levels of trust, quality of communication and mutual respect and understanding. Harbert's studies took place very early in the formative phase of the Children's Initiative. She noted that more time was required to determine whether or not the SAC would be able to develop and implement a strategic plan which would fulfill it's vision.

The Annie E. Casey Foundation concluded that the network and relationships created were an extremely positive unintended consequence of the New Futures Collaboratives. Although the actual results of the five communities studied over 5 years yielded fewer measurable improvements than had been hoped for or anticipated, the Annie E. Casey Foundation found that "people who work hard together and in good faith on problems of enormous importance to the community can provide, in time, the impetus for taking risks, for talking about things most often not raised directly, and ultimately for building mutual respect" (Annie E. Casey Foundation, 1995, p. 5). The evaluators of the New Futures efforts noted that in New Futures cities there was less turfism over time, greater communication and "the spirit of working together on complex problems sparked the zeal of professionals and lay persons alike" (Center for the Study of Social Policy, 1995, p. 26). These conclusions are consistent with those of Harbert (Harbert, Finnegan, \& Reynolds, 1995; Harbert, Finnegan, \& Tyler, 1995) and those of this descriptive case study. Furthermore, in their recent publications on the subject of evaluating comprehensive community change efforts, the Annie E. Casey Foundation asserted: "real improvement requires an infrastructure and environment that 
can drive and support change in multiple systems simultaneously" (Annie E. Casey Foundation, 1997, p. ii). The relationships built by SAC members with one another created precisely that kind of infrastructure and environment.

\section{Initial Actions of Collaboration}

When the SAC began to meet, the Chairman and advisors sought a vehicle for the organizations and individuals to become better known to one another. Chapter two presented in detail the initial actions and activities of the Strategic Action Committee. At that time the Planning Team tried to create a vehicle which would be the most efficient and effective way for each organization to organize information about itself. The Planning Team devised four questions to be answered by each organization and in doing so, each organization was asked to create and present an organizational profile. The executives responded to the four questions in relation to both the overall organization and how it related to children, youth and families. The questions were:

1. What is your organization's mission?

2. What services do you provide? (Please indicate if the services are primarily remedial or preventive.)

3. Who, specifically, benefits from your services? (Please describe your client population.)

4. How are these services delivered?

Several months were devoted to this important getting to know one another phase of the work of the SAC. It was hoped that this extensive sharing would create a camaraderie and level of trust among the SAC members. 
These questions would certainly have familiarized the organizations with one another's mission and services. It is unclear, however, how these questions are related to the vision, mission and goals of the collaborative or how they move the organizations toward collaborative thinking and acting. There are many questions that might have been as useful in attempting to build trust and familiarize the organizations with one another and at the same time begin to pursue the goal of collaboration. Perhaps, even from the beginning, tackling some of the more probing questions may have moved the effort forward. Any number of methods might have been chosen to promote the collaborative and systems change agenda from the onset of the effort. Adding questions, like the following, for example, represent an approach that emphasizes the importance collaboration from the very beginning of the effort.

1. What is it that you do best?

2. In a collaborative setting what is it that you would want to hold on to?

3. In a collaborative setting what is it that you might be willing to give up?

4. In a collaborative setting how can your organization assist and promote integrated service delivery systems?

Perhaps other questions and not those above, or an entirely different vehicle for becoming acquainted with the organizations would have better served the collaborative goal. The point is that the questions addressed by the SAC did not promote or facilitate the vision of the initiative. Collaboration as part of these introductory presentations was missing from the questions designed by the planning team of the Children's Initiative. Collaboration was, after all, the overriding and stated purpose of the 
Children's Initiative. The four questions pursued by the SAC members may have introduced the SAC to the work of each individual organization but they did not, in and of themselves, further the collaborative purposes of the SAC.

Gray noted that:

Collaboration establishes a give and take among the stakeholders that is designed to produce solutions that none of them working independently could achieve. Therefore, an important ingredient of collaboration is interdependence among the stakeholders. Initially, the extent of interdependence may not be fully appreciated by all the parties. Therefore, the initial phase of any collaboration usually involves calling attention to the ways in which the stakeholders' concerns are intertwined and the reasons why they need each other to solve the problem. Parties in conflict especially lose sight of their underlying interdependence. Heightening parties`awareness of their interdependence often kindles renewed willingness to search for trade-offs that could produce a mutually beneficial solutions. (Gray, 1989, p. 11)

The initial activities of the Children's Initiative would have benefited by focusing toward the understanding of interdependence described by Gray.

The review of related literature in chapter three further underscores the importance of focusing on integrated service delivery systems, definitions of mutual relationships and shared vision, systems of authority and accountability, and methodologies for sharing and seeking resources (Edelman \& Radin, 1991; Gardner, 1994: Mattessich \& Monsey, 1992). Directing the SAC toward these outcomes from 
the beginning of their initial meetings may have better facilitated the collaborative transformation. The "Transformational and Systemic Change Pyramid" presented in the second chapter identified the first and lowest level of the pyramid as the information exchange. Beside that level is the statement that this represents the status quo. Since the SAC began with just this kind of information exchange, they may have inadvertently been condemning themselves to maintaining the status quo. Therefore, from the initial meetings and actions of the SAC there was not enough emphasis on collaborative goal.

At the same time the SAC may have taken some actions initially that served its purposes very well. Garvin and Young (1994) who reviewed the New Orleans collaborative found that the most important elements in creating a successful collaboration were:

1. Identifying one person with the vision and energy to pull the elements of the program together and to keep them together.

2. Creating the time necessary for effective planning and implementation to occur (many programs, especially collaborative ones, need longer periods of time for the elements to gel sufficiently)

3. Creating opportunities for effective communication among partners who had historically kept away from each other, thus lessening the felt need to protect turf from each other.

The responses of the SAC participants presented in chapter five addressed each of these criteria at length and demonstrated that the Children's Initiative fulfilled each of these 
important elements. The talent and devotion of the convener, the time required for the endeavor and the value of effective communication were duly noted and elaborated upon. It can be concluded that the strengths of the initial activities may have compensated for its omissions. However, how much stronger might the collaborative effort have been if from the beginning collaboration and roads toward it had been kept in the driver's seat.

\section{The Systemic Change Effort}

This descriptive case study was not an effort to understand systems change efforts per se. However, the Children's Initiative presented itself as this kind of reforming effort and it is important to comment upon systems change as it relates to the collaborative effort. The New Futures publications and analyses emphasized that the most important lesson learned was that "comprehensive reforms are very difficult" (Annie E. Casey Foundation 1995, p. xi). These comprehensive, systems, reforms may be so incredibly difficult that they require more than a shared vision, the correct stakeholders and even a consistency between the theories-in-use and espoused theories.

The commitment to systems change can be seen as a consistent theme of the SAC. Several strategic methodologies are presented to master systemic change and establish the criteria by which to achieve systemic change. In September of 1994, the SAC was asked to wrestle with the issues. At its monthly meeting the SAC was given the tasks of establishing the magnitude and root causes of the problem, identifying current successful strategies in San Diego and elsewhere, and attempting to determine priorities and strategies. From there the focus area committees were created. These 
focus area committees pursued the actual investigation into the status quo and the desired outcomes and these focus area committees created over time the systems and program strategies. The systems strategies represerited the areas of systems change designed by the SAC.

What may have been missed was an analysis of the system that was being changed. There was much talk about changing the system in order to put the child in the center, to be focused toward the client rather than the organization. But what did that mean? What were the sources of decision making, authority, accountability, rewards, and sanctions that were operating in the old system? What were the characteristics of the present system? How was the system to be re-structured? Did the present system, as a whole, have to change in order to establish collaborative relationships and fulfill the collaborative goals? Were they attempting to begin with what they had and knew? Were they seeking a top down system of generalized control for all services delivered to, and dealing with, children and families? What was implementation going to look like? These questions may not have been dealt with fully enough. Systems change in the broadest and most detailed sense may have been required to fulfill the collaborative vision. At the same time, it may have been important to ask change from what to what? It may also have been critical to attempt to understand the dynamics that create a system and how they were to be ordered in the future. 


\section{Summary and Recommendations}

From the data presented we may infer that the collaborative benefited from unintended consequences and may have been impeded by its initial steps and the hazy focus on the systemic change effort. Building collegial, respectful, networking relationships is what the members of the SAC did best. These relationships would benefit all sectors of the community. This was the greatest strength of the collaborative and is consistent with the findings of the New Futures Collaborations. For the Children's Initiative, it was an unintended consequence of the collaborative effort. In the future perhaps it will be a deliberately planned and fully intended consequence. In future efforts to create large-scale, multi-sector collaborative efforts, those that organize and design the initial phase may do well to keep the collaborative purpose integrated into the community building actions. The initial activities must create a collaborative mindset among stakeholders. Finally, rather than focusing on systems change, perhaps a focus on collaborative change would better direct the effort toward implementing its strategies. It is possible that the SAC organizations were doing some things very well and that the entire system was not in need of a comprehensive systems change effort. For the Children's Initiative, systems change meant the opposite of joint projects. Perhaps they are not opposites but complimentary. It may have been logical to use the strategic plan to determine what could be accomplished with collaborative partnerships, what required systems change, and what might be done through joint projects. Asking and answering the question, what will it take to get from here to there, will encourage collaborative changes necessary for success. 
Purpose 4: Insights

At the Children's Summit in April of 1995, the systems and program strategies were introduced. The Summit represented the conclusion of the first phase of the work of the SAC. SAC members pledged their ongoing commitment to action. The morning of the Children's Summit ended with a commitment by the collaborating organizations to transition from the visioning phase of the Children's Initiative Collaboration to the implementation phase. At that time, the SAC intended to begin implementing the strategic plan which involved the systems and program strategies. So what happened to the Children's Initiative following the Children's Summit? In order to answer the last research question and truly provide insight into the large-scale multi-agency collaborative process, members of this dissertation committee suggested that I research the Children's Initiative beyond the scope of its initial phase. To that end, I spoke with the current Executive Director of the Children's Initiative, the chairman of the Board of Directors of the Children's Initiative, and a member of the funders group.

The purpose of my conversations was to investigate what happened in the implementation phase of the initiative. I brought to these individuals the vision, mission and goals that were the conclusion of the efforts of the Initial Phase of the SAC and unveiled at the Children's Summit on April 27, 1995. These are the same vision, mission, and goals that were used by the SAC participants at the time that the interviews were conducted for this dissertation. They are included here as Appendices $\mathrm{D}$ and $\mathrm{F}$. Each one was asked to review these documents and to share the role that these original goals played in the agenda of the Initiative as it has evolved over time. 
After consultation with advisors I believed that unless we investigated something about what happened next as it related to the vision. mission and goals of the collaborative, it would be difficult to offer insights, perceive implications or suggest learnings.

While these conversations were not interviews, I asked that the individuals sign a participant consent form and assured them that they would be able to edit whatever notes I collected from our meetings. The notes were sent to the respective individuals. The following information is presented with their permission.

According to the individuals involved with the Children's Initiative at the beginning of the year 2000, the Children's Initiative has accomplished better than anyone would have predicted. It is a force in the community and has what it takes to move things forward. The SAC, per se, no longer exists. It was replaced in 1998 by a Board of Directors, made up of 15 community representatives that meets approximately eight times per year. According to the current Chairman of the Board, soon after the Children's Summit, the SAC had reached a crisis between the visioners/analyzers and the do something/doers. They were ready to and about to abandon ship. For all the time that had been spent sitting, talking and creating a strategic plan, the time had come to affect lives. Until the rubber meets the road the Initiative hadn't accomplished a thing. Of course there had to be the period of strategic planning with the steps that planning took, but the time had come to put the pack on and take the hike. The chairman of the board discussed a change of approach took place on the SAC which was either they do something, or it's not going to live. So the SAC members either retrenched or they left. 
At that time, according to the chairman, the vision, mission and goals were divided into cubicles. This referred to the systems strategies and the program strategies presented at the Children's Summit. Subsequently they found that the work wasn't a neat enterprise, so subconsciously and consciously they evolved into prioritized programs. Some of these programs were prioritized by task forces and some created task forces from the framework that had been outlined previously. The Children's Initiative began to seize opportunities to become responsive to what came along. The priority became fitting into something that they could do, for example the very successful Critical Hours program. Critical Hours, the San Diego County Regional After School Consortium, is an unprecedented countywide collaboration of school districts, government agencies, community based organizations and the Children's Initiative. The collaborators recognized that the hours between three o'clock and six $o^{\circ}$ clock in the afternoon were magnets for destructive behaviors for youths who were at-risk and often unsupervised. Critical Hours provides after school supervision, activities and programs for at-risk youth in a variety of locations and settings throughout San Diego County. The Children's Initiative created the opportunity for Critical Hours and money poured in from the city, state and other funding sources.

The chairman described the Children's Initiative as the adventurous, risk taking, imaginative part of the programmatic undertaking. The Children's Initiative gets it up and running and gives it to the managers. The Children's Initiative is one of the players in most collaborative programmatic endeavors. In the early days, the SAC broke down the barriers, developed lines of communication and commitments to 
integrate services. The Children's Initiative collaborative continues to bring together people with information and expertise from all sectors and uses that to address a particular project or problem. It is a grand collaboration. The current chairman suggested that San Diego County is light years away from where it was in 1993 prior to the onset of the Children's Initiative. At that time children's and family's issues may have been about seventh on the county agenda, because of the Children's Initiative, children's and family's issues are the second most important agenda item. This researcher was amazed by this perspective. The current chairman credited this result to the passion and commitment of the original SAC and the ripple effect it had throughout the county.

Today the Children's Initiative considers itself the voice for the children, youth and families of San Diego County. Its current brochure is included as Appendix M. It asserts that:

The Children's Initiative is dedicated to assisting children, youth and families to reach their full potential by working for integrated service delivery systems that promote the values of collaboration and prevention, and for measurable outcomes in the fields of health, education, safety and economic security.

The above mission statement has evolved from the mission statement adopted by the SAC in 1993 which stated that:

The Children's Initiative is a collaborative effort among individuals and organizations representing the government, private nonprofit, and business 
sectors of San Diego County. It is dedicated to strengthening children and families by working for integrated service delivery systems that promote the values of collaboration, prevention, and measurable outcomes in the fields of health, education, safety and economic security.

What is missing from the current mission statement is that the Children's Initiative existing in and of itself as a collaborative. As such it no longer sees itself as promoting integrated service delivery systems. It has evolved into more of an oversight board. The vision statement of the current Children's Initiative mirrors the precise wording of the vision statement adopted by the SAC in 1993.

According to current literature, the Children's Initiative acts as a "Neutral Convener/Partner/Collaborator, Facilitator, Advocate and Participant" for a variety of programs, councils, task forces, and summits which closely resemble portions of the program and systems strategies identified 5 years earlier. The myriad of systems and program strategies, designed to have been implemented in the phase following the Children's Summit have been implemented on a limited basis. The extent to which implementation has occurred can be seen in the brochure included as Appendix $\mathbf{M}$. Of the seven systems strategies which can be found in Appendix D, progress has been made on five of them. As far as collaboration is concerned, the Children's Initiative brochure notes "We believe that more can be accomplished by organizations working collaboratively toward common agendas with meaningful inclusion of youth, families and communities than by any one organization working independently." That statement still includes the top-down/bottom-up concerns and reinforces the commitment to 
collaborative relationships where they are relevant. Supporting 10 staff members, the Children's Initiative itself operates with an annual budget about half a million dollars, that is about five times its budget in 1994.

I spoke to a current member of the Children's Initiative board who was one of the members of the original funders group and therefore has had consistent involvement in the Children's Initiative. The Children's Initiative started a mindset that said "let's look for every partner we can find and not inadvertently antagonize anyone." San Diego is unique because of the existence of the Children's Initiative, people who are critical to the well being of children and families can be called together. The primary value of the Children's Initiative is that people, who may have at one time been competitive and strangers, know each other and no longer attempt to damage one another. When somebody new comes to town there's a group that greets the newcomer and informs her or him that in this community we do our best to figure out how to compliment one another's work.

This glimpse into the evolution of the Children's Initiative over the last several years was presented to add greater perspective to the conclusions of this descriptive case study. By analyzing the data, it is no surprise the Children's Initiative strongly resembles its original purposes and built a foundation vigorous enough to evolve over the years. At the same time, data demonstrated that from the initial phase, dynamics were present that would have made fulfilling the original vision and implementing its strategies almost impossible. While the vision was strongly accepted and the stakeholders found that they had more to gain than lose through the collaborative 
endeavor, the process by which a true collaboration could be built overlooked some key issues that have been presented in detail in this chapter. There are in fact, no largescale examples of having successfully fulfilled the vision, mission and goals of this kind of public private collaborative effort.

Perhaps it is unfair to judge the outcome by the standards with which it began. We may conclude that the initial vision, mission, and goals were simply an exercise in visioning and a vehicle to create better relationships among key players. That conclusion would trivialize the intent of those who devoted countless hours to the Children's Initiative with the sincere belief that the well being of children and families would be greatly improved through the implementation of those collaborative strategies.

Having said that, those still involved with the Children's Initiative consider it to be a resounding success. The Children's Initiative no longer advocates for expansive systems change but works within existing frameworks and collaborative partnerships. The Children's Initiative evolved over time into more of an advocacy, neutral. supervisorial, convening kind of organization. The strong and trusting relationships built on the SAC continued to allow for collaborative programmatic efforts to be easily and comfortably accomplished. Certain of the collaborative/systems change pieces remain a priority of the Initiative.

Limitations of Studying Comprehensive Community Initiatives

Recent publications by the Annie E. Casey Foundation add even greater light to the findings of this research project. The Annie E. Casey Foundation, who convened the New Future Collaboratives discussed at length in chapter three, sponsors an annual 
research and evaluation conference for implementers of large-scale comprehensive community initiatives. The most recent report, the Annie E. Casey Foundation (1997), makes several poignant comments that illuminate this research as well as their own. These ideas are presented here in order to enrich the perspective by which to understand the results of this case study of the San Diego Children's Initiative. The staff of the Annie E. Casey Foundation emphasized that:

Unlike most traditional interventions, comprehensive community initiatives are very complex. They operate within and across many sectors of society, from local congregations to large public agencies, and they seek changes at many levels: for individuals and families, communities, organizations, and service systems. The strategies these initiatives use, and the goals they pursue, often are flexible and evolving. Comprehensive community initiatives support both broad outcomes that affect general populations and subtler changes designed to build local capacity for leadership and decision making. Finally, CCIs (Comprehensive, Community, Initiatives) operate within social, economic, and cultural contexts that they cannot control and these environments directly influence the initiatives' accomplishments. Together, these characteristics raise special issues for evaluators of comprehensive community initiatives. (Annie E. Casey Foundation, 1997, p. 3)

The report clearly cautions against facile conclusions and oversimplification. While this case study attempts to isolate particular dynamics which are its focus, the breadth of the Initiative itself makes direct linkages almost impossible. Therefore, it is 
climbing a slippery slope to attempt to simplify the recipe for success. The report further notes that:
A healthy community initiative has strong interrelationships among institutions, and evaluations should focus on these connections--a focus that may be at odds with efforts to isolate variables. . . . Comprehensive community initiatives typically evolve during the course of an evaluation in response to contextual factors, including the evaluation itself. . . . If your research is of any quality, of any utility, you're contributing to that change. (p. 6)

These comments are of the utmost significance to this effort because they caution the researcher and the reader not to oversimplify or assume that the variables being investigated can be isolated from the larger context. At the same time the above comments note the importance of research and evaluation in order to further hone the process of creating successful comprehensive community initiatives.

This study was severely limited by its size and scope. Designed as a descriptive case study, it did just that. It described the case of the San Diego Children's Initiative. In order to do so, 10 members of the SAC were selected and interviewed. Although the data was rich and evocative, a sampling of 10 cannot be generalized. As the data demonstrated, participants believed that a magical and propinquitous set of individuals assembled in San Diego in the early 1990s. These individuals were called together by their passion for the vision of the Children's Initiative. This case study focused on this unique set of individuals and their efforts. Although the findings of this descriptive 
case study mirror the findings of other researchers and the New Futures Collaborations, it is possible that the results are unique to this population and cannot be transferred to the pool of general knowledge. Additionally, due to the limited time-frame of this case study, the value of the insights may be equally limited. Longer time-frames and larger studies, both qualitative and quantitative, are required to learn more about the comprehensive community collaborative effort.

\section{Recommendations for Further Study}

This descriptive case study found that both the Children's Initiative and reports of the New Futures Collaboratives were quite successful in gathering a salient group of stakeholders and building a strong community but they fell short in the area of implementing the strategic plan. In general, further study of all phases of large-scale collaborative efforts is needed to increase the potential for success during implementation phases. Research using a variety of approaches to collect and interpret data from many sources would produce a fuller picture of the collaborative effort. It is essential to design quantitative and qualitative research and evaluation tools that explain or measure appropriate collaborative process and outcome indicators and changes. Evaluation and research are essential in understanding the dynamics that can help comprehensive community collaboratives build capacity and potential for greater success.

Specifically, additional research is needed to understand the organizational dynamics that may influence the success of the large-scale collaborative effort. This descriptive case study identified several discrepancies between espoused theories and 
theories-in-use. Those included: protecting turf, maintaining business as usual, patronizing of certain kinds of SAC members, accommodating, and lack of commitment of resources. These findings lend themselves to further study and investigation. The results of the discrepancies among the espoused theories and theories-in-use pointed toward significant tensions that developed in the SAC. Three categories of tension were identified in this descriptive case study. They were bureaucracy vs. grass roots, doers vs. processors, and self-critical vs. take it from here. Further research is required to understand the dynamics that create these paralyzing tensions. For example, do the differences of characteristics among stakeholders, including ethnicity, educational background, and gender, contribute to creating the tensions? Do differences among stakeholders, based on which sector they represent, contribute to creating the tensions? Is it possible to identify common characteristics among the doers and the processors so that these tensions might be better anticipated and avoided? Each of the dynamics and tensions, disclosed through this descriptive case study, offers significant opportunity for further research and learning.

\section{Implications}

It is hoped that this case study of the initial phase of the San Diego Children's Initiative will add to the growing base of research focused on comprehensive community initiatives. The results of this descriptive case study suggest that:

1. Comprehensive collaborative initiatives are very difficuit. 
2. The passion inspired by the vision of the San Diego Children's Initiative created a strong network among key professionals who provided services to and influenced the well-being of children and families.

3. The San Diego Children's Initiative attempted to design system and program strategies that would be implemented collaboratively as its comprehensive strategic plan.

4. As the San Diego Children's Initiative evolved, it departed from its strategic plan.

5. If the SAC had intention of implementing the comprehensive strategic plan, actions needed to be taken to support and promote the implementation of the strategic plan.

This case study suggested that during the initial phase, the foundation for collaboration might have been built with a more deliberate blueprint. Using this descriptive case study and others may assist those pursuing the large scale collaborative efforts in designing the initial and implementation phases of their initiatives. I hope that this research will enhance what is known about successfully launching comprehensive community initiatives.

\section{Reflections of the Researcher}

I want to share an editorial comment about the process of having been involved with the initial efforts of the Children's Initiative and the SAC in particular. Studying the large-scale collaborative process is an exciting and a relatively new endeavor. What an opportunity it has been to probe and analyze the dynamics of this new social 
phenomenon. In the process of completing this study, I experienced the same feelings of exhilaration that I felt sitting at the SAC meetings in 1994 and 1995 . There was a tangible sense that we were sitting on the edge of something momentous and historic, we were trying something new, we were attempting a breakthrough. The journey was bumpy. particularly because (as one SAC member was fond of reminding the group), "we were building this plane as we were flying it." I experienced similar feelings when working with the rich data collected for this study. In the previous chapter, I strove to present that sense of excitement through the words and ideas of the SAC participants. I profoundly admire the individuals who volunteered their time and so many other resources in attempting to create a successful collaborative effort. I was honored to get to know them throughout my time with the SAC and all the more so to have the opportunity to interview ten of the SAC members. I was genuinely impressed by their individual and collective brain power and heart power. The SAC was, in fact, building that plane as they were flying it. For this reason, both documenting the experience of the initial phase of collaboration as well as asking some questions about the process may provide insight to those involved and to others who will attempt this kind of bold effort.

\section{Conclusion}

This investigation sought to understand dynamics which would encourage the success of a large-scale, multi-agency collaborative effort. In so doing, the initial phase of the San Diego Children's Initiative was studied. The research demonstrated that the Children's Initiative created a strong and enduring collaborative community. The 
research also demonstrated that certain dynamics between the stakeholders may have impeded the implementation of the comprehensive strategic plan. Over time the collaborative evolved significantly. Did it still qualify as a large scale, multi-agency collaborative effort? Perhaps not as it was originally designed and planned. However, the San Diego Children's Initiative remains a thriving organization which pursues priorities similar to those created by the comprehensive strategic plan 5 years ago. The San Diego Children's Initiative forced children's and family issues to be among the highest priorities on the county agenda. The Children's Initiative, as an entity, continues to be ready to take advantage of collaborative funding opportunities. It is a lobbying and policy making organization on local, state and federal levels. The Children's Initiative has fulfilled its vision by creating a local environment where communities of people and organizations are more nurturing, caring, and supportive of one another. 


\section{REFERENCES}

Ackoff, R. L. (1974). Redesigning the future. New York: John Wiley \& Sons, Inc.

Adler, L., \& Gardner S., eds. (1994). The politics of linking schools and social services: The 1993 yearbook of the Politics of Education Association.

Washington, DC: The Falmer Press.

Aharoni. Y. (1981). The no-risk society. Chatham, NJ: Chatham House Publishers, Inc.

Alinsky, S. D. (1946). Reveille for radicals. Chicago: University of Chicago Press.

Alinsky, S. D. (1971). Rules for radicals: A practical primer for realistic radicals.

New York: Random House.

Annie E. Casey Foundation. (1995). The path of most resistance: Reflections on lessons learned from New Futures. (Available from The Annie E. Casey Foundation, 701 St. Paul Street, Baltimore, MD 21202)

Annie E. Casey Foundation. (1997). Evaluating comprehensive community change. (Available from The Annie E. Casey Foundation, 701 St. Paul Street. Baltimore, MD 21202)

Argyris. C. (1976). Increasing leadership effectiveness. New York: Wiley. Argyris, C. (1980). Inner contradictions of rigorous research. New York: Academic Press. 
Argyris. C. (1982). Reasoning, learning and action: Individual and organizational. San Francisco: Jossey-Bass.

Argyris, C. (1992). On organizational learning. Cambridge: Blackwell Publishers. Argyris, C. (1993). Knowledge for action. San Francisco: Jossey-Bass Inc. Argyris. C., Putnam, R., \& Smith, D. McL. (1985). Action science. San Francisco: Jossey-Bass.

Argyris, C., \& Schon, D. (1974). Theory in practice. San Francisco: Jossey-Bass. Argyris, C., \& Schon, D. (1978). Organizational learning: A theory of action perspective. Reading, MA: Addison-Wesley Publishing Company.

Center for the Study of Social Policy. (1994). Collaborative strategies in five communities of the National Alliance for Restructuring Education. (Available from the Center for the Study of Social Policy, 1250 Eye Street, NW, Suite 503, Washington, DC 20005)

Center for the Study of Social Policy. (1995). Building New Furures for at-risk youth: Findings from a five-year multi-site evaluation. (Available from the Center for the Study of Social Policy, 1250 Eye Street, NW, Suite 503, Washington, DC 20005).

Chynoweth, J. K. (1994). A guide to community-based, collaborative strategic planning. (Available from the Council of Governors' Policy Advisors, 400 North Capitol Street, Suite 390, Washington, DC 20001)

Coffey, A.. \& Atkinson, P. (1996). Making sense of qualitative data. Thousand Oaks, CA: Sage Publications. 
Edelman, P. B., \& Radin, B. A. (1991). Serving children and families effectively: How the past can help chart the furure. (Available from IEL, 1001 Connecticut Avenue, NW, Washington, DC 20036-5541)

Emery, F. E., \& Trist, E. L. (1965). The causal texture of organizational environments. Human Relations. 18, 21-32.

Emery, F. E., \& Trist, E. L. (1973). Towards a social ecology. New York: Plenum Press.

Freeman. E. R. (1984). Strategic management: A stakeholder approach. Boston: Pitman.

Frombrun, C. (1986). Structural dynamics within and between organizations. Administrative Science Quarterly. 31(3), 403-421.

Galaskiewicz, J. (1979). The structure of community organizational networks. Social Forces, 57, 1346-1364.

Gardner, S. (1989, Fall). Failure by fragmentation. California Tomorrow, Bulletin of California Tomorow's Youth At Risk Project, pp. 18-25.

Gardner, S. (1992). The four stages of collaboration. Unpublished manuscript, Center for Collaboration for Children, California State University Fullerton.

Gardner, S. (1993). The ethics of collaboration. Georgia Academy Journal _ (1), 2-4. Garvin. J., \& Young, A. (1994). Resource issues: A case study from New Orleans. In L. Adler \& S. Gardner S, eds., The politics of linking schools and social services: The 1993 yearbook of the Politics of Education Association (pp. 93106). Washington, DC: The Falmer Press. 
Gray. B. (1989). Collaborating: Finding common ground for multiparty problems. San Francisco: Jossey-Bass.

Gray, B., \& Hay, T. M. (1986). Political limits to interorganizational consensus and . change. Journal of Applied Behavioral Science. 22(2), 95-112.

Guba. E.. \& Lincoln, Y. S. (1989). Fourth generation evaluation. Newbury Park, CA: Sage Publications.

Habana-Hafner, S., Reed, H. B., \& Associates. (1989). Partnerships for community development. (Available from the Center for Organizational and Community. Development, University of Massachusetts)

Hammiller, R. (1994). Neighborhood-based interagency collaboration and selected aspects of the school's role. Unpublished doctoral dissertation. University of. Wisconsin.

Harbert. A. S., Finnegan, D., \& Reynolds, B. (1995). A framework for evaluating interagency collaboration. Unpublished manuscript, San Diego State University.

Harbert. A. S., Finnegan, D., \& Tyler, N. (1995). Collaboration: A srudy of a children's initiative. Unpublished manuscript, San Diego State University. Harman. W. (1988). Global mind change. Sausalito, CA: Warner Books.

Hercik, J. M. (1994). Improving public policy through collaboration: States. communities and grantmakers working together. (Available from the Council of Governors' Policy Advisors, 400 North Capitol Street, Suite 390, Washington, DC 20001) 
Horwitch. M., \& Prahalad, C. K. (1981). Managing multi-organizational enterprises: The emerging strategic frontier. Sloan Management Review. 22(2), 3-16.

Johnson. O. S. (1993). Everybody talkin' 'bout collaboration ain't collaborating. Georgia Academy Joumal. 1(1), 5-7.

Kadel. S.. \& Routh, D. (1994). Implementing collaborative services: New challenges for practitioners and experts in reform. In L. Adler \& S. Gardner, eds., The politics of linking schools and social services: The 1993 yearbook of the Politics of Education Association (pp. 121-134). Washington, DC: The Falmer Press.

Keith. J., Perkins, D., Zongqing, Z., Clifford, M., Gilmore, B., \& Townsend, M. Z. (1993). Building and maintaining community coalitions on behalf of children. youth and families (Research Report No. 529). East Lansing, MI:

Michigan State University, Agricultural Experiment Station.

Leaders back plan to better kids' lives. (1995, April 28). San Diego Union-Tribune, sec. B, pp. 1-2.

Lowi. T. J. (1979). The end of liberalism: The second republic of the United States. New York: W. W. Norton \& Company, Inc.

Mason, R., \& Mitroff. I. (1981). Challenging strategic planning assumptions: Theory, cases and techniques. New York: John Wiley \& Sons.

Mattessich, P. W., \& Monsey, B. R. (1992). Collaboration: What makes it work. (Available from the Wilder Research Center, 1295 Bandana Boulevard North, Suite 210, Saint Paul, MN 55108) 
McCann, J. E. (1983). Design guidelines for social problem solving interventions. Journal of Applied Behavioral Science. 19 177-189.

Melaville, A. T. (1994). What it takes: Structuring interagency partnerships to connect children and families with comprehensive services. (Available from the Education and Human Services Consortium c/o IEL, 1001 Connecticut Avenue, NW, Suite 310, Washington, DC 20036-554l)

Merriam. S. B. (1988). Case study research in education. San Francisco: JosseyBass.

Meyer, J. W., \& Scott, W. R. (1983). Organizational environments: Ritual and rationality. Beverly Hills: Sage Publications.

Miles, M. B., \& Huberman, A. M. (1984). Qualitative data analysis. Beverly Hills: Sage Publications.

Moon. S.. \& Welch, V. (1995). A proposal to improve the health and well being of San Diego's children. Proposal presented at Children's Summit. San Diego, CA, April 27.

Morgan, G., Frost, P., \& Pondy, L. (1983). Organizational symbolism. In L. Pondy, P. Frost, G. Morgan, \& T. Dandridge, eds., Organizational symbolism (pp. 335). Greenwich, CT: Jai Press Inc.

Morgan, G., \& Ramirez, R. (1984). Action learning: A holographic metaphor for guiding social change. Human Relations, 37 1-28.

Nanus, B. (1992). Visionary leadership: Creating a compelling sense of direction for your organization. San Francisco: Jossey-Bass. 
National Assembly of National Voluntary Health and Social Welfare Organizations. (1991). The community collaboration manual. (Available from $1319 \mathrm{~F}$ Street, Suite 601, Washington, DC 20004)

Negandhi, A. R. (1969). Interorganizational theory. Kent, OH: Comparative Administration Research Institute.

Neu. C. H., Jr. (1988). Strategic governance: A community integration process. National Civic Review, 77(2), 133-142.

Patton. M. Q. (1982). Practical evaluation. Beverly Hills: Sage Publications.

Patton, M. Q. (1987a). Creative evaluation. Newbury Park, CA: Sage Publications.

Patton. M. Q. (1987b). How to use qualitative methods in evaluation. Newbury Park, CA: Sage Publications.

Patton. M. Q. (1990). Qualitative evaluation and research methods. Newbury Park, CA: Sage Publications.

Perlmutter, H. V., \& Trist, E. (1986). Paradigms for societal transition. Human Relations. 39(1), 1-27.

Pondy. L. (1983). The role of metaphors and myths in organization and in the facilitation of change. In L. Pondy, P. Frost, G. Morgan, \& T. Dandridge, eds., Organizational symbolism (pp. 157-166). Greenwich, CT: Jai Press Inc. Redford, R. (1987, May-June). Search for common ground. Harvard Business Review, pp. 107-112. 
Roueche. J., Baker G. A., III, \& Rose, R. R. (1989). Shared vision: Transformational leadership in American colleges. Washington, DC: The Community College Press.

SANNO Management Development Research Center. (1992). Vision management:

Translating strategy into action. Cambridge, MA: Productivity Press.

Senge. P. M. (1990). The fifth discipline. New York: Doubleday.

Senge. P. M., Roberts, C., Ross, R. B., Smith, B. J., \& Kleiner, A. (1994). The fifth discipline fieldbook. New York: Doubleday.

Smith, B. L. R. (1983). Changing public-private sector relations. Annals, pp. 149164.

Strauss. A.. \& Corbin. J. (1990). Basics of qualitative research: Grounded theory procedures and techniques. Newbury Park, CA: Sage Publications.

United Way/CHAD. (1993). Children's future scan. (Available from United Way/ CHAD, P.O. Box 223543, San Diego, CA 92193)

Van de Ven, A., Walker G., \& Liston, J. (1979). The dynamics of interorganization coordination. Administrative Science Quarterly, 29(4), 598-621.

Williams, T. A. (1982). Learning to manage our furures. New York: John Wiley \& Sons.

Walsh, J. (1995). The eve of the storm: Ten years on the front lines of New Futures. (Available from the Annie E. Casey Foundation, 701 St. Paul Street, Baltimore, MD 21202) 
Yin. R. K. (1984). Case study research: Design and methods. Newbury Park, CA: Sage Publications. 


\section{APPENDIX A}

\section{THE FUNDERS’ BELIEF STATEMENT}

Reproduced with permission of the copyright owner. Further reproduction prohibited without permission. 


\section{SAN DIEGO COUNTY CHILDREN'S INITIATIVE}

\section{MULTI-YEAR FUNDING COMMITMENT}

(Community Foundation, Fieldstone Foundation, Junior League. Parker Foundation and United Way)

WE BELIEVE

WE BELIEVE

WE BELIEVE

WE BELIEVE

WE BELIEVE

WE BELIEVE

WE BELIEVE

THEREFORE
The Children's Initiative is positioned to play a major role in San Diego County in helping create a more nurturing. caring and supportive environment that places priority on children and families and encourages them to reach their potential.

The Children's Initiative will be effective in addressing both long-term action strategies developed by the Strategic Action Committee as well as short-term actions, i.e.. immunization and youth visioning.

The commitment to collaboration has never been stronger among the original funders of the Initiative than it is today.

It is important for the original funders to continue their model of collaborative funding by providing operating support for the Initiative.

It is necessary to employ a qualified staff in order to make the Children's Initiative a success, both in its short and long-term endeavors.

We must provide salaries commensurate with the expertise. skills and knowledge required to make the Initiative a success.

Multi-year funding commitments will provide the stability necessary to attract the most competent and appropriately skilled employees for the effort.

We are committed to securing the resources necessary to ensure multiyear (three fiscal years - 1994-95; 1995-96: 1996-97) operation of the Children's Initiative at least at the current budget level approved by the Steering Group.

This commitment provides at least three fiscal years of job stability to current and potential employees of the Children's Initiative assuming performance standards are met.

Individual Organization 
APPENDIX B

PARTICIPANT CONSENT FORMS

Reproduced with permission of the copyright owner. Further reproduction prohibited without permission. 


\section{Participant Consent}

I understand that I am being asked by Laurie Coskey, a doctoral candidate in the School of Education at the University of San Diego, to participate in a study of the collaborative process because of my involvement with the San Diego Children's Initiative. I am one of ten members of the SAC who will be interviewed in relation to our work during Phase 1 which concluded April 1995. The interview will take approximately one hour of my time.

The following is an agreement for the protection of my rights in this study:

1. The purpose of the research is to identify the extent to which perceived gains and losses (personal or professional) may influence SAC members commitment to the stated vision of the Children's Initiative

2. One source of data will be gathered through the use of interviews. I give my permission for the interview with me to be audio taped and transcribed verbatim. Some time after the interview and before the material is used I will receive a copy of the transcription and be invited to review, amend or delete and statements so that they accurately reflect my point of view.

3. If any quotes from my reviewed interview are used in any part of the study, I give my permission to attribute those to me in my position since it would be impossible to keep most of these statements confidential. I understand that there may be findings arising from the study that may be considered positive or negative.

4. My participation is completely voluntary and may be withdrawn at any time without risk of penalty.

5. I am invited to ask any questions I may have at any time during the study.

6. There is no agreement, written or verbal, beyond that which is expressed in this consent form.

7. Little risk or discomfort is expected as a result of participating in this study.

I, the undersigned, understand the above explanation and on that basis give consent to my voluntary participation in this study.

Signature of Participant

Date

Signature of Researcher

Date

Location 


\section{Consent Form}

I understand that I am being asked by Laurie Coskey, a doctoral candidate in the School of Education at the University of San Diego, to participate in a study of the collaborative process because of my involvement with the San Diego Children's Initiative. This meeting takes place because I am the current Chairman of the Strategic Action Committee. It serves as a post script to a dissertation which studied the first phase of the Children's Initiative. As part of the study, ten members of the SAC were interviewed in relation to the work of the Initiative which took place during Phase 1 (which concluded April 1995). The meeting will take forty five minutes of my time.

I understand that:

1. The purpose of the research was to identify the extent to which perceived gains and losses (personal or professional) may have influenced SAC members commitment to the stated vision of the Children's Initiative

2. I am going to be asked questions about the current work of the Children's Initiative in order to provide a long term perspective for the study which will be used in the final chapter of the study.

3. I will may choose to be identified by name and position as have been the previous chairman of the Children's Initiative or I can be referred to as the current Chair of the SAC. Use my name Use current Chairman

4. Before anv material is attributed to me I will be able to review it in writing and edited it.

5. I understand that there may be findings arising from the study that may be considered positive or negative.

6. My participation is completely voluntary.

7. There is no agreement, written or verbal, beyond that which is expressed in this consent form.

8. Little risk or discomfort is expected as a result of participating in this study.

I, the undersigned, understand the above explanation and on that basis give consent to my voluntary participation in this study.

$\overline{\text { Signature of SAC chairman }}$

Signature of Researcher

\section{Date}

\section{Date}

Location 


\section{Consent Form}

I understand that I am being asked by Laurie Coskey, a doctoral candidate in the School of Education at the University of San Diego, to participate in a study of the collaborative process because of my involvement with the San Diego Children's Initiative. This meeting serves as a postscript to a dissertation which studied the first phase of the Children's Initiative. As part of the study, ten members of the SAC were interviewed in relation to the work of the Initiative which took place during Phase I (which concluded April 1995). The meeting will take forty-five minutes of my time.

I understand that:

1. The purpose of the research is to identify the extent to which perceived gains and losses (personal or professional) may influence SAC members commitment to the stated vision of the Children's Initiative

2. I am going to be asked questions about the current work of the Children's Initiative in order to provide a long term perspective for the study which will be used in the final chapter of the study.

3. I will be referred to as one of the members of the original funders group who has maintained involvement from the inception of the Children's Initiative.

4. Shortly after this meeting. Laurie will send me her notes from our conversation. I will be able to review them in writing and edit them. Only material from these notes will be used in the conclusion of the dissertation.

5. I understand that there may be findings arising from the study that may be considered positive or negative.

6. My participation is completely voluntary.

7. There is no agreement, written or verbal, beyond that which is expressed in this consent form.

8. Little risk or discomfort is expected as a result of participating in this study.

I. the undersigned, understand the above explanation and on that basis give consent to my voluntary participation in this study.

Signature of Participant

Signature of Researcher
Date

Date

Location 


\section{Consent Form}

I understand that I am being asked by Laurie Coskey, a doctoral candidate in the School of Education at the University of San Diego, to participate in a study of the collaborative process because of my involvement with the San Diego Children's Initiative. This meeting takes place because I am the current executive director of the Children's Initiative. It serves as a postscript to a dissertation which studied the first phase of the Children's Initiative. As part of the study, ten members of the SAC were interviewed in relation to the work of the Initiative which took place during Phase I (which concluded April 1995). The meeting will take forty-five minutes of my time.

I understand that:

1. The purpose of the research is to identify the extent to which perceived gains and losses (personal or professional) may influence SAC members commitment to the stated vision of the Children's Initiative

2. I am going to be asked questions about the current work of the Children's Initiative in order to provide a long term perspective for the study which will be used in the final chapter of the study.

3. I will be identified by name and position as the previous executive director of the Children's Initiative.

4. Before any material is attributed to me I will be able to review it in writing and edit it.

5. I understand that there may be findings arising from the study that may be considered positive or negative.

6. My participation is completely voluntary and may be withdrawn at any time.

7. There is no agreement, written or verbal, beyond that which is expressed in this consent form.

8. Little risk or discomfort is expected as a result of participating in this study.

I, the undersigned, understand the above explanation and on that basis give consent to my voluntary participation in this study.

$\overline{\text { Signature of Executive Director }}$

Signature of Researcher

\section{Date}

\section{Date}

Location 
APPENDIX C

THE ROSTER OF THE STRATEGIC ACTION COMMITTEE 


\section{CHILDREN'S INITIATIVE \\ STRATEGIC ACTION COMMITTEE PARTICIPANTS \\ with Alternates}

BLAIR SADLER, CHAIR

President and CEO

Children's Hospital

3020 Children's Way

San Diego. CA 92123

PH: $576-5911$

FAX: $576-7134$

\section{GENE BELL}

President and CEO

Union-Tribune Publishing Co.

P. O. Box 191

San Diego, CA 92112

PH: 293-1101

FAX: 293-2335

\section{MARTIN BLOCK}

Assistant Dean of Education

San Diego State University

P. O. Box 608132

San Diego, CA 92160

PH: $\quad 292-5800$

FAX: $594-7082$

DR. GEORGE CAMERON

Superintendent

National School District

1500 "N" Avenue

National City, CA 91950

PH: $\quad 474-6791 \times 215$

FAX: 477-5144

MICHAEL CARR

Executive Director

Social Advocates for Youth

3615 Kearny Villa Road \#101

San Diego, CA 92123

PH: $\quad 565-4148$

FAX: $565-4178$
Cheri Fidler

Community Relations Director

Children's Hospital

3020 Children's Way

San Diego, CA 92123

PH: $\quad 495-7748$

FAX: $467-1882$ 
DR. RUDY CASTRUITA

Superintendent

County of San Diego

Office of Education

6401 Linda Vista Road

San Diego, CA 92111

PH: 292-3500

FAX: 268-5864
Justin Cunningham, Director

California Department of Education

Healthy Kids California

6401 Linda Vista Road

San Diego, CA 92111

PH: $\quad 292-3543$

FAX: 571-6046

Dr. Carol Pugmire

Assistant Superintendent

County of San Diego

Office of Education

6400 Linda Vista Road

San Diego, CA 921 i1

PH: $\quad 292-3645$

FAX: 571-5943

Linda Duffy

Deputy Chief Probation Officer

Juvenile Services

County of San Diego, Dept. of Probation 2901 Meadowlark Drive MS-P31

San Diego, CA 92123

PH: $\quad 694-4438$

FAX: $694-4649$

\section{DR. AUGUSTINE GALLEGO}

Chancellor

San Diego Community College District

3375 Camino del Rio South

San Diego, CA 92108

PH: 584-6957

FAX: 584-6541

\section{RADM FRANCIS K. HOLIAN}

Commander

Naval Base San Diego

937 North Harbor Drive

San Diego, CA 92132-5100

PH: $\quad$ 532-2925

FAX: 532-1511
LCDR Cindy Jones

Commander Naval Base

(Code N10)

937 North Harbor Drive

San Diego, CA 92132-5100

PH: $\quad 556-8809$

FAX: 532-1511 


\section{MARGARET IWANAGA-PENROSE}

President and CEO

Union of Pan Asian Communities (UPAC)

$103125^{\text {th }}$ Street

San Diego, CA 92102

PH: 232-6454

FAX: 235-9002

\section{DAVID JANSSEN}

Chief Administrative Office

County of San Diego

1600 Pacific Highway Room 209

San Diego, CA 92101

PH: $\quad 531-5250$

FAX: $557-4060$

\section{AURELIA KOBY}

Chief Executive Officer

San Diego Consortium and

Private Industry Council

1551 Fourth Avenue Suite 600

San Diego, CA 92101

PH: 238-1445

FAX: 238-6063

\section{DR. LEONARD KUTNIK}

Chair

American Academy of Pediatrics

4690 Genesee Avenue

San Diego, CA 92117

PH: $\quad 578-4330$

ALT: $578-4330$

FAX: $560-6340$

DR. STEVE LILLY

Dean, College of Education

California State University San Marcos

San Marcos, CA 92160

PH: $\quad 292-5800$

FAX: $594-7082$
Brene Patrick

Assistant Chief Executive

Youth Division

San Diego Consortium and

Private Industry Council

1551 Fourth Avenue Suite 600

San Diego, CA 92101

PH: 238-1445

FAX: 238-6063

Dr. Richard Walls

7300 Girard Avenue \#106

La Jolla, CA 92037

PH: $\quad 459-4351$

FAX: $459-4399$ 


\section{HONORABLE ROBERT O'NEIL}

Superior Court

P. O. Box 2724

San Diego, CA 92112-2720

PH: $\quad 531-3178$

ALT: $531-3889$ (Court)

FAX: 531-3291

\section{GIL PARTIDA}

President

Greater San Diego Chamber of Commerce 402 West Broadway Suite 1000

San Diego, CA 92101-3585

PH: $\quad 544-1311$

FAX: 234-0571

HONORABLE WILLIAM C. PATE

Presiding Judge

Juvenile Court MS P-299

2851 Meadowlark Drive

San Diego, CA 92123

PH: $694-4224$

FAX: $694-4773$

\section{DAN PEGG}

President

San Diego Economic Development

Corporation

701 B Street Suite 1850

San Diego, CA 92101

PH: $\quad 234-8484$

FAX: 234-1935

\section{DR. BERTHA PENDLETON}

Superintendent

San Diego City Schools

4100 Normal Street

San Diego, CA 92103

PH: $\quad 293-8418$

FAX: 293-8267

\section{Kay Davis, Director}

Business Roundtable for Education

Greater San Diego Chamber of Commerce 402 West Broadway Suite 1000

San Diego, CA 92101-3583

PH: $\quad$ 544-1327

FAX: 234-0571

\section{Dominique Alessio}

Marketing Services Director

San Diego Economic Development

Corporation

701 B Street Suite 1850

San Diego, CA 92101

PH: 234-8484

FAX: 234-1935

\section{Jeanne Jehl}

Administrator on Special Assignment

San Diego City Schools

4100 Normal Street

San Diego, CA 92103

PH: $293-8371$

FAX: 293-8267 
SCOTT REED

Director

San Diego Organizing Project $463030^{\text {th }}$ Street, Suite C

San Diego, CA 92116

PH: $\quad 285-0797$

FAX: 285-9283
James Mason

San Diego Organizing Project

$463930^{\text {th }}$ Street, Suite C

San Diego, CA 92116

PH: $\quad 285-0797$

FAX: 285-9283

Lt. Jerry Finley

Central Investigations Department

Child Abuse Unit

3502 Kurtz Street

San Diego, CA 92110

PH: $\quad 692-8001$

FAX: $692-8050$

Paul Simms

DR. ROBERT ROSS

Deputy Director

County of San Diego

Community Health Services

6255 Mission Gorge Rod

San Diego, CA 92101

PH: $\quad 285-6452$

FAX: 236-2664

Assistant Deputy Chief Dave Worden

San Diego Police Department

1401 Broadway

San Diego, CA 92120

PH: $\quad 531-2720$

FAX: $531-2530$

\section{Paul Watson}

Senior Associate Executive Director

Executive Director

San Diego Youth and Community Services 3255 Wing Street, Suite 550

San Diego, CA 92110

PH: $221-8600$

FAX: 221-8611
San Diego Youth and Community Services 3255 Wing Street, Suite 550

San Diego, CA 92110

PH: $\quad 221-8600$

FAX: 221-8611 


\section{CHIEF JACK SMITH}

El Cajon Police Department

100 Fletcher Parkway

El Cajon, CA 92020

PH: 579-3351

FAX: $444-8312$

\section{CECIL STEPPE}

Director

County of San Diego

Department of Social Services

1250 Imperial Avenue

San Diego, CA 92101

PH: $\quad 338-2888$

FAX: $338-2967$

DR. RENE TOWNSEND

Superintendent

Coronado Unified School District

555 "D" Avenue

Coronado, CA 92118-1714

PH: $\quad 522-8900$

FAX: $435-4672$

\section{STAFF:}

Sammy Moon

Projector Director

Children's Initiative

c/o United Way of San Diego

4699 Murphy Canyon Road

San Diego, CA 92123

PH: $\quad 492-2137$

FAX: 492-2059

Veronica Welch

Strategic Action Coordinator

Children's Initiative

c/o United Way of San Diego

4699 Murphy Canyon Road

San Diego, CA 92123

PH: $\quad 492-2075$

FAX: 492-2059

\section{Lana Willingham}

County of San Diego

Department of Social Services

1250 Imperial Avenue

San Diego, CA 92101

PH: $\quad 338-2888$

FAX: 338-2967 
APPENDIX D

SYSTEM STRATEGIES 
Children's Initiative

STRATEGIC ACTION COMMITTEE

SYSTEM STRATEGIES

COMMUNITY ENGAGEMENT

- Plan Development

- Phase 1 / Stage 1

X Media Summit

ORGANIZATIONAL EFFECTIVENESS

- Dual Mission statement

- Organizational readiness for collaboration

- Organizational commitment to learning

YOUTH PARTNERSHIP

- Your involvement

- Mentoring

COLLABORATIVE GRANT SEEKING

- Collaborative grantswriter

DATA INTEGRATION

- Major data systems linked for monitoring

RESULTS BASED CHILDREN'S BUDGET

- Children's Budget for accountability

- Annual outcome review

- Results based findings

PUBLIC POLICY COUNCIL

- Council for public policy review related to SAC goals 
APPENDIX E

PROGRAM STRATEGIES 


\section{Children's Initiative \\ STRATEGIC ACTION COMMITTEE \\ PROGRAM STRATEGIES}
GOAL I: INFANTS WILL BE BORN HEALTHY.
- Increase Perinatal Network
- Culturally Appropriate Provides
- Youth Education Programs

GOAL II: CHILDREN WILL STAY HEALTHY.

- Health Passport

- Tracking System

- Integrated Data

- Immunization Education

- Home Visitor Program

- Health Plan Package

GOAL III: CHILDREN WILL STAY IN SCHOOL READY TO LEARN.

- Parenting Information Programs

- Development Enrichment

- Quality Child Care

- Coordinated School Efforts

GOAL IV: CHILDREN AND YOUTH WILL EXPERIENCE AN INCREASE IN PEACE THROUGH A REDUCTION IN INTENTIONAL VIOLENCE.

- Media Strategy

- Community Centers

- Family Violence Awareness

- Safe Schools

- Identify High Risk Factors

- Reduce Use of Weapons by Youth

GOAL V: CHILDREN AND YOUTH WILL EXPERIENCE AN INCREASE IN SAFETY THROUGH A REDUCTION OF UNINTENTIONAL INJURY AND DEATH.

- Awareness of Injuries as Preventable

- Educational Curriculum on Transportation Safety

- Clearinghouse for Injury Prevention

- Increase Awareness of Injuries Related to Alcohol and Drug Use 
GOAL VI: CHILDREN WILL BE PROTECTED AND NURTURED

THROUGH A REDUCTION IN ABUSE AND NEGLECT.

- Home Visiting

- Abuse Prevention Educational Programs

- Comprehensive Intervention and Protection

- Preventative Treatment for Abused Children and Parents

GOAL VII: YOUTH WILL BE PREPARED TO ENTER THE WORLD OF WORK AND/OR PURSUE POST-SECONDARY EDUCATION.

- School to Career Program Implementation

- Status Assessments of Collaboratives

- Parent and Community Involvement Strategies

- Outcome Tracking After Graduation

- Physical and mental health Services and Programs

GOAL VIII: YOUTH WILL EXPERIENCE AN INCREASED OPPORTUNITY FOR HIGHER SKILLED. HIGHER WAGE JOBS THROUGH THE ENHANCEMENT OF ECONOMIC DEVELOPMENT.

- Public-Private Economic Development

- Investment in Youth Development Recognized and Supported

- Teacher Education and Awareness

- Media Strategies to Support Business Involvement

GOAL IX: FAMILIES WILL BECOME MORE EFFECTIVE AT SUPPORTING THEIR CHILDREN.

- Effective Parenting Practices

- Family/Community Support System

- Resources to Develop Family Life Plans

- Model Participation in Community Life

- Adult Education Opportunities

GOAL X: NEIGHBORHOODS WILL BECOME MORE EFFECTIVE AT MEETING CHILDREN AND FAMILY NEEDS.

- Definition of Needs by Neighborhood Members

- Identification of Resources by Neighborhood Members

- Identification of Strategies and Solutions by Neighborhood Members 


\section{Children's In itiative \\ STRATEGIC ACTION COMMITTEE \\ PROGRAM STRATEGIES}

GOAL I: INFANTS WILL BE BORN HEALTHY.

A. Support and expand the regional prenatal network and improve access to prenatal care throughout public awareness and education.

B. Ensure that there are prenatal care providers who are trained in cultural issues and cultural sensitivity for all major ethnic groups and that adequate translation services are available.

C. Institute or maintain programs in al! ethnic groups in which youth are provided with information about abstinence, pregnancy prevention, and examples of healthy alternatives to health compromising behavior.

\section{GOAL II: CHILDREN WILL STAY HEALTHY.}

A. Ensure that every child receives a health passport at birth that travels with him or her and that is easily portable and uniform.

B. Implement and expand the integrated database and tracking system model being developed by "All Kids Count" for the tracking of immunizations and eventually other health indicators for all children and youth in the county.

C. Support the work of the "Infant Immunization Initiative" by expanding the public awareness/education media campaign that focuses on the need for immunizations and expanding the low or no cost "Vaccines for Children" program.

D. Test the feasibility of a multi-tiered home visitor program supported by public health nurses and volunteers to begin in selected neighborhoods to offer support, problem identification, referral, and parenting skills.

E. Advocate that all health plans offer an affordable, competitive, child health maintenance package to include physical, mental, and dental health and preventative services for all children. 
GOAL III: CHILDREN WILL START SCHOOL READY TO LEARN.

A. Support programs that encourage parents to acquire information, skills, and social support they need to raise their children to be ready to learn.

B. Ensure that all children will have the opportunity to participate in developmentally enriched environments.

C. Support local child care coalitions in their efforts to improve access, training, and quality.

D. Coordinate early child care/preschool efforts with local school districts.

GOAL IV: CHILDREN AND YOUTH WILL EXPERIENCE AN INCREASE IN PEACE THOUGH A REDUCTION IN INTENTIONAL VIOLENCE.

A. Create a comprehensive media strategy that defines violence as unacceptable and as a preventable condition, and that promotes community norms for positive behavior (i.e. Heroes)

B. Encourage and support communities to redefine utilization of public facilities, especially schools, to serve as community centers that function in partnership with neighborhoods to be a focal point for community involvement and support of the healthy, non-violent behaviors of youth.

C. Create training experiences that increase knowledge and ability to identify and refer cases of family violence for all organizations that are represented by the SAC.

D. Support schools to implement strategies that ensure safety, that foster norms among the students that make violent behavior and weapons unacceptable, and that increase mentoring, peer education, conflict resolution, and diversity education and training.

E. Identify the high risk factors, including the use of drugs and alcohol, that most closely correlate with violent crime and develop neighborhood based, collaborative, early intervention strategies to reduce their incidence. 
F. Support a coordinated, comprehensive plan for reducing the access and use of firearms and other weapons by youth.

GOAL V: CHILDREN AND YOUTH WILL EXPERIENCE AN INCREASE IN SAFETY THROUGH A REDUCTION OF UNINTENTIONAL INJURY AND DEATH.

A. Carry out a coordinated public awareness campaign which positions preventable injuries as a major public health threat to our children, including injuries related to alcohol and drug abuse, and that changes the common perception that injuries are accidental vs. preventable.

B. Support an educational curriculum on motor vehicle. school bus. pedestrian and bicycle safety through the schools and communitybased organizations. and link with a major law enforcement effort.

C. Support the centralization of data collection and planning, and through a county-wide coalition, such as "Safe Kids." engage the community at the neighborhood level in strategies to reduce unintentional injuries.

D. Provide educational programs and prevention strategies about disabilities and deaths from injuries related to alcohol and drugs with emphasis on injuries that involve physical recreation and the operation of motor vehicles.

\section{GOAL VI: CHILDREN WILL BE PROTECTED AND NURTURED THROUGH A REDUCTION IN ABUSE AND NEGLECT.}

A. Extend the development of prevention programs that utilize home visiting and that are linked with many other services. including other forms of violence prevention, primary care and public health to reduce the isolation and increase the supports to families with children.

B. Extend the education of children and families about how to avoid abusive behavior and enhance personal safety utilizing schoolbased programs as well as businesses, physician's offices, and other public sites.

C. Increase the capacity to intervene in reported and ongoing instances of child abuse and neglect that supports families that can be rehabilitated, and removes children when they are in danger. while working with the family to eliminate the danger. 
D. Provide assessment and intervention services to abused and neglected children and parents that will enable them to avoid generational repetition of abusive, neglectful. or violent behaviors.

\section{GOAL VII: YOUTH WILL BE PREPARED TO ENTER THE WORLD OF WORK AND/OR PURSUE POST-SECONDARY EDUCATION.}

A. Support the county-wide adoption and implementation of the school to career transition initiative especially as it relates to curriculum and instruction for grades K-16.

B. Establish a database to collect information on the status of existing school to career partnerships between employers and schools. and develop strategies to increase these partnerships.

C. Support the development of a parent and community involvement strategy to increase awareness of and participation in school to career transition activities in their local school site.

D. Develop a system to track the success of school and college graduates after graduation for outcome information that will be used to improve curriculum and programs.

\section{GOAL VIII: YOUTH WILL EXPERIENCE AN INCREASED OPPORTUNITY FOR HIGHER SKILLED, HIGHER WAGE JOBS THROUGH THE ENHANCEMENT OF ECONOMIC DEVELOPMENT.}

A. Support public-private partnerships specializing in regional economic development as essential to the future development of jobs for youth and adults in the region.

B. Educate businesses to recognize and support youth and the school to career programs in their schools as a means of creating a more productive work force and as key investments in their own corporate future and the future economy of the region.

C. Support various ongoing methods of teacher education. including on site job observation and employer shadowing, to help teachers and schools keep curriculum and programs responsive and relevant to today's rapidly changing business climate and job skill requirements for the youth they teach.

D. Encourage media coverage of positive business and community partnerships that support or involve youth and their schools and neighborhoods. 
GOAL IX: FAMILIES WILL BECOME MORE EFFECTIVE AT SUPPORTING THEIR CHILDREN.

A. Support an increase in availability of educational programs and training opportunities that teach effective. developmentally appropriate parenting practices.

B. Support the use by parents and caregivers of extended family/community support systems which offer care and comport in stressful times to reduce parental abuse and neglect.

C. Support the awareness of and use of resources to assist families in developing positive family life plans.

D. Support and encourage opportunities for families to model participation in the enhancement of community life.

GOAL X: NEIGHBORHOODS WILL BECOME MORE EFFECTIVE AT MEETING CHILDREN AND FAMILY NEEDS.

A. Support members of neighborhoods to define the needs of their children and youth and identify factors which put their youth at risk.

B. Support members of neighborhoods in identifying organizations and other neighborhood resources which can and will address the issues concerning their children and youth.

C. Support members of neighborhoods in identifying and implementing appropriate strategies to meet the needs of the children. youth, and families in their neighborhoods. 


\section{APPENDIX F}

\section{INTERVIEW QUESTIONS}

Reproduced with permission of the copyright owner. Further reproduction prohibited without permission. 
Interview Questions

1. What is the vision of the Children's Initiative?

2. What is your vision for the Children's Initiative?

3. Do others share your vision?

4. Is there any discrepancy between your vision and the existing vision?

5. How important do you think it is for there to exist a shared vision by the members of the collaborative? Can you tell me why/more?

6. Would you describe the vision as risk taking? If so, it what ways?

7. Do you find the vision courageous? If so, in what ways?

8. Blair Sadler, president and CEO of Children's Hospital and chair of the SAC, was recently quoted in the San Diego Union Tribune as saying. "The jury is still out on whether the initiative is a well-meaning ideal that went nowhere. or something that will really change children's lives." What do you think?

9. What do you perceive are the ways in which the SAC members can gain from the collaboration, organizationally and/or professionally?

10. What are the losses, organizationally and/or professionally?

11. What are the potential gains and losses for your organization?

12. What are the potential gains and losses for you personally and professionally?

13. What kinds of sacrifices, organizationally and professionally, are you prepared to make in support of the vision?

14. Do you think that the Children's Initiative can impact a positive change or is it just another committee? 
15. Are the right people sitting at the table?

16. Who else should be there?

17. How many other collaborative groups are part of your work right now? 


\section{APPENDIX G}

\section{CHART OF DATA ON SHARED VISION}




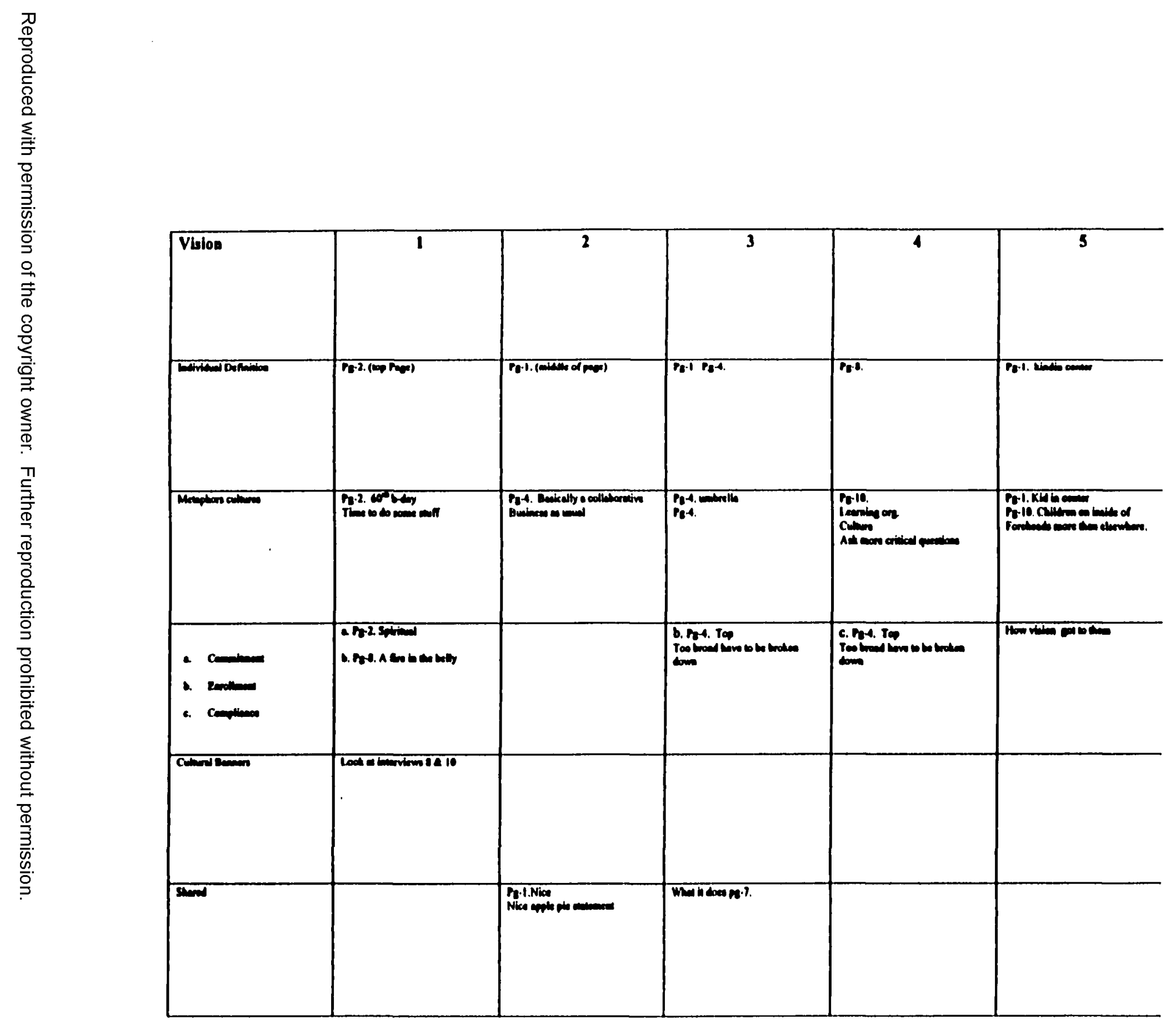




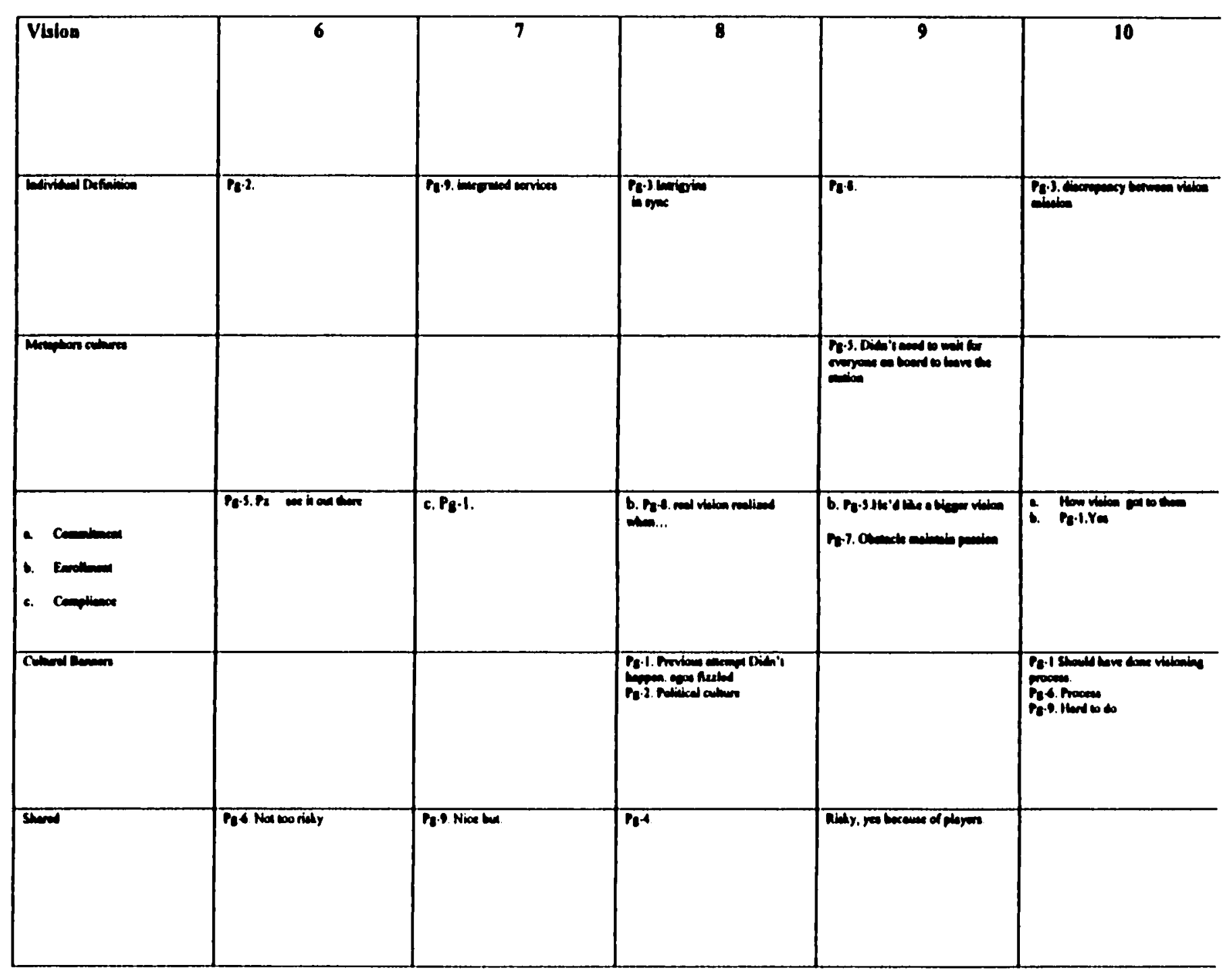




\section{APPENDIX H}

\section{CHART OF DATA OF ESPOUSED THEORY AND THEORIES-IN-USE}




\begin{tabular}{|c|c|c|c|c|c|}
\hline Theory-la-use & 1 & 2 & 3 & 4 & 3 \\
\hline Exacendinar & 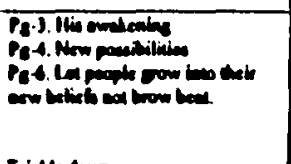 & 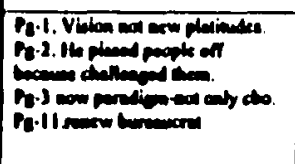 & 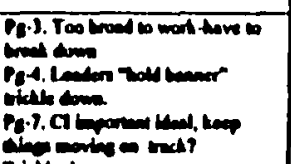 & & Dind \\
\hline 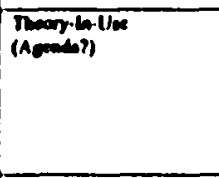 & 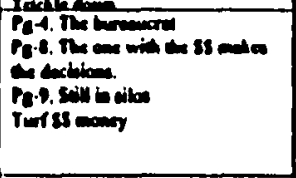 & 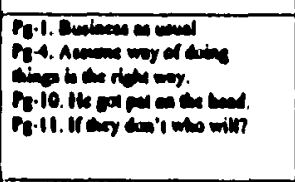 & 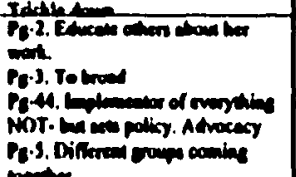 & 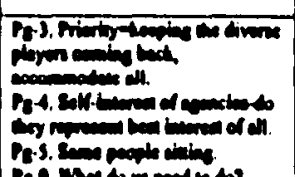 & \\
\hline Tath & 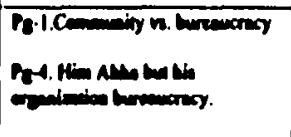 & 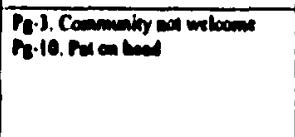 & & 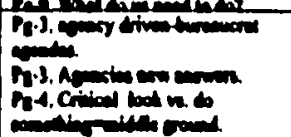 & 勇 \\
\hline Dom & & & & $x^{n}$ & \\
\hline Doult bop hasing & 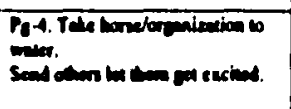 & 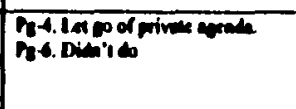 & & & \\
\hline 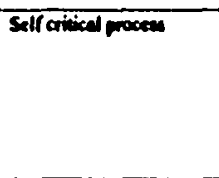 & 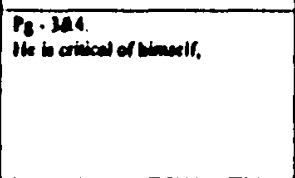 & 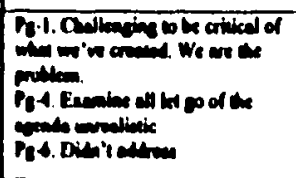 & & 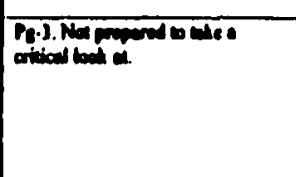 & \\
\hline 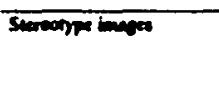 & & Po.10 masenter & & 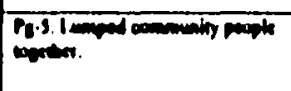 & \\
\hline sementer & Pa.12 ruection & 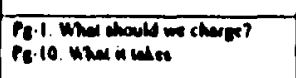 & 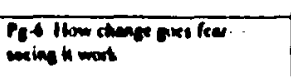 & & \\
\hline
\end{tabular}


APPENDIX I

CHART OF DATA OF STAKEHOLDER ISSUES 


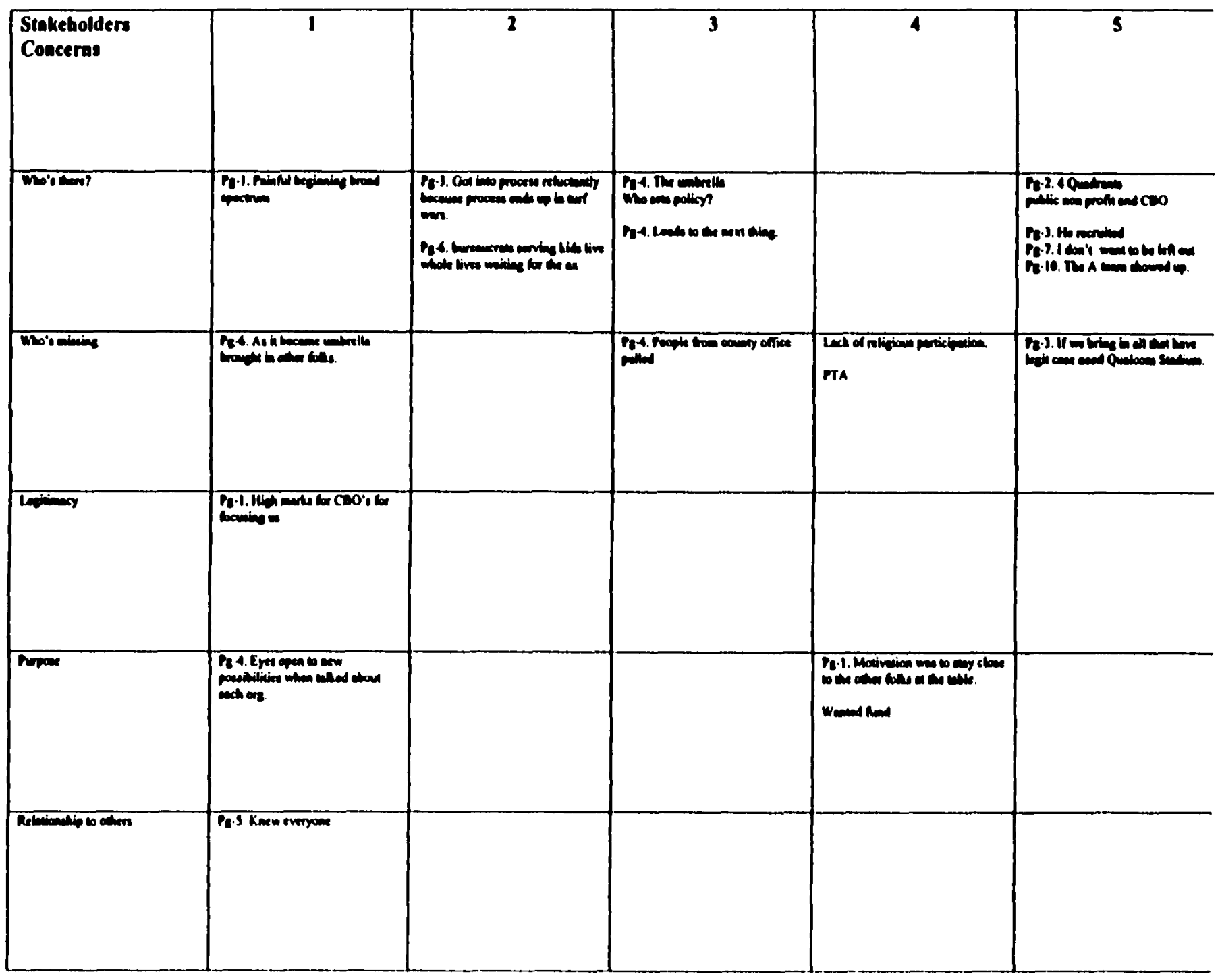




\section{APPENDIX $J$ \\ CHART OF DATA ON ISSUES OF COLLABORATION}




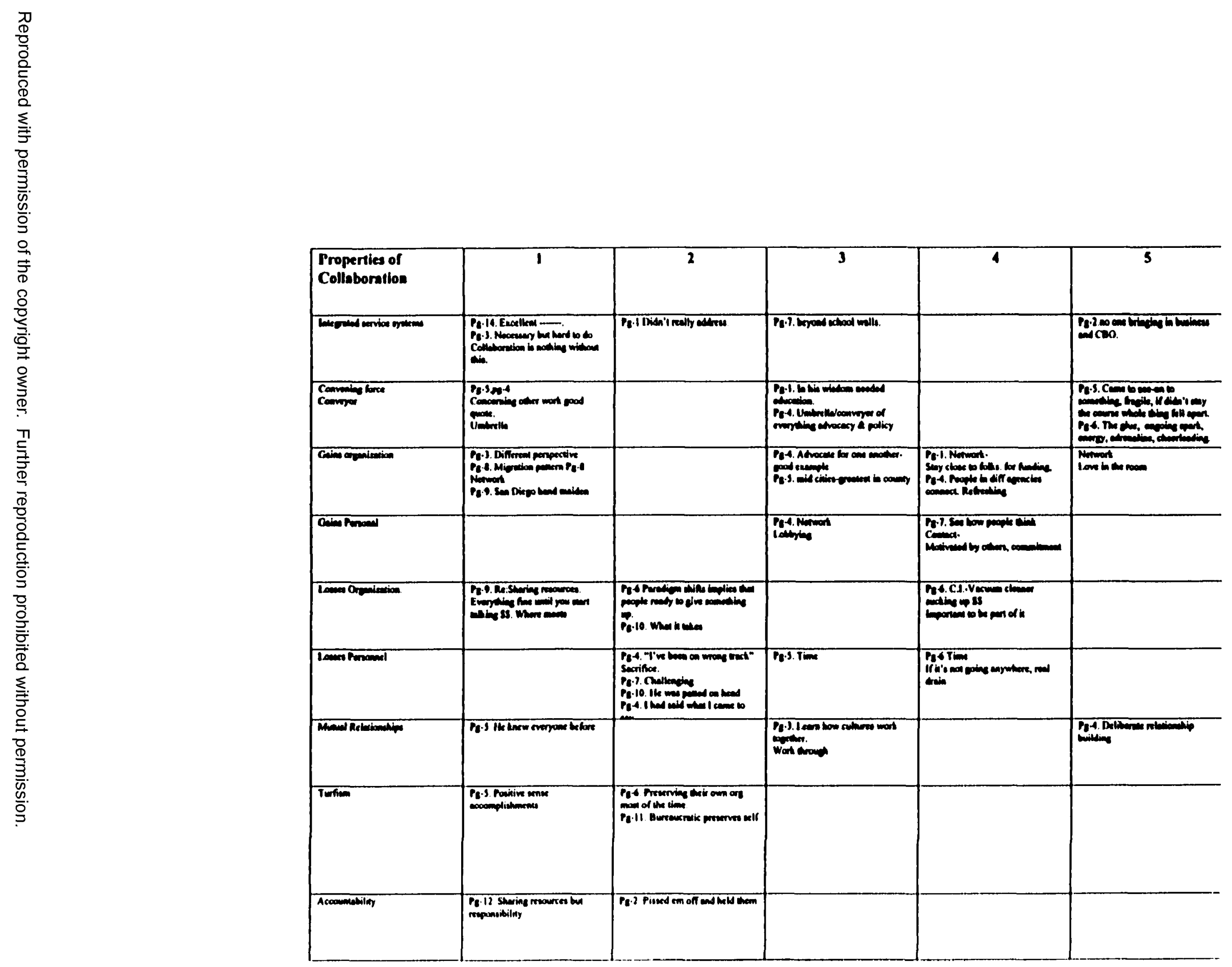




\begin{tabular}{|c|c|c|c|c|c|}
\hline 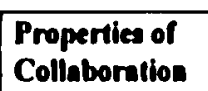 & 6 & 7 & 8 & 9 & 10 \\
\hline 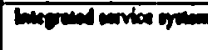 & & & & & \\
\hline 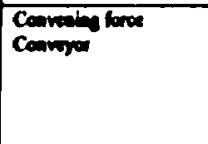 & 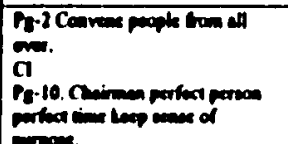 & & 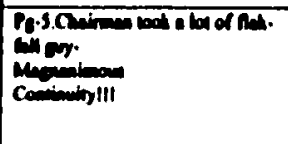 & 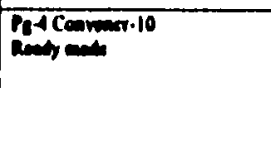 & 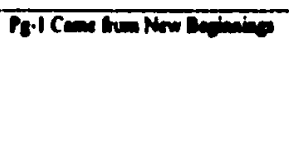 \\
\hline 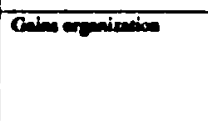 & 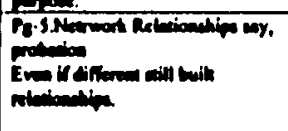 & 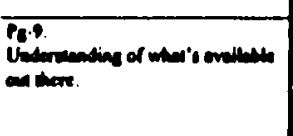 & 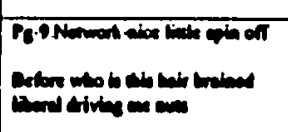 & 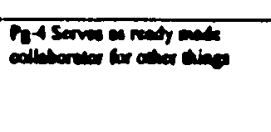 & 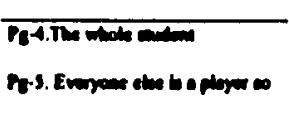 \\
\hline 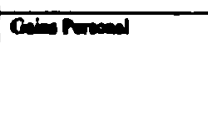 & & & 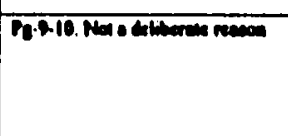 & 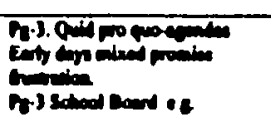 & \\
\hline Lemonomination & 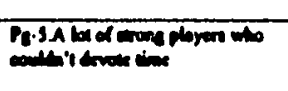 & serrifices & & & 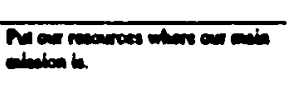 \\
\hline 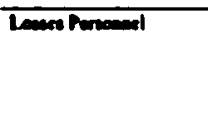 & 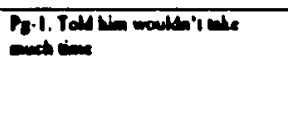 & 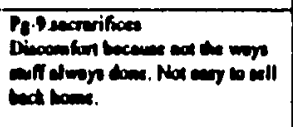 & & 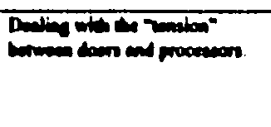 & \\
\hline 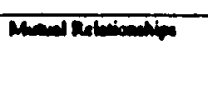 & $\sqrt{3.2}$ & & & & \\
\hline Terive & & 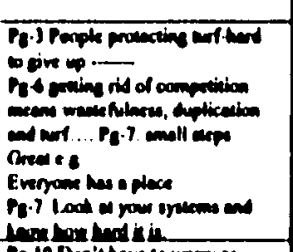 & & 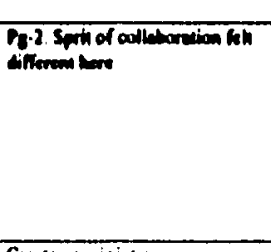 & \\
\hline conomescility & & 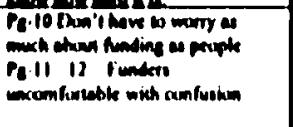 & & 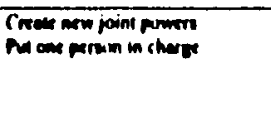 & \\
\hline
\end{tabular}


APPENDLX K

THANK YOU LETTER TO SAC PARTICIPANTS 


\section{Laurie Coskey \\ 5825 Tulane St. \\ San Diego, CA 92122 \\ 658-9582 \\ Coskle@AOL.com}

July 8,1997

Dear $x x$

I hope that you enjoyed a spectacular $4^{\text {th }}$ of July.

As I promised, I am sending you an unedited transcript of our interview. As you will see the transcriber missed words from time to time and sometimes even whole sentences. Please look it over, fill in the blanks and edit it in any way. Then send it back to me in the enclosed envelope and I will make the changes. Feel free to call me or use the e-mail if you have any questions.

I want to thank you again for participating in my dissertation project. All of the interviews were more inspiring and profound than I could have imagined. It was really an honor for me to spend that time with you. Thank you!

Have a super summer!

Sincerely, 


\section{APPENDIX L \\ DECLARATION OF INTERDEPENDENCE}




\title{
SAN DIEGO COUNTY CHILDREN'S INITIATIVE
}

\author{
STRATEGIC ACTION COMMITTEE
}

\section{DECLARATION OF INTERDEPENDENCE}

\section{OVERALL INITIATIVE VISION STATEMENT}

To create a more nurturing, caring, and supportive community of people and organizations that places top priority on children and families and encourages them to reach their potential.

\section{OVERALL INITIATIVE MISSION STATEMENT}

The Children's Initiative is a collaborative effort among individuals and organizations representing the government, private nonprofit, and business sectors of San Diego County. It is dedicated to strengthening children and families by working for integrated service delivery systems that promote the values of collaboration. prevention. and measurable outcomes in the fields of health, education, safety and economic security.

WE BELIEVE All children deserve a chance to be born healthy, to be free from hunger. and to receive regular medical care.

WE BELIEVE All children deserve an education that prepares them to meet the future and inspires them to reach their potential.

WE BELIEVE All children deserve to grow up free from abuse, free from the devastation of drugs and alcohol.

WE BELIEVE

All children deserve to grow up in economically stable families, and to have hope for a secure future.

WE BELIEVE More can be accomplished by organizations working collaboratively toward common agendas for children and families than by any one organization working independently.

\section{INITIAL STRATEGIC ACTION COMMITMENTS}

I pledge. as a member of the Strategic Action Committee. to seek my organization's "official" endorsement of the Ten Goals of the children's Initiative and the Systems change Strategies contained in our reports. I further pledge to support my fellow SAC members in this effort. 


\section{APPENDIX M}

1999 BROCHURE OF THE CHILDREN'S INITIATIVE 


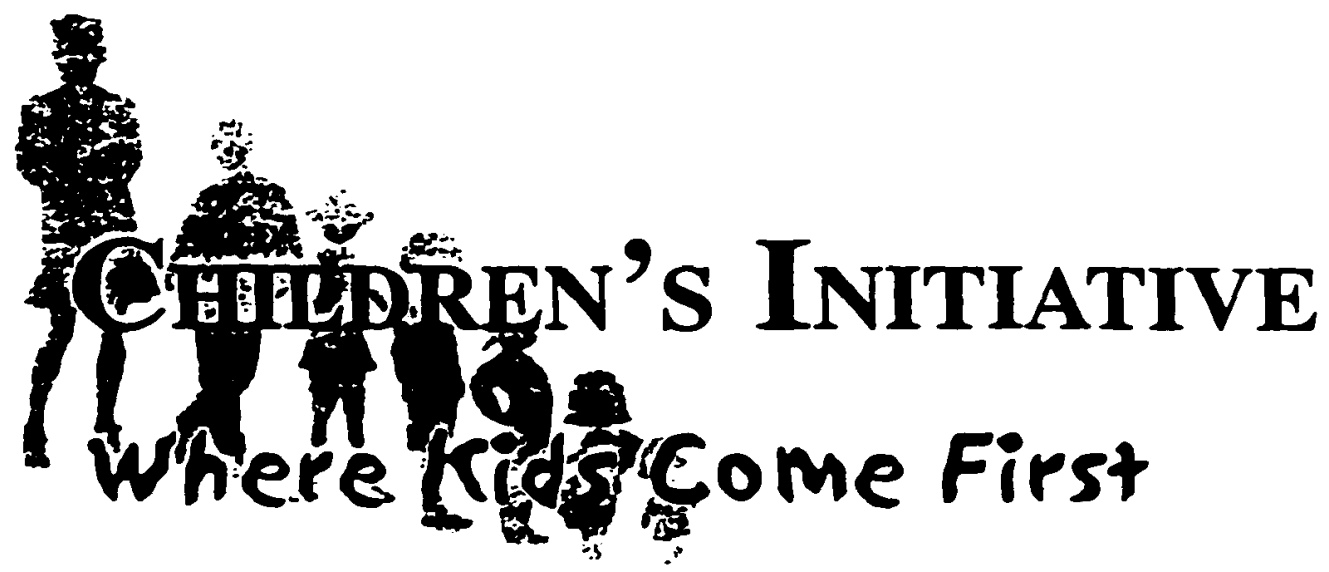

\section{A Voice for the Children, Youth \& Families of San Diego County}

The Children's Initiative is dedicated to assisting children, youth and families to reach their full potential by working for integrated service delivery sistems that promote the values of collaboration and prevention. and for measurable outcomes in the fields of health, education, safety and economic securing.

\section{Our Vision}

The Children's Initiative seeks to create a more nurturing. caring and supportive communiry of peopls' and organizations that places top priority on children, youth and families.

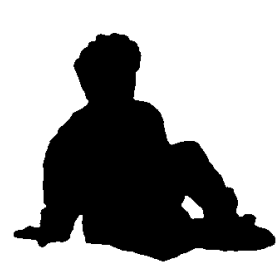
and encourages them to reach their full potential. 


\section{Health}

We believe that all children deserve a chance to be born healthy. 10 be free from hunger, and to receive regular medical care.

\section{Education}

We believe that all children deserve an education that prepares them to meet the future and inspires them to reach their potential.

\section{Safety}

We believe that all children desenve to grow up free from abuse, free from violence. and free from the devastation of drugs and alcohol.

\section{Economic Security}

We believe that all children desenie to grow up in economically stable families and to have hope for a secure future.

\section{Collaboration}

We believe that more can be accomplished by organizations working collaboratively toward common agendas with meaning ful inclusion of youth. families and communities than by any one organization w'orking independently:

\section{Children's Initiative}

The Children's Initiative acts as Neutral Convener. Partner/Collaborator, Facilitator, Adwocate and Participant for each of the following:

\section{A Comprehensive Stratery for Youth, Family and Community Juvenile Justice Coordinating Council}

A blueprint of strategies and actions for prevention. intervention and graduated sanctions developed in partnership by the County of San Diego Boord of Supervisors and Children's Iniriative.

\section{Critical Hours}

The San Diego Counny Regional Afeer School Consortium

An unprecedented coungwwide collaboration of school districts. government agencies, communipybased organizations and Children's Initiative.

\section{San Diego's Promise}

San Diego Counny 5 Response to the Presidents' Summit

The Children's Initiative fosters collaboration among service providers. both public and private, and the business community on behalf of children. youth and fanilies. as part of the national volunteer mobilization America's Promise spearheaded by Gen. Colin L. Powell. USA (Ret).

\section{Family Resource Centers / Regional Advisory Councils}

The Children's Inixianive works in partnership with the San Diego Counn. Health \& Human Senices .tgencr on redesign and strategic planning for senice deliven. systems.

\section{The Youth Summit}

A collaborative project of Children's Initiative and Youth Congress that inviles youth to join adult deciston mokers at the sable, not only as participants. hut as fill and equal pariners.

\section{A Neutral Convener} Task Forces facilitated by. Children's Initialive

Coordinated Public Policy Tark Force

Sofery \& Violence Task Force

Zero 10 Sir Tusk Force

\section{Capacity Building}

Developing Mutual Support with the .Media.

Working in Partnership with Elected Officials at the National. State and Local Level.

Encourcging and Honoring the Support of the Business Communing on Behalf of Children. Youth and Families.

Advocating on Behalf of Public Policy Issues that effect Children. Youth and Families.

Taking the Message 10 - and from - the Commumn 